\title{
SOCIAL SCIENCE TEACHERS' CRITICAL ENGAGEMENT WITH BEST EVIDENCE SYNTHESIS RESEARCH
}

\author{
BY
}

MICHAEL ALAN TAYLOR

\begin{abstract}
A thesis
submitted to Victoria University of Wellington

in part fulfilment of the requirements for the degree of Masters in Education
\end{abstract}

Victoria University of Wellington 


\section{Abstract}

This thesis draws on qualitative data gathered in focus group discussions, and interviews with ten teachers and three academics to examine social science teachers' critical engagement with Effective Pedagogy in the Social Sciences /Tikanga-a-iwi Best Evidence Synthesis (Aitken \& Sinnema, 2008). To assess teachers' critical engagement with the Social Science BES, the thesis develops a modified model designed to encourage critical thinking. The methodological approach involved recording two phases of self-directed teacher discussion before and after the introduction of the modified critical thinking model. The findings suggest that the model supported teachers in the short term, especially those participants for whom critical thinking about research evidence was a novelty. The model had little impact, however, for teachers with more critical thinking skills. A lack of accountability, entrenched teacher identity, and socio-centric dialogue were identified as barriers to the teachers' critical engagement with the Social Sciences BES. Further findings provide insight into how over-assimilation and inattention to the complexity of research evidence risk undermining the integrity of teacher inquiry. The thesis concludes with a discussion about the difficulty of teachers critically engaging with the Social Sciences BES and offers recommendations for different levels of the education system that might help facilitate critical engagement with Social Sciences $B E S$ research. 


\section{Table of contents}

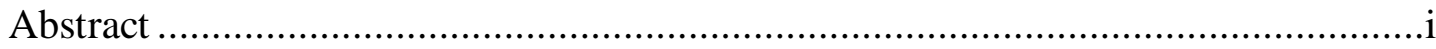

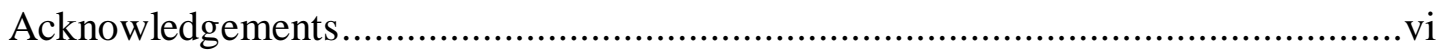

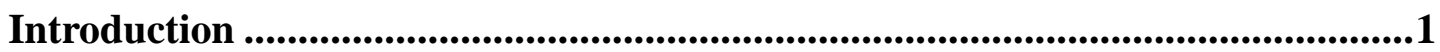

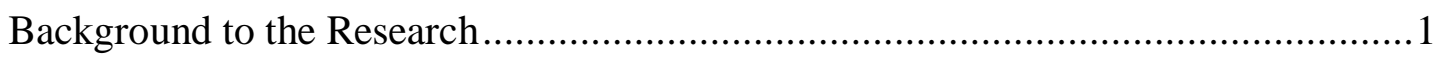

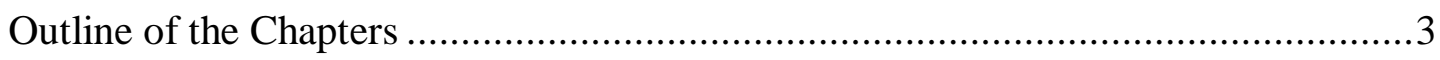

Chapter 1: Encouraging teacher criticality in an evidence-based environment? .....6

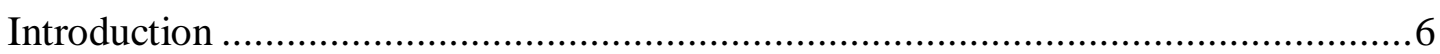

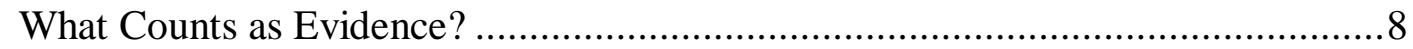

The Contestability of Evidence-Based Practice................................................. 10

Evidence-Based Practice in Education........................................................... 11

New Zealand's Iterative BES Programme and the Need for Critical Thinking .....13

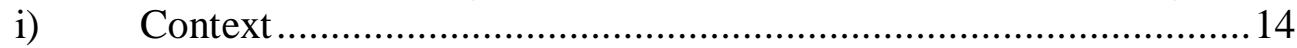

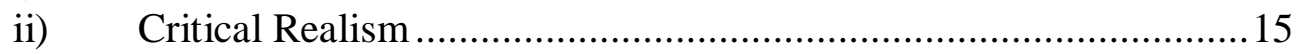

iii) Rigorous Eclecticism ............................................................. 16

Unintended Barriers to Teachers' Critical Thinking.......................................... 16

(i) Student Outcome Sets ............................................................ 17

(ii) Four Explanatory Mechanisms............................................ 17

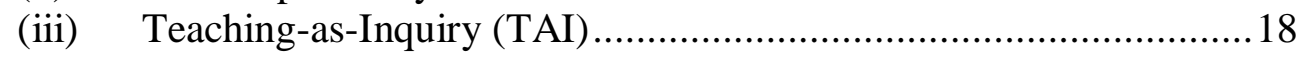

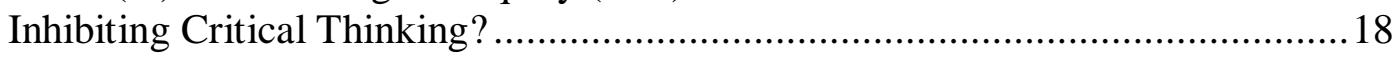

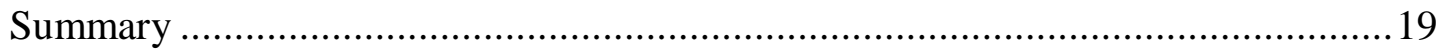

Chapter 2: Critical thinking and teacher engagement with published research evidence .............................................................................................21

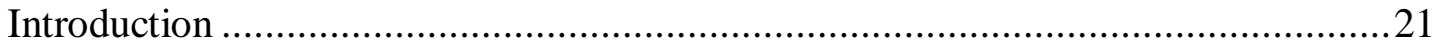

Teaching-as-Inquiry Necessitates Critical Thinking.....................................22

Definitions of Critical Thinking are Multi-faceted .......................................25

Paul and Elder's (2000) Critical Thinking Model as an Analytical Tool ..............28

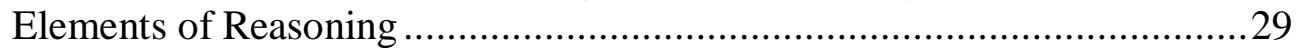

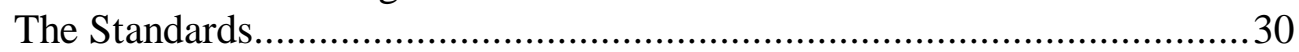

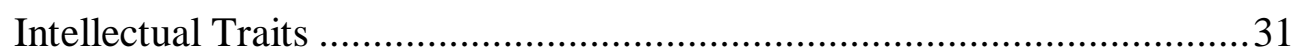

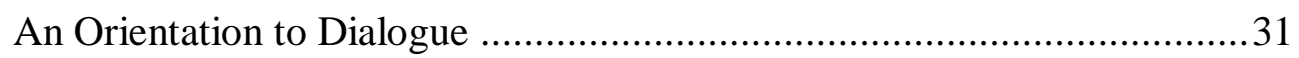

Paul and Elder's Model Requires Adaptation for this Thesis............................... 32

Published Research Evidence and Teachers' Day-to-Day Practice ........................35

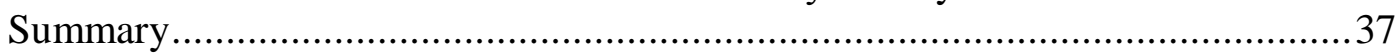

Chapter 3: Methodology ..................................................................................38

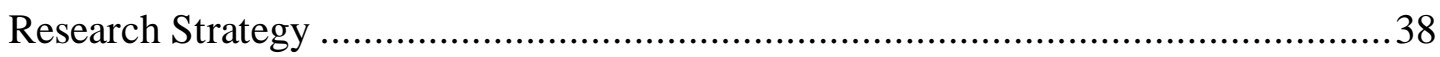

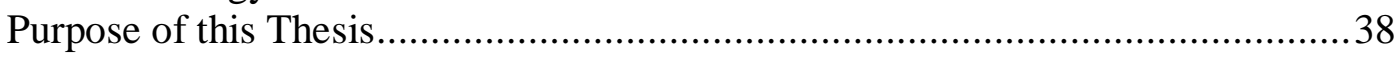

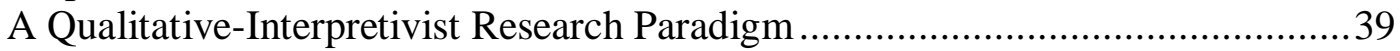

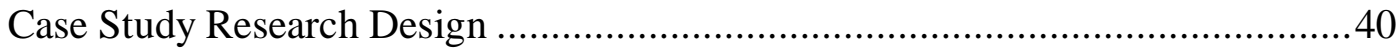

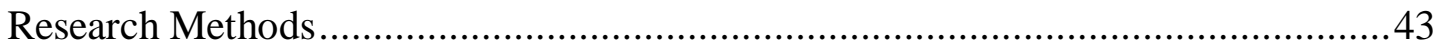

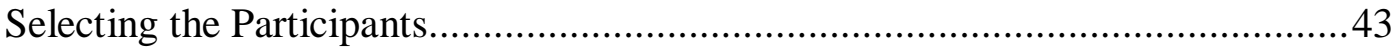




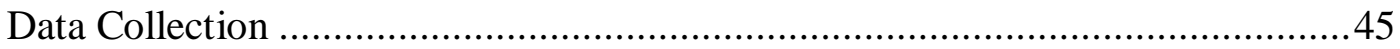

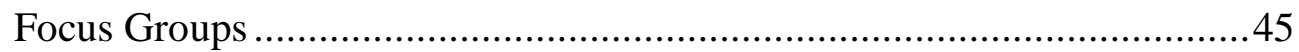

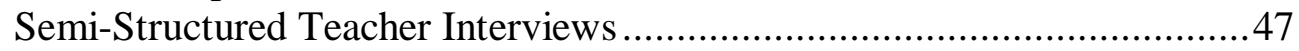

Semi-structured Interviews with Key Contributors ................................48

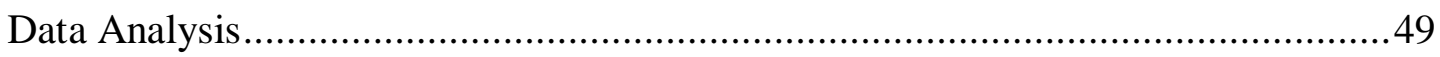

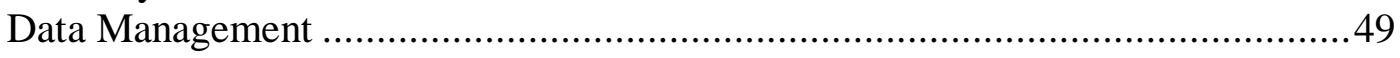

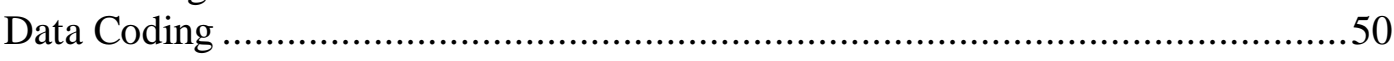

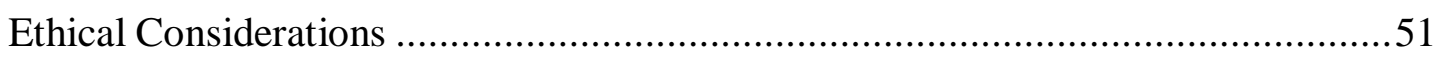

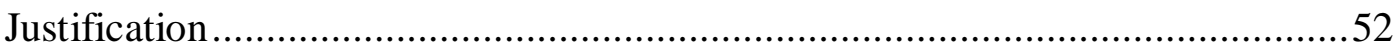

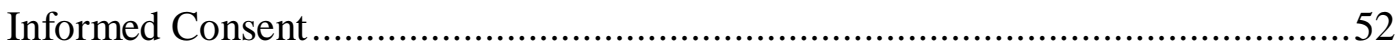

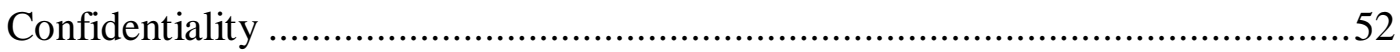

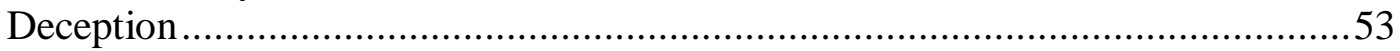

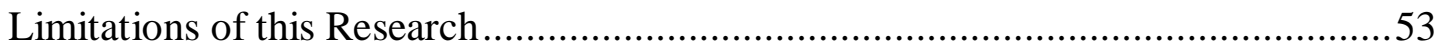

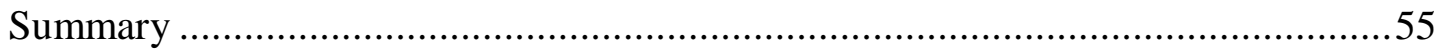

Chapter 4: Towards teacher critical engagement? The views of three key contributors to the Social Sciences BES.............................................56

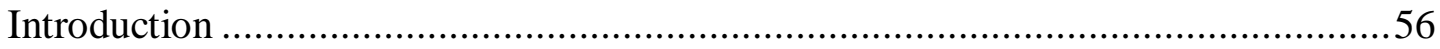

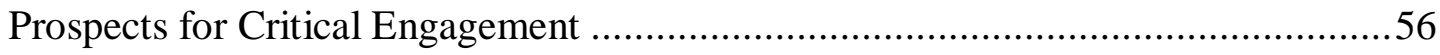

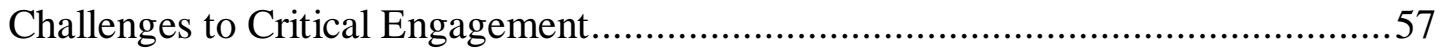

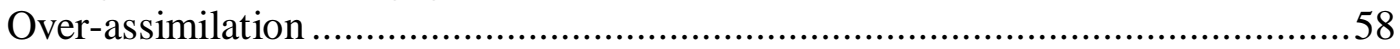

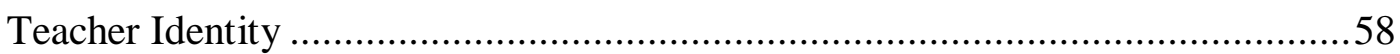

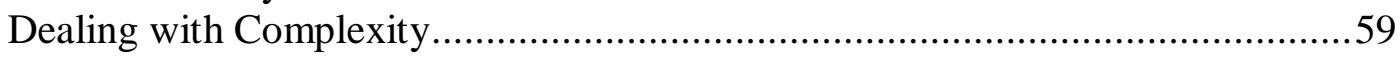

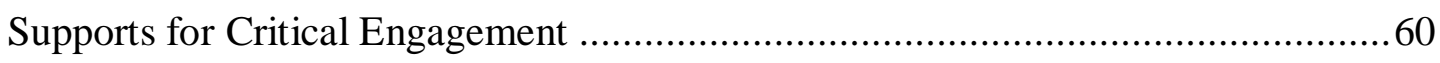

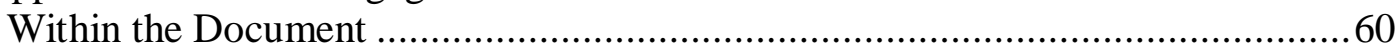

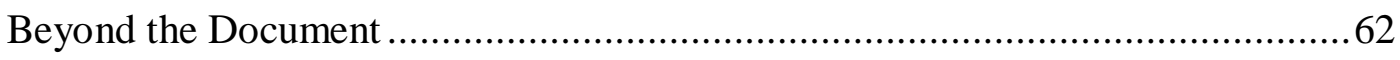

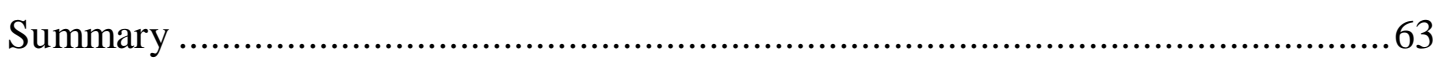

Chapter 5: Teachers' critical engagement with the Social Sciences BES ...........64

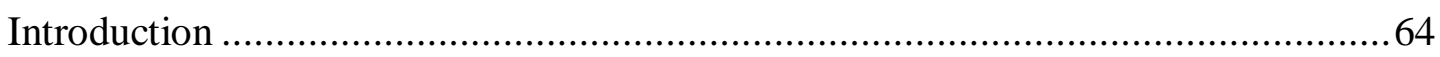

How Accustomed were Cherry Tree and Waterside Teachers at Using Research

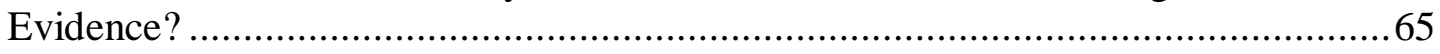

What have been the Outcomes of Critical Engagement with the Social Sciences

BES for Cherry Tree and Waterside Social Science Teachers? ..............................67

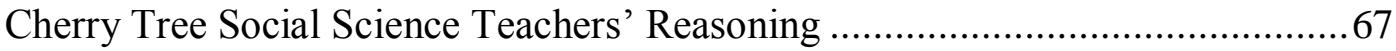

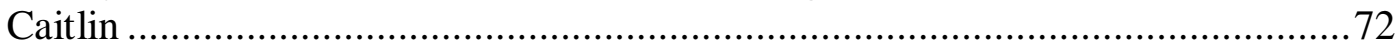

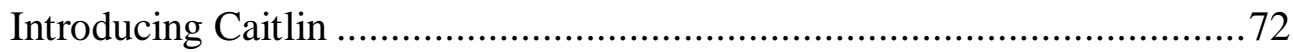

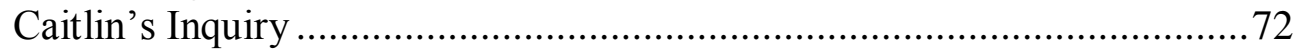

Analysing Caitlin's Critical Engagement with BES Literature .............................74

Absence of a Theoretical Orientation............................................................... 75

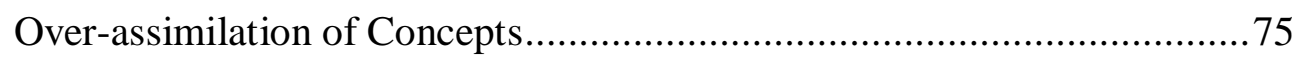

Methodological Information ......................................................... 76

Reasoning About Purpose of Research .................................................76

Waterside Social Science Teachers' Reasoning ............................................. 77 
What were the Facilitators and Constraints for Critical Engagement with Social

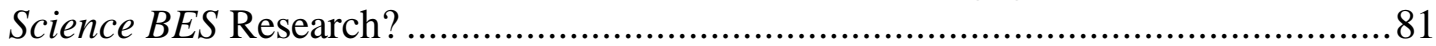

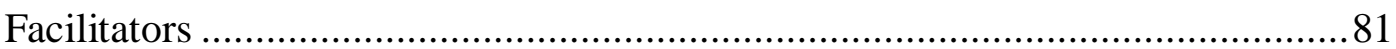

The Critical Thinking Model ........................................................... 81

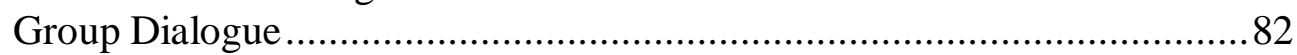

Focusing on Specific Pieces of Research ......................................... 84

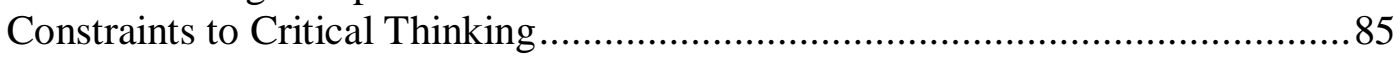

Lack of Group Structure and Accountability...........................................85

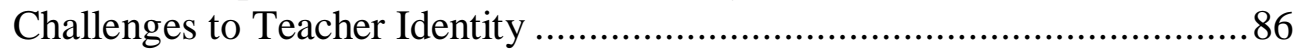

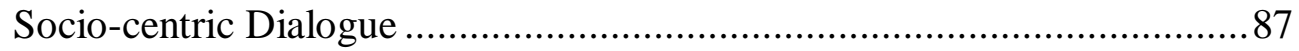

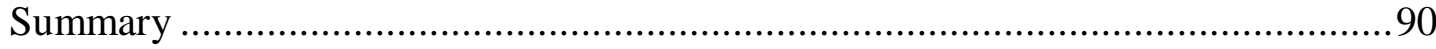

Chapter 6: Conclusions..............................................................................91

Recommendations for Enhancing Critical Engagement with the Social

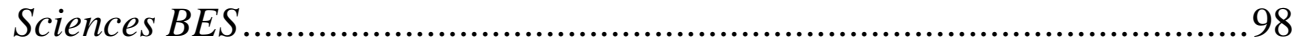

Future Research Directions for Critical Engagement with Social Sciences BES ..... 100

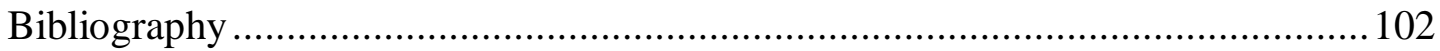

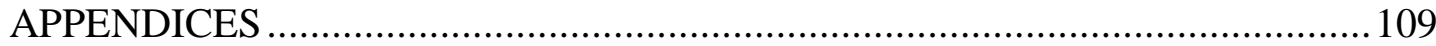

Appendix A: New Zealand Teacher's Council Teacher Self Assessment Tool...110

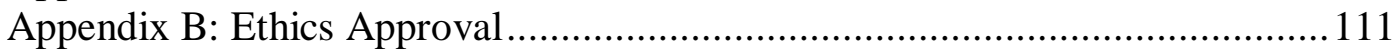

Appendix C: Time line of Data Collection................................................... 112

Appendix D: Framework for Participant Interviews (After Kvale, 1996) ............113

Appendix E: Phase 1 teacher interview schedule .......................................... 114

Appendix F: Phase 2 teacher interview schedule............................................ 115

Appendix G: Interview schedule for BES key contributors. .............................116

Appendix H: Principal Information Sheet and Consent form .......................... 117

Appendix I: Teacher Information Sheet and Consent form ..............................119

Appendix J: Key Contributor Information Sheet and Consent form ..................123 


\section{List of Figures}

Figure 2.1: Comparing 'Teaching-as-Inquiry' to action research models ................23

Figure 2.2 A framework for critical thinking definitions .................................26

Figure 2.3: Paul and Elder's (2000) Critical Thinking Model ................................29

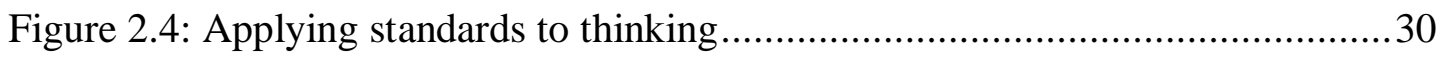

Figure 2.5 Adapted model to support critical engagement with Social Sciences

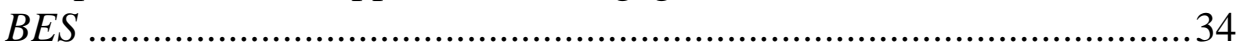

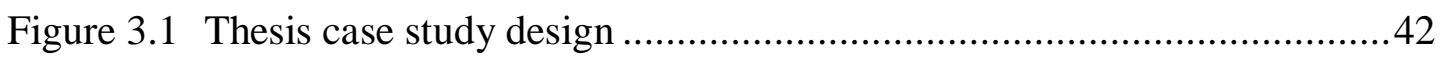

Figure 3.2: An example of unitizing codes from a focus group discussion...............50

Figure 5.1: Cherry Tree teacher reasoning before and after the introduction of the

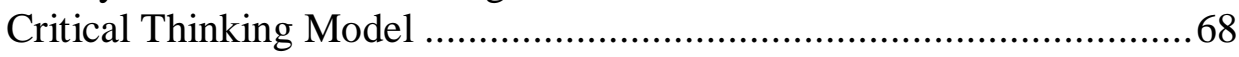

Figure 5.2: Cherry Tree teacher's reasoning during engagement with Social Sciences BES....

Figure 5.3: Waterside teachers' reasoning before and after the introduction of the

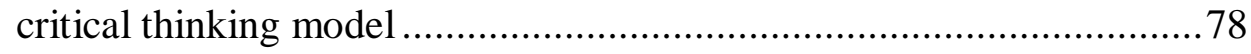

Figure 5.4: Waterside teachers' reasoning during engagement with Social Sciences $B E S$ .79

Figure 5.5: Waterside teachers' critique of a section of the Social Sciences BES .....80

Figure 5.6 Cherry Tree teachers' reasoning through dialogue .83

Figure 5.7: Socio-centric dialogue at Cherry Tree School 89

\section{List of Tables}

Table 3.1: Study participant demographics 


\section{Acknowledgements}

Whāia te iti kahurangi

Ki te tūohu koe, me he maunga teitei.

I would like to acknowledge, with sincere gratitude, the input and support from the following:

The teachers in this study: for giving so generously of your time and being so open with each other and me.

The three key contributors of the Social Sciences BES: for so graciously sharing a fraction of your prodigious knowledge and insights.

To Andrea Milligan, my supervisor: your ability to conceptualise so clearly and guide me how to write, without allowing me to become defeated, are greatly appreciated.

To Susan Kaiser, proof reader: your eagle eye and speed for edits are quite extraordinary. Bon Voyage!

To the VUW Faculty of Education Grants and Leave Committee: I appreciate the grant that allowed me to 'buy out' my teaching commitments for a trimester during the early stage of drafting this thesis.

I save the most important acknowledgement to last. To Katharine, Ella and Ollie: thank you for your patience and understanding for a project that took far longer than was originally intended. 


\section{Introduction}

\section{Background to the Research}

This thesis draws on qualitative data gathered in focus group meetings and interviews from ten teachers as well as interviews from three academics to examine social science teachers' critical engagement with Effective Pedagogy in the Social Sciences /Tikanga-a-iwi Best Evidence Synthesis (Aitken \& Sinnema, 2008) ${ }^{1}$. The release of the Social Sciences BES in 2008 marks the first time that New Zealand social science educators have had access to a synthesis of empirical evidence designed to support "policy makers, researchers, teacher educators, and - most importantly [my emphasis] teachers" (Aitken \& Sinnema, 2008, p. 45) in the exploration of 'what works' to improve student valued learning outcomes. By exploring classroom teachers' critical engagement with evidence-based pedagogical research, this study contributes to enduring debates about pedagogical-content knowledge. For example, there is considerable debate internationally about how, if at all, research should be utilised by teachers to improve their practice (Atkinson, 2000; Biesta, 2007a, 2007b; Broekkamp \& Van Hout-Wolters, 2007; Cordingley, 2008, 2010; Hargreaves, 1996; Hillage, Pearson, Anderson, \& Tamkin, 1998; Kennedy, 1999; Miretzky, 2007; Saunders, 2007 ; Tooley \& Darby, 1998).

The establishment of the New Zealand Ministry of Education's Iterative Best Evidence Synthesis Programme (Alton-Lee, 2008) reflects a desire on the part of successive administrations in New Zealand to increase the impact of teaching on student learning and to increase the impact of state investment in education. The programme is typical of many others established by Western nations to strengthen the knowledge bases of professions such as health, social care, and education (Hemsley-Brown \& Sharp, 2003). By bringing all the available research on teaching in the social sciences together and synthesising the results in a more usable form, the Social Sciences BES, as part of the wider Iterative BES Programme, is an attempt to

\footnotetext{
${ }^{1}$ Hereafter referred to as the Social Sciences BES
} 
support such improvements. However, it remains an open question as to what extent a synthesis of research evidence is able to support teachers, given that:

All research, however large-scale, brilliantly conceived, executed and communicated, needs to be actively interpreted by users for their own context...generic policy interventions will not work as recipes - they will always depend upon skilled teacher interpretation and judgement if they are to impact on day-to-day practice. (Cordingley, 2008, p. 49)

The need for skilled teacher interpretation resonates with an experience of mine, which, in part, was a driver for the topic of this thesis. Shortly after the release of the initial BES research (Alton-Lee, 2003), I was a teacher in a secondary school which had organised a group discussion of the findings of Alton-Lee's (2003) research. The prolonged silences at the meeting were deafening. The list of ten characteristics of quality teaching derived from the research were passed off as 'not rocket science' while the document was labelled as being 'self-serving' by one member of staff. I felt I was complicit in the lack of critical engagement. At the time I felt the language of the research was impenetrable and the weight of other administrative duties had relegated the BES document to 'future holiday reading'.

Emerging evidence suggests that the Social Science BES is being used to support inservice teachers in postgraduate study, facilitated by advisers (Dreaver, 2009; Sinnema, Sewell \& Milligan, 2011). However, in general there has been little exploration of the effect of the Iterative Best Evidence Synthesis Programme on practice, including how the Social Sciences BES might impact on social sciences teachers' practices. In particular, and though the purposes of social sciences education in New Zealand are strongly aligned to critical thinking about societal issues (Ministry of Education, 2007a), the extent to which social science teachers think critically about the nature of research evidence is hitherto unexplored. Exploring teachers' critical engagement with research literature is vital given that the Social Sciences BES strongly advocates a critical stance towards evidence, through the 'Teaching-as-Inquiry' framework (Aitken \& Sinnema, 2008), an approach intended to develop teachers' ability to actively engage in researching their own practice. This thesis suggests that a necessary condition of this is teachers' capacity to think critically about published research evidence. To this end, the following question has been considered: 
What impact does the use of a modified model for critical thinking have on secondary school teachers' critical engagement with Social Science BES research?

\section{Outline of the Chapters}

The first chapter explores what is meant by 'evidence' in the context of teachers' work. The argument advanced is that teachers have always drawn upon evidence in their teaching, although what counts as evidence is contested. The chapter locates the origins of evidence-based practice in the new managerial discourse of the medical profession, which has resulted in 'gold-standard' forms of medical research based on large scale meta-analyses of randomised controlled trials being considered the pinnacle of evidence. While New Zealand's Iterative Best Evidence Synthesis Programme distances itself from the narrow approach of the medical model of metaanalysis (Alton-Lee, 2008), Moore's (2006) study of the link between best evidence synthesis and policy advice registered comment from a policy analyst that the Iterative BES Programme may assume its own hierarchal position, potentially suppressing critical engagement:

I still think there is some debate in there, I don't think it is as cut and dried as saying that everything that [BES] says must be good and everything else must be bad...there is a danger that, that it becomes the Holy Grail. (Moore, 2006, p. 49)

The first chapter also highlights two competing arguments about evidence-based practice in education. On the one hand, according to its advocates, evidence-based practice is an effort to professionalise the teaching workforce by establishing a collective evidence base from which teachers can make wise decisions for the needs of their students. On the other, critics of evidence-based practice maintain this is a normative stance to the role of research evidence and is dangerous because it tends to focus teachers on efficient strategies for reaching pre-determined ends rather than giving due consideration to the value of those ends. The argument here is that evidence-based practice disempowers teachers by reducing their work to an instrumental function. This is because when the evidence is presented to teachers as 'what works', the possibility exists that they will cease to make their own critical judgements about what constitutes effective practice. Finally, in setting the scene for this thesis, the chapter outlines some of the features of the wider Iterative BES 
Programme that require critical thinking on the part of teachers, and explores key elements of the Social Sciences BES that may unintentionally prove a barrier to critical thinking.

The second chapter considers what is meant by 'critical thinking' in the context of this thesis. The first part of the chapter establishes the need for critical thinking about published research literature as an important component of the 'Teaching-as-Inquiry' framework. The second part acknowledges the difficulty in defining critical thinking, given the many meanings of the term. This difficulty notwithstanding, and in the third part of this chapter, the use of Paul and Elder's (2000) critical thinking model is introduced as a heuristic for examining teacher reasoning about published research evidence. Finally in this chapter, in order to locate this study in the cumulative evidence base of teacher engagement with published research literature, an examination of the barriers and facilitators to teachers' use of research evidence is presented.

The third chapter outlines the methodological approach of this thesis. The smallscale, exploratory case study design is located in the broad sweep of the qualitative tradition of educational research. I take an interpretivist stance in relation to the research question, recognising that there are multiple paradigms within the qualitative tradition. The perspectives and experiences of three academics that made key contributions to the Social Sciences BES and teachers from Cherry Tree and Waterside Schools are used to gain insight into teachers' critical engagement with published research evidence. This chapter describes how the empirical data for the study were collected using focus group meetings and semi-structured interviews, and analysed using coding conventions typical of qualitative research practices. The chapter concludes by considering some of the ethical implications and limitations of the methodological approach.

The fourth and fifth chapters are the empirical components of the thesis, incorporating analysis of interviews with three key contributors to the Social Sciences BES and the focus-group discussion and interview data from Cherry Tree School and Waterside School social science teachers. Chapter 4 presents key contributors' perceptions of the possibilities for, and challenges to teachers' critical engagement with published 
research literature. In Chapter 5, the analysis of focus-group discussions and teacher interviews explores the teachers' critical thinking before and after being introduced to an adapted version of Paul and Elder's (2000) critical thinking model. Chapter 5 also presents extended analysis of what is referred to in the thesis as an 'exceptional case'. The testimony of this teacher warrants close consideration because she was the only teacher in the sample who seemed to strive for something akin to 'pedagogic autonomy' (Castle, 2006), by which I mean she sought to integrate the Social Sciences $B E S$ evidence into her practice in order to enhance outcomes for her students in an inquiry orientated fashion. The case, therefore, has special significance to the research questions addressed in this study. The facilitators and constraints to these teachers' critical engagement with the Social Sciences BES are also identified in this chapter.

Chapter 6 is the conclusion of this study. This chapter links the findings of the research to existing literature about teachers' critical engagement with published research evidence. In particular, the conclusions focus on the need for intermediary support structures to promote teacher critical thinking about research. Implications of this research are indicated and further recommendations are made for the multiple stakeholders which have roles to play in advancing teacher critical engagement with published research. The chapter finishes by noting possible avenues for future research. 


\section{Chapter 1}

\section{Encouraging teacher criticality in an evidence- based environment?}

This first chapter locates the Social Sciences BES in the wider evidence-framed environment of education policy and practice. As part of the introductory framework for this thesis I defend three propositions, the first being that published research is privileged within what counts as evidence, yet its role in evidence-based practice is problematic. I note that teachers have always used evidence, although what counts as evidence has become increasingly contested. Second, I argue that the Iterative Best Evidence Synthesis Programme commitment to context, critical realism and methodological pluralism are all underpinned by critical thinking. Third, I suggest that despite the explicit acknowledgement of the fallibility of evidence and need for teacher inquiry mindedness, some aspects of the Social Sciences BES may inadvertently impede teacher critical thinking about published research.

\section{Introduction}

In response to governments' desire for value for money in the public sector, the Iterative Best Evidence Synthesis programme may be viewed as typical of a global agenda to strengthen the knowledge bases of professions such as health, social care and education (Hemsley-Brown \& Sharp, 2003). The requirement that research strengthens knowledge bases reflects a new order of global education governance in which international league tables of student achievement are regularly cited as cause for concern in New Zealand (Alton-Lee, 2005a, 2007, 2008). These internationally comparative data sets have generated an increasingly competitive policy playing field in which countries seek out effective policies to advance student social and economic prospects, improve school efficiency, and mobilize resources to meet increasing demands (Figazzolo, 2009). A consequence for education policy has been increased focus on evidence of 'what works' for lifting student achievement. 
In New Zealand, the search for robust evidence of what works has permeated the education policy environment. For example, Making a Bigger Difference for all Students: Schooling Strategy 2005-10 (Crown, 2005) includes evidence-based practice as a strategic priority to ensure 'high academic and social outcomes for students' in New Zealand. Likewise, the Statement of Intent 2009-2014 indicates that the New Zealand Ministry of Education will use "new and emerging data and evidence: national and international studies... and research such as Best Evidence Synthesis" (Ministry of Education, 2009, p. 6). Notably, in the context of this thesis, the New Zealand Teachers Council requires teachers to use evidence as part of the Registered Teacher Standards. Specifically, teachers are expected to "use critical inquiry and problem-solving effectively in their professional practice" of which one indicator is to "systematically and critically engage with evidence and professional literature [my emphasis] to reflect on and refine practice" (New Zealand Teachers Council, 2010). However, just what 'systematic and critical engagement' might look like is open to interpretation (see Appendix A).

The publication of the Social Sciences BES is the first time that a collection of social science specific research evidence has become widely available in New Zealand. The Social Sciences BES encourages teachers to inquire into what works in their classrooms, a component of which is the need for teachers to critically engage with published research evidence (Bell, Cordingley, Isham, \& Davis, 2010). As outlined in Chapter 2, my notion of critical engagement draws heavily upon Western liberal conceptions of critical thinking. To set the scene for teachers' critical engagement with published research evidence, this chapter explores three related propositions: (a) that published research is privileged within what counts as evidence, yet its role in evidence-based practice is problematic - this section advances the argument that teachers' critical engagement with research evidence is a necessary component of their decision making, particularly when set against a backdrop of competing arguments about the 'empowerment' and 'entrapment' of teachers by evidence-based practice; (b) that underpinning commitments of the Best Evidence Synthesis Programme require teacher critical thinking - this section highlights New Zealand's approach to synthesising research, which eschews the search for certainty, instead promoting the fallible and contingent nature of research evidence; and (c) that, despite acknowledging the fallibility of evidence, some aspects of the Social 
Sciences BES may inadvertently prove to be a barrier to teacher critical thinking about published research.

\section{What Counts as Evidence?}

In this section I note that teachers have traditionally used many forms of evidence as they make decisions about their work. What counts as evidence is open to debate; however, I argue that of the different forms of evidence available to teachers, published educational research is currently privileged.

The use of evidence by teachers has a long history that might tempt some to believe that championing teaching as an evidence-based profession is akin to presenting old wine in new bottles. In New Zealand, the writing of Sylvia Ashton-Warner (1963) provides a vivid auto-biographical account of her effort to connect with and improve the reading and writing of her predominantly Māori pupils. In her account, Ashton-Warner describes how an orthodox reading series (published in the USA) used with early readers offered scant cultural relevance to the children she was teaching in rural New Zealand. Her personal and critical theory was the result of hours of observations of her students which built an evidence base through identifying the reading and writing problems, developing a pedagogical approach more suitable for her young learners and determining the effectiveness of her approach. The development of professional knowledge through experience, or craft knowledge, has long been acknowledged as a dominant source of knowledge for teachers (Lortie, 1975); a 'learning by doing' approach that firmly places teacher experience at the centre of the evidence base (Kennedy, 2002).

In a keynote address to the UK's Teacher Training Agency annual conference, David Hargreaves (1996) critiqued the teaching profession's over-reliance on craft knowledge and, moreover, the failure of educational research to provide teachers a robust evidence base. He argued that the lack of classroom-based systematic research evidence challenged the professional legitimacy of the teaching profession:

In education there is simply not enough evidence on the effects and effectiveness of what teachers do in classrooms to provide an evidence-based corpus of knowledge. The failure of educational researchers, with a few exceptions, to create a substantial body of knowledge equivalent to evidencebased medicine means that teaching is not - and never will be - a researchbased profession unless there is a major change in the kind of research that is done in education. (p. 4) 
This critique of 'what counts' as evidence in the teaching profession soon began to appear in high level inter-governmental reports where craft-practice was positioned as an inhibiting factor to the development of a profession-wide knowledge base:

The art of teaching probably remains largely self-taught through individual trial-and-error learning in the busy but professionally isolated world of the classroom where there is little opportunity for reflection. In consequence the teacher's knowledge base is unusually rich in personal, tacit know how but impoverished in terms of shared, codified knowledge. (Organisation of Economic Co-operation and Development, 2000, p. 45)

Such a statement signals that sources of published research evidence have, generally speaking, failed to make a widespread, enduring impact on the daily routines of teachers' professional lives. Rather, teachers tend to rely on more immediate sources of 'evidence' such as curriculum directives and student assessments (Kennedy, 2002). As a consequence of this perception, there has been a concerted effort to support teacher decision making with the use of evidenced-based initiatives that demonstrate best practice approaches. For example, the What Works Clearinghouse ${ }^{2}$ (hosted by the United States Department of Education), the Evidence for Policy and Practice Information and Co-ordinating Centre (EPPI-Centre) ${ }^{3}$ and The Centre for the Use of Research and Evidence in Education (CUREE) ${ }^{4}$ are leading examples of the desire to foster the link between published research evidence and teachers' daily work. With the desire for rigorous research evidence to inform teacher decision making, it appears that what now counts most is 'gold standard' evidence that attempts to create generalisations through large scale meta-analyses, underpinned by randomised controlled trials in order to put:

emphasis on determining which educational programs and practices have been proven effective through rigorous scientific research. Federal funding is targeted to support these programs and teaching methods that work to improve student learning and achievement. In reading, for example, No Child Left Behind supports scientifically based instruction programs... (United States Department of Education, 2004, p. 1)

The trend to privilege education research is borne out of a desire to define the prospects for a science of teaching, producing knowledge of such robustness that teachers would waste their own time trying to rediscover them and their students'

\footnotetext{
${ }^{2} \mathrm{http}: / /$ ies.ed.gov/ncee/wwc/

3 http://eppi.ioe.ac.uk/cms/

${ }^{4} \underline{\mathrm{http}: / / \text { www.curee.org.uk/content/about-us }}$
} 
time by focusing on anything less certain (Edwards, 2000). Basing practical decisions on the strength of compelling research evidence follows an engineering / medical model, but is this applicable to education?

\section{The Contestability of Evidence-Based Practice}

In this section I outline the origins of evidence-based practice, which can be located in the broader rise of 'new-managerialism' in the medical profession, in response to perceived inefficiencies and insufficient accountability in the public health system. I signal that, while evidence-based medicine has become the orthodoxy, it has proven contentious.

The evidence-based practice movement has its origins in the field of medicine, as a result of concerns that much medical decision-making was based on individual clinician preferences rather than scientifically substantiated claims. For example, Evans and Benefield (2001) cite a report from the UK Department of Health that estimated a mere $15 \%$ of medical interventions used in the National Health Service could be supported by exacting scientific evidence, and many practices with a strong evidence base were not being used. Evidence-based medicine uses published research findings as an indispensable part of the decision-making processes of health-care professionals. Common to models of evidence-based medicine are a) the identification of a problem/need for change, b) the search for relevant research literature, c) the critical appraisal of that literature, d) integration of these findings into reality, and e) evaluating the impact of the implementation of research evidence (Mantzoukas, 2006). At the centre of evidence-based medicine is the development of 'gold-standard' research, which enables maximum standardization of practice and reduction in errors. Mantzoukas argues that the desire for this gold-standard of research has promoted a hierarchy of research evidence, in which meta-analyses of randomised control trials are the pinnacle, inevitably leading to:

...the de-emphasis of intuition, unsystematic clinical experience and pathologic rationale for clinical decision making...[and] instead places emphasis on the examination of evidence from clinical research (p. 216)

Moreover, it is an open question whether the use of 'gold-standard' evidence involves critical appraisal of the literature, or whether the positioning of such 
evidence at the apex of the evidence hierarchy results in uncritical acceptance by practitioners who use it.

Evidence-based medicine is, however, not without its critics (Hancock \& Easen, 2004; Michelson, 2004; Porta, 2004; Rosenfeld, 2004). While the medical world does not dispute the importance of good decision-making informed by research, it also recognises the limitations of evidence-based practice if it becomes privileged to such an extent that other credible sources of evidence are not given due regard. While evidence-based medicine may be particularly useful for the application of certain drugs when high levels of transferability are possible, many if not most, fields of medicine are cognisant of the context in which the intervention is being administered (Harding et al., 2011). Such findings point towards evidence-based medicine serving as an informant rather than a determinant of medical decision making, in order to accommodate medical expertise and patient preferences in the decision-making process. Ironically, this more recent 'softening' of the position of medical research indicates it may have come full circle, given an early, influential definition of evidence-based medicine which highlighted the evidence 'mix', involving:

conscientious, explicit, and judicious use of current best evidence in making decisions about the care of individual patients. The practice of evidence based medicine means integrating individual clinical expertise with the best available external clinical evidence from systematic research. (Sackett, Rosenberg, Muir Gray, Haynes, \& Richardson, 1996, p. 71)

Similar to the field of medicine and health, evidence-based practice has pervaded education policy and practice and, as the next section outlines, the contestability of evidence-based practice continues to surface.

\section{Evidence-Based Practice in Education}

Having outlined the contestability of evidence-based medicine, in this section I shift attention to how similar debates have also permeated education. I chart how evidence-based practice has been championed as empowering the teaching profession, by providing a robust evidence base that can help improve pedagogical decisions in order to improve student learning outcomes. I contrast this with critiques of evidence-based practice, that challenge the positioning of teachers as providers of the means of education (this is, how to do it) without due consideration of the ends of education (why, if at all, should we be doing it?). 
Building a systematic evidence base for 'what works' in education is considered a worthwhile investment in order to enhance pedagogical practice across the profession (Alton-Lee, 2006a). Research syntheses are designed to empower teachers by deepening their understanding of the impact of pedagogical approaches, which they may successfully integrate with other practice knowledge bases to improve educational outcomes for student learning (Nuthall, 2004). Part of this is an attempt to support teachers by improving access to better quality research of greater relevance, to apply in their classroom. Teacher empowerment is clearly evident in New Zealand's Best Evidence Synthesis Programme, the goal of which:

is not one of tired educators negotiating rapidly changing policies and fads... [but] of shared knowledge about what works and why in local contexts as a valued, dynamic and transformational resource enabling an education system to renew and sustain itself. (Alton-Lee, 2007, p. 1)

According to Elliott (2004), the empowerment of teachers is facilitated by evidencebased practice when teachers not only consume research evidence, but are responsible for the creation of new knowledge as a component of their inquiries into professional practice. Thus, the empowerment of the teacher is not through the transmission of knowledge from researcher to practitioner, but as a result of teachers becoming active creators of knowledge as a result of participating in research procedures in their own contexts. An aim of this thesis is to explore the role that critical thinking has in this process.

In contrast to the empowerment trajectory, Elliot (2004) charts the possibility of 'entrapment' if evidence-based practice constrains teachers' thinking about what type of evidence matters, and encourages the use of evidence in instrumental fashion without due consideration of the ends of educational practice. This argument is closely aligned to other academic critiques of evidence-based practice, such as Biesta (2007a) who argues that focussing simply on 'what works' narrows the scope of teachers' questions, and obscures more fundamental issues about what is desirable for education. Nuthall similarly decries an instrumental approach to the use of research evidence:

While there is a place for the comparison and evaluation of specific methods and techniques of classroom management and teaching, such research presumes that the non-creative or non adaptive replication of methods and techniques is an appropriate way to teach effectively. It also leads directly into the use of research as a means of controlling how teachers interact with their students. (Nuthall, 1999, cited in Alton-Lee, 2006a, pp. 621-622) 
International critiques of evidence-based practice run along at least three lines of argument. First, Atkinson (2000) argues that the 'what works' agenda has the potential of reducing the significance of theoretical research in favour of empirical studies. Second, the methodological preference for stringent inclusion criteria for systematic reviews is the concern of some writers. For example, systematic reviews that are generated from journal articles only may exclude work of equally high quality published in other places, might reduce the overall number of reviewed articles to single digits, or are so standardized in their format that they miss the richness of the contexts of the contributing studies (Kennedy, 2007; Maclure, 2005). A third line of critique argues that the positivist assumption that 'what works' in one classroom setting can be readily transferred to a different group of students belies the complexity of open systems of interacting elements (Biesta, 2007a; Pring, 2004). Despite the best intentions of a teacher to replicate research evidence to improve student outcomes, it is very unlikely that the conditions of the classroom are the same as those in the original study, leading to the probability that while the teaching 'inputs' may be very similar, the learning 'outputs' could be very different (Pring, 2004).

\section{New Zealand's Iterative BES Programme and the Need for Critical Thinking}

The Social Science BES is one publication of New Zealand's wider Iterative BES Programme, which at the time of writing has seven titles with the common purpose of explaining 'what works' for a range of desired outcomes for diverse learners. The Iterative BES Programme is a New Zealand contribution to the global evidenceframed policy environment, in which research has been synthesised to provide an explanatory framework for the effectiveness of classroom pedagogies in relation to desired outcomes for diverse learners (Alton-Lee, 2006a). Established by the Medium Term Strategy Policy Division of the New Zealand Ministry of Education, the BES Programme is expected to inform the decision-making of stakeholders across the education system:

Underpinning the approach [of the BES programme] is a systematic policy agenda to highlight the rich resource that $\mathrm{R} \& \mathrm{D}$ offers and to strengthen capability across the teacher education and educational research sector overall to be more helpful to teachers and educational leaders. (Alton-Lee, 2005a, p. 7) 
Although part of the global syntheses research stable, Alton-Lee (2006) has stressed that comparisons of the Iterative BES Programme to synthesising randomised controlled trials or systematic reviews are misguided. This is because such comparisons wrongly assume the Iterative BES Programme is "a clone of those approaches despite its explicit commitment to the significance of context, critical realism, rigorous eclecticism, use of outcomes-linked case study examples" (AltonLee, 2006b, p. 8). The very existence of different synthesising approaches, not to forget the diversity of research within each synthesis, is partly the rationale for this thesis:

Teachers need to know about the basics of good research, whether or not they ever conduct their own research. They need to be able to analyse critically the research evidence that they read as part of their professional role, and to judge its findings and conclusions from a well informed point of view. (Campbell, Freedmand, Boulter, \& Kirkwood, 2003, p. 4)

The following section examines aspects that stand the Iterative BES Programme apart from other international approaches to synthesising large bodies of evidence and notes implications that this has for the critical engagement of teachers.

\section{i) Context}

Commitment to context is an acknowledgement that 'what works' solutions to education problems are problematic for teachers in diverse classrooms, schools, and communities. At a broad level, the Iterative BES Programme "emphasises the importance of cultural identity in education, but counters the stereotyping of individuals by group affiliation, and denotes diversity...by intersections of gender, cultural heritage(s), socioeconomic background, and talent" (Alton-Lee, 2004, p. 23). For this reason, the Iterative BES Programme seeks to synthesise material in a way that offers rich accounts of educational practice, using vividly illustrated vignettes and case studies in order that teachers are able to explore what works, for whom, in what circumstances. I suggest that critical thinking when engaging with context is important. Uncritical acceptance of research evidence may mean that teachers simply take findings from the Social Science BES and graft them on to their own (different) groups of students. Conversely, and if teachers privilege the uniqueness of their own teaching context, they may be sceptical about research which does not appear to explicitly relate to their own context (Castle, 2006; Coburn $\&$ Talbert, 2006). 


\section{ii) Critical Realism}

Drawing on her experience of co-authoring the Mathematics BES, Walshaw (2008) argues that the development of the Iterative BES Programme is a post-modern alternative to other jurisdictions" evidence-based research that overplay "the vantage point of scientificity" (p. 21). It is also interesting that Walshaw notes a critical realist sensibility in the conceptual framework of the Iterative BES programme, a paradigm which marks middle ground behind the naïve realism of positivist research and the radical relativism of post-modernism (Guba \& Lincoln, 2005). This middle ground is marked by critical realism's position that although social objects exist in reality (an untenable position for most post-modern thinkers), our knowledge about them remains a social construct. Thus, although a critical realist ontology is of a 'real' reality, that reality works on many different levels as the result of impartial knowledge (Scott, 2010).

While the debates around critical realism are much wider in scope than necessary for this thesis, it is suffice to note that by seeking a middle ground between certainty and relativism, critical realism offers considerable explanatory power that neither overpromises nor under sells. In the context of the Social Sciences BES this explanatory power manifests itself in the four 'mechanisms' which acknowledge "the context dependent nature of pedagogy-outcomes links and avoids the suggestion that the findings are prescriptive and certain" (Aitken \& Sinnema, 2008, p. 43); in other words, "student outcomes are not caused by teaching practice, as they are occasioned by a complex web of relationships" (Walshaw, 2008, p. 21). This critical realist ontology of probability over certainty is sharply outlined in the Teaching-as-Inquiry section of the Social Sciences BES, which acknowledges the inherent complexity in teaching situations and that teachers are unlikely to find recipes for 'best practice'. Moreover, the need for critical thinking is imperative if teachers are to honour the spirit of the critical realist view of the world to which the Iterative BES Programme is committed. Because knowledge about social reality is socially constructed, it requires a reciprocal commitment of criticality from those who engage with its findings in order for deeper understandings about 'what works' to be explored by teachers. 


\section{iii) Rigorous Eclecticism}

A further feature of the Iterative BES Programme is its commitment to a 'rigorously eclectic' approach to synthesising research (Alton-Lee, 2004). In essence, this approach is an effort to avoid the pitfalls of meta-analyses which have alienated researchers and practitioners because of the narrow use of a natural science model of what counts. A reason for this alienation, as noted earlier in this chapter, is that the drive for 'goldstandard' research has excluded many other forms of educational research, particularly from the qualitative paradigm. In contrast, the Iterative BES Programme has been inclusive of a wide range of research paradigms and methodological approaches. Although influenced by international best evidence synthesis (especially Slavin, 1986), the New Zealand version has established its own identity by incorporating evidence from the broad paradigms of quantitative and qualitative research.

It follows then, that because the Iterative BES Programme is eclectic, teachers will need to be attentive to the varied forms of research it has synthesised. While Aitken and Sinnema (2008) produce a methodologically robust synthesis, this does not diminish the need for teachers to be attuned to differences in theoretical and methodological approach as they engage with specific pieces of research.

\section{Unintended Barriers to Teachers' Critical Thinking}

Having examined key commitments of the wider BES Programme, the remainder of this chapter examines the Social Sciences BES, a landmark publication, which as noted above, is the first in New Zealand in which research evidence specific to the social sciences subject domain has been synthesised. Historically, the social sciences learning area has been relatively underserved by pedagogical research compared to other curriculum areas such as maths, literacy and science. Moreover, what is known suggests that some social science pedagogical practices have worked against the aims of the subject, for example, developing the very racism and bullying that effective social science teaching and learning seeks to address (Alton-Lee, 2008).

In this next section I briefly outline three key structural dimensions of the Social Science BES - (i) student outcomes; (ii) explanatory mechanisms; and (iii) teaching as inquiry. I then argue that despite the explicit commitment of the document to the fallibility of evidence and an 'inquiry-minded' approach to the teaching-learning 
nexus, the Social Sciences BES might unintentionally impede teachers' critical thinking.

\section{(i) Student Outcome Sets}

The research within the Social Sciences BES is anchored to a series of outcome sets. What differentiates the Social Sciences BES from other jurisdictions' synthesised research is that the outcome sets go beyond the traditional (and easier to measure) focus on knowledge and skill outcomes and include identity, social participation and affective outcome sets. Student outcomes were an aspect of the inclusion criteria of research in the Social Sciences BES. Student outcomes influenced the weight of evidence each study was given, according to the degree of detail about student outcomes in the original research. Of the 242 studies that offered a causal explanation or information from which a causal explanation could be derived, 100 studies described in detail outcomes for particular students or sub-groups of students, while a further 75 studies included details of the outcome(s) as generalised to a whole group (Aitken \& Sinnema, 2008).

\section{(ii) Four Explanatory Mechanisms}

The four explanatory pedagogical mechanisms of 'connection', 'alignment', 'community' and 'interest' are, in essence, the 'what works?' findings of the Social Science BES. At the heart of the Social Science BES is an important distinction about the nature of causality between teaching and learning, reflecting the largely unstated critical realist theoretical orientation noted earlier in this chapter. This distinction is alluded to on pages 41-43 of the Social Sciences BES in which it is stated that "the research aimed to explain - not just identify - these relationships [between pedagogy and student outcomes]...to avoid narrow linear conceptions of causality" (Aitken \& Sinnema, 2008, p. 41). To this end, the Social Sciences BES supplements a) descriptive causal knowledge claims (did x cause y/ 'what works?') with b) an explanatory model of the processes (why or how is the relationship between $\mathrm{x}$ and $\mathrm{y}$ happening?/ 'in what circumstances'?). Such a distinction is important, insomuch as it marks the philosophical schism between research which has the primary aim of describing the consequences attributable to deliberately varying a treatment, and research which may significantly help explain the mechanisms and the conditions under which that causal relation holds (Maxwell, 
2004). It follows then, that the four Social Sciences BES mechanisms are not variables, but an account of the makeup, behaviour and interrelationship of those processes which are responsible for the regularity between pedagogy and outcomes (Pawson \& Tilley, 1997). The four explanatory mechanisms of 'connection', 'alignment', 'community' and 'interest' that frame the entire Social Sciences BES thus loosen the tight-knit cause and effect link typically presented in evidence-based research that seeks to identify and generalise 'best practice'.

\section{(iii) Teaching-as-Inquiry (TAI)}

Drawing on the notion of an inquiry-stance to teaching (Cochran-Smith \& Lytle, 1999), TAI is strongly advocated to underpin teachers' professional practice as they engage with and in evidence. The TAI model developed in the Social Sciences BES helps teachers "inquire into the impact of their actions on their students and into interventions that might enhance student outcomes" (Aitken \& Sinnema, 2008, p. 52). The TAI model, which I will explore in greater depth in Chapter 2, identifies a number of key stages of teacher inquiry. At the heart of the TAI model, and consistent with the commitments to context and critical realism of the overarching Iterative BES Programme, is the idea of the fallibility of evidence. Thus each stage of TAI requires critical engagement with evidence.

\section{Inhibiting Critical Thinking?}

The Social Sciences BES might be considered as a 'gold-standard' of New Zealand educational research, due to its robust rationale, significant amount of stakeholder input, ${ }^{5}$ transparent methodological approach, and clear communication of findings. This positioning of the Social Sciences BES may unintentionally lead to a lack of critical engagement with the evidence contained within, such that it becomes a recipe book for best practice rather than a source of current best evidence.

A barrier to critical engagement with the Social Sciences BES is also the potential for teachers to over-assimilate its content. In the context of curriculum policy implementation, Spillane, Reiser and Reimer (2002) argue that over-assimilation is

5 The 'Iterative' nature of the Social Sciences BES reflects, in part, the contractual obligation between the Ministry of Education and BES authors, to present findings to key stakeholders, including: authors of the original work being synthesised, advisory panels of education professionals, and international peer reviewers. 
the tendency for ideas to be understood in superficial ways, such that they are incorporated into pre-existing schemas without generating changes to practice, even if policy signals are for fundamentally different approaches. In the Social Sciences $B E S$ for example, the titles of the four mechanisms outlined earlier: 'Community', 'Alignment', 'Connection', and 'Interest' are such accessible ideas that there is the possibility that they receive only superficial attention. Each of the four simply worded mechanisms carries with it layers of complexity that require skilled interpretation and sustained examination, otherwise the vocabulary may be appropriated to describe business as usual, with little sign of changes in practice.

The possibility of inhibited critical thinking lies in the very challenge of synthesising hundreds of pieces of research. Because that synthesis strongly foregrounds student outcomes, the wider theoretical background in which pedagogical research is located is sent to the background. While the Guidelines for Generating a Best Evidence Synthesis Iteration (Alton-Lee, 2004) do indeed request that authors examine the theoretical underpinnings of included research, theoretical frames of research were not emphasised in the final publication. ${ }^{6}$ This observation is important, because without a clear signposting of theoretical orientation of research, teachers may not see the potential to critically link particular teaching methods or classroom interventions with the kind of theoretical vision of students as learners, classrooms as cultures, and the possible worlds open to students (Cochran-Smith, Barnatt, Friedman, \& Pine, 2009). An implication of not critically viewing pedagogical approaches situated in their wider theoretical frame is that teaching strategies become cherry picked 'attractivities'?

\section{Summary}

This chapter builds the argument advanced in the thesis, namely, that there is a need to test teachers' critical engagement with Social Sciences BES research evidence. This is because if the wider Iterative BES Programme is going to contribute to the empowerment of the profession then it requires teachers to be able to critically think

6 There are, of course, times in which theoretical underpinnings of research are elaborated, including some of the 10 case studies.

7 'Attractivities' signal teaching pedagogies that appear useful for their interest to students, yet may not serve the intended purpose of learning. With thanks to a group of VUW BTeach 200 level students who coined this phrase. 
about the weight of research evidence in order to decide how it might support pedagogical decision making in their local setting. To avoid such critical engagement, however, may result in the unintended consequence of teachers placing the Social Sciences BES at the summit of the hierarchy of evidence, such that it becomes the 'how to' manual for teaching social sciences - resulting in the type of entrapment that critics of evidence-based practice fear will take place if teachers cease to make their own critical judgements about what constitutes effective practice.

The need to test teachers' critical engagement with the Social Sciences BES as part of the wider Iterative BES Programme is also necessary because of the complexity of the project. As the chapter has outlined the commitment to context, critical realism and rigorous eclecticism that underpin the BES Programme mark the project out as a unique approach to international field of research synthesis. It behoves New Zealand based teachers to have a grasp of this uniqueness if the Iterative BES Programme is to meet the aim of sustaining the profession through research and development (Alton-Lee, 2007). 


\section{Chapter 2:}

\section{Critical thinking and teacher engagement with published research evidence}

This chapter draws on literature that explores critical thinking and teachers' relationship with published research evidence. It is my first and central contention that the TAI model, a central platform of the Social Sciences BES, necessitates critical thinking. Second, I consider some of the key dimensions of 'critical thinking', and highlight points of convergence and divergence among its varying definitions. Third, I present a model that reflects these dimensions and is key to the methodology of this thesis. Fourth, I identify some of the known barriers to teachers' engagement with published research evidence.

\section{Introduction}

It is the purpose of this thesis to explore a small, but significant, component of a critical stance to evidence: critical thinking about Social Sciences BES research. This chapter focuses on two dimensions of this question: critical thinking and teachers' engagement with research. I begin by arguing that the TAI model, a key feature of the Social Sciences BES, necessitates critical thinking in line with other action research models. Defining what 'critical thinking' might be is far from straightforward, however, and many definitions are associated with the term. Nevertheless, a review of the critical thinking literature suggests that over time there appeared some broad congruence between definitions that stress skills and dispositions. Borrowing from a model of critical thinking by Paul and Elder (2000), I will defend why a focus on eight elements of reasoning, which are part of critical thinking, is a suitable heuristic for analysing teachers' engagement with published research evidence. Finally, I explore the wider literature that focuses on the facilitators and barriers to teachers engaging with research. 


\section{Teaching-as-Inquiry Necessitates Critical Thinking}

Though the TAI model may appear newly conceptualised in the Social Sciences $B E S$, it in fact draws on the long established tradition of practitioner research which enables teachers to test the assumptions of educational theory in practice (CochranSmith, et al., 2009; Coghlan \& Brannick, 2010; Hopkins, 1994; Lewin, 1946). The process of practitioner research is necessarily underpinned by the ability to think critically, echoed in Coghlan and Brannick's (2010) rationale for action research which “expects us to stop just going through the motions, doing what we've always done because we've done it, doing it the same way because we have always done it that way" (p. 16).

As demonstrated in Figure 2.1, the main stages of the TAI model are broadly aligned to the traditional steps of action research which involve variations on planning, action and evaluation stages (Carr \& Kemmis, 1986; Coghlan \& Brannick, 2010; Lewin, 1946; Torbert \& Associates, 2004). The requirement for critical thinking cuts across all models of action research, and this is no less the case for the TAI framework. For example, the focusing inquiry stage requires a teacher to establish a direction and collect baseline data. To do so requires critical consideration of what is desirable and what evidence there is that warrants changes to practice. The interrogation of research literature is likely to occur at some point during a focusing inquiry as teachers seek out ideas from across the profession that may support them in choosing a direction to take. The teaching inquiry stage of the TAI model may also consist of critical engagement with published research literature as teachers seek out potential teaching strategies. Moreover, the teaching inquiry stage will likely involve reflection-in-action (Schön, 1983) as the teacher skillfully implements ideas suitable to the context of learning. Critical thinking is also required in the learning inquiry stage as teachers reflect on the success or otherwise of their teaching as they examine the outcomes of student learning. Each of these three related inquiries is an open-ended invitation to explore questions of purpose, practice and performance. 


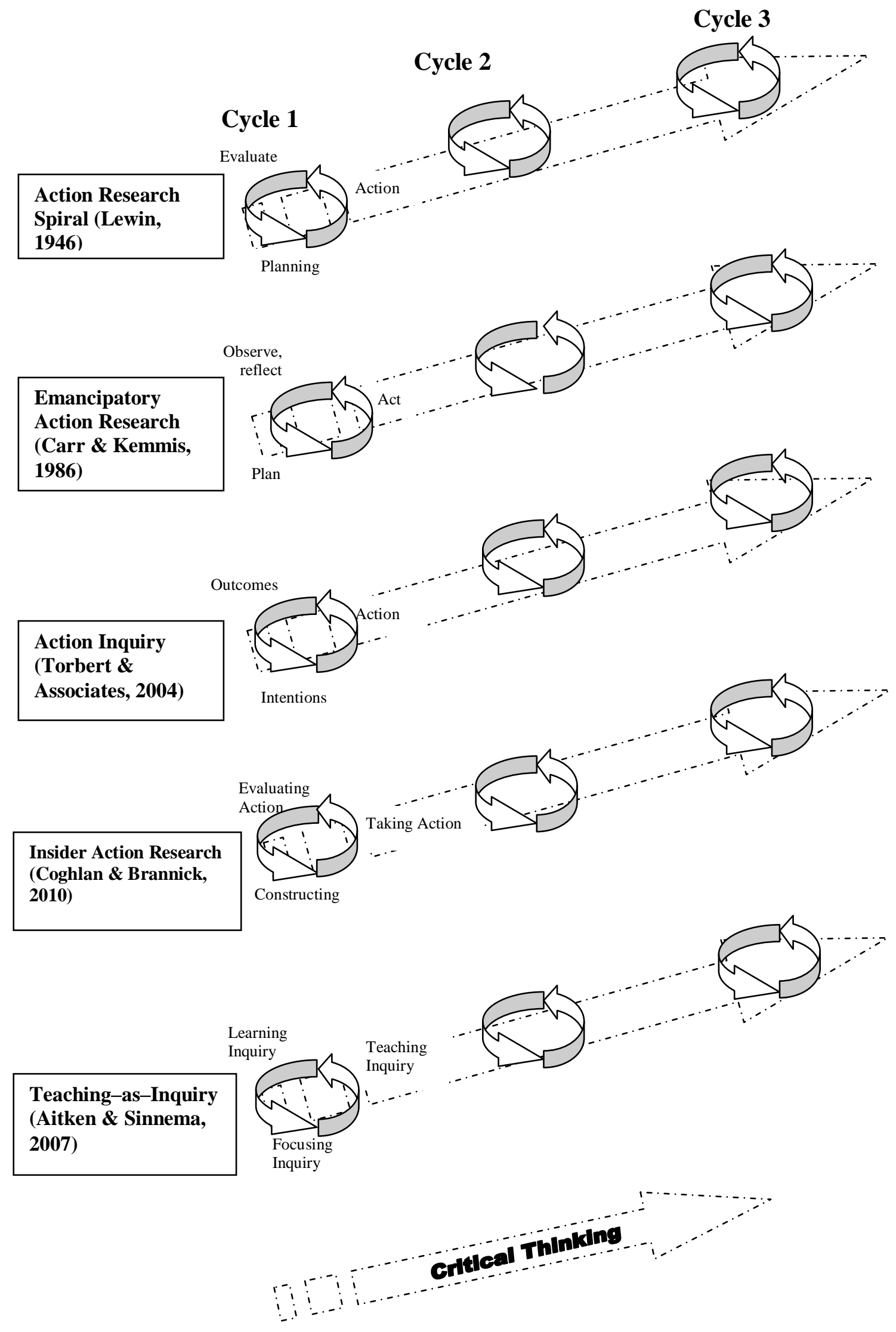

Figure 2.1: Comparing 'Teaching-as-Inquiry' to action research models 
Like conventional models of action research, the TAI model adopts a cyclical design, in recognition that inquiry into teaching practice will often require multiple iterations of adjustment and refinement. To this effect, the TAI model is a framework that aims for recursive critical inquiry, as teachers look and then look again at their practice (CochranSmith, et al., 2009). While there are structural similarities between TAI and action research models, there are also nuanced differences. For example, while emancipatory action research (Carr \& Kemmis, 1986) articulates an aim for the social, cultural and political transformation of organizations and education in general, the link between the overall social justice orientation of the Iterative BES Programme and the TAI framework as a tool for transformative education is not an explicit feature of the Social Sciences BES. Moreover, the TAI model differs from action research in its fullest sense, because TAI is an investigation into personal practice without the need to adhere to strict research conventions, that might be expected in the process of peer review and public dissemination (Cordingley, 2003). Perhaps Saunder's (2007) list of desirable features of practitioner research offers some aspirational guidelines for TAI, in that it is a) grounded in what is already known, whether in terms of academic literature or in terms of other colleagues' professional knowledge, b) fit for purpose in its design, including methods and an analytical framework, c) reflexive and exploratory, d) honest about its limitations, and e) open to challenge and further development.

Evidence-informed practice requires teachers to consider the findings of research in order to determine whether the general precepts derived from the research apply to their classroom contexts, students' circumstances and preferences to learning. Castle (2006) argues that rather than privileging the highly contextual nature of a classroom, pedagogically autonomous teachers refuse to inquire in a vacuum, preferring instead, to seek out established knowledge from professional literature and peers. In her empirical study of three primary school 'pedagogical researchers', Castle (2006) suggests that their pedagogical autonomy was manifested in several ways: perceiving that something is wrong; questioning; seeking out knowledge from others; risk taking; reflecting on results leading to confidence; increased understanding of children's understanding; and taking action. The parallel with TAI is evident, and furthermore, demands that critical thinking is a thread woven through the practice of a pedagogically autonomous teacher. 
A recent review of literature on practitioners' use of evidence has noted that a prelude to engagement in research is nearly always consumption of research (Bell et al., 2010). Teacher consumption of research has been critiqued for the way that it positions teachers as passive recipients of research from academics, which feeds into the instrumentalisation of the teaching profession critique noted in Chapter 1 (Korthagen, 2007; Liberty \& Miller, 2005; Neyland, 2010; Saunders, 2007). I suggest, however, that if consumption of research is critical in nature - interrogated to understand, say, the theoretical underpinning, methodological approaches, and conclusions drawn then it offers a strong platform for focusing attention as teachers engage in their own research. Critical engagement with research requires skilled teacher interpretation and judgement (Campbell et al., 2003; Cordingley, 2008).

\section{Definitions of Critical Thinking are Multi-faceted}

In the previous section, I argued that TAI requires critical thinking. While the Social Sciences BES clearly articulates a dispositional orientation to criticality, ${ }^{8}$ it is relatively quiet on the critical thinking required by teachers when engaging with research evidence. It is, however, important to note that definitions of critical thinking vary. If I am to examine teacher's critical engagement with published research literature, then it is necessary that I offer some clarity about this term.

Although critical thinking is closely associated with the rapid social change of the mid-twentieth century onwards, it has a history extending back 2500 years to the Socratic principle that the unexamined life is not worth living. It is important to acknowledge therefore, that not only does critical thinking act as a means for individuals to make sense of information in the age of mass-media, but also strives for ends underpinned by notions of the 'good life' by which sophistic and manipulative thinking are avoided (Cosgrove, 2010). As such, critical thinking is closely associated with what it means to be an educated person in the Western world.

Critical thinking is a concept broadly applied across a variety of disciplines, such as logic, decision-theory, rhetoric, philosophy, science, linguistics, and psychology, and it is perhaps unsurprising that what constitutes critical thinking is a matter of some

8 More specifically, Aitken and Sinnema (2008) signpost a critical "set of attitudes towards teaching and learning" (p. 53) that include, open mindedness, fallibility, and persistence. 
debate. Critical thinking may be viewed cognitively (what mental processes and mechanisms are happening) or using normative (what the purpose and functions of critical thinking should be) definitions (Cohen, Salas, \& Riedel, 2002). Figure 2.2 below shows the scope that is given to meanings of critical thinking. For example, early definitions of critical thinking that emphasised logic and an overtly rationalist stance were eschewed by writers who acknowledged the affective dimension of critical thinking. Those writers who view critical thinking as broader than simply a rational pursuit in logic and argumentation, point out that critical thinking leads to a re-evaluation of one's own assumptions, beliefs and worldviews in personal and professional realms (Facione, 1990; Simpson \& Courtney, 2002). Furthermore, critical thinking may be viewed as both a set of skills and dispositions, because even a most analytically skilled individual may not always be disposed to use those skills and vice versa.
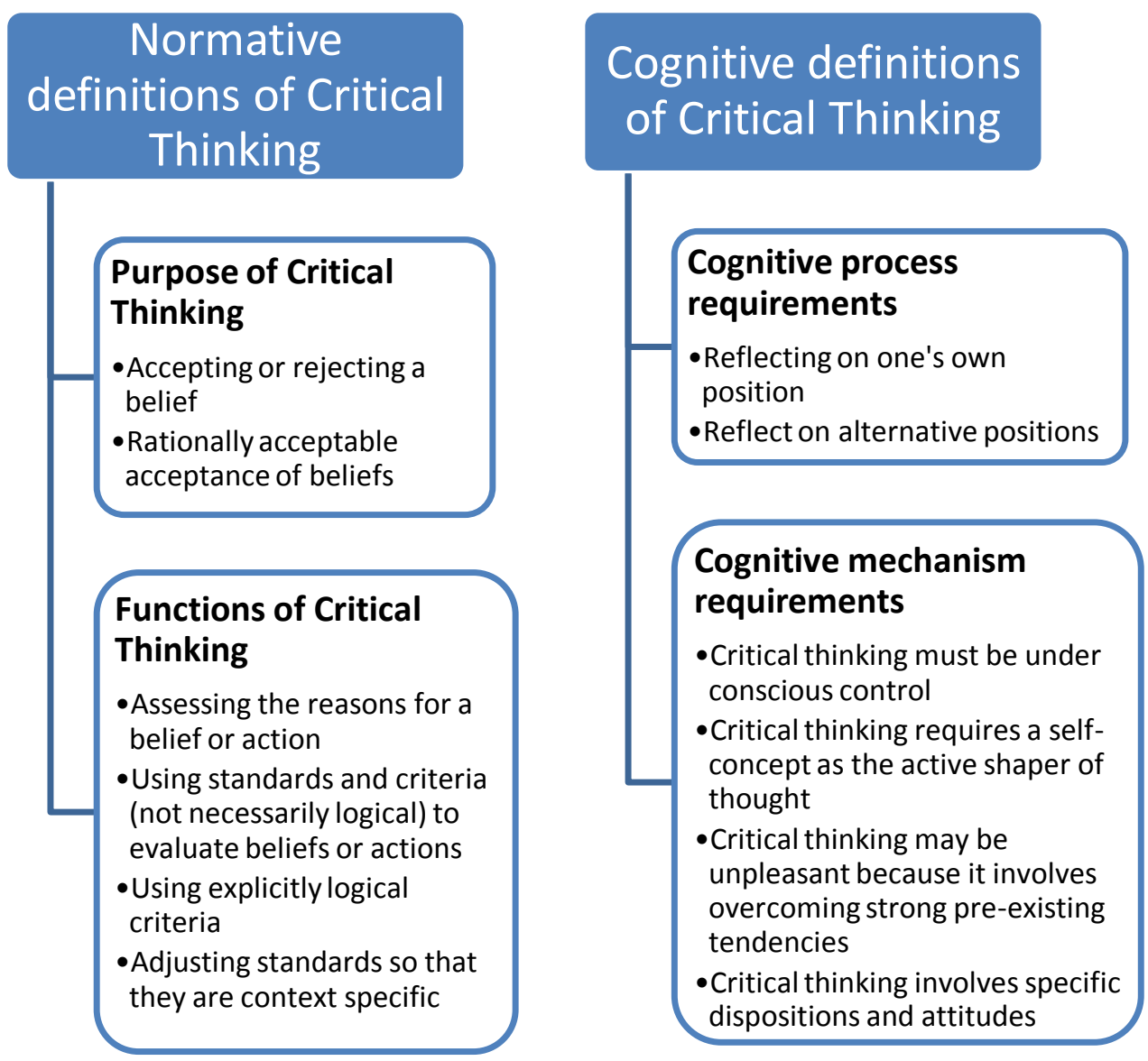

Figure 2.2 A framework for critical thinking definitions (based on Cohen et al., 2002) 
Earl and Timperley (2008) suggest a form of teacher criticality or 'inquirymindedness' that incorporates dispositions such as valuing deep understanding, reserving judgement, having a tolerance for ambiguity, and centralising interpretation. 'Inquiry mindedness' also refers to a suite of skills such as taking a range of perspectives and posing increasingly focused questions, using relevant data, clarifying purpose, recognising sound and unsound evidence, and having knowledge of statistical and measurement concepts. Such a range of dispositions and skills when combined, aim to further the quality of teachers' thinking, particularly with a view to improving student achievement through analysis of data and evidence specific to classroom contexts.

In order to draw together the many threads of meaning given to critical thinking, the American Philosophical Association convened a panel of forty-six North American experts. This panel reached the consensus that:

We understand critical thinking to be purposeful, self regulatory judgment which results in interpretation, analysis, evaluation and inference as well as explanation of the evidential conceptual, methodological, criteriological or contextual considerations upon which that judgement was based. Critical thinking is essential as a tool of inquiry. Critical thinking is a pervasive and self-rectifying human phenomenon. The ideal critical thinker is habitually inquisitive, well-informed, honest in facing personal biases, prudent in making judgements, willing to consider, clear about issues, orderly in complex matters, diligent in seeking relevant information, reasonable in selection of criteria, focused in inquiry and persistent in seeking results which are as precise as the subject and the circumstances of inquiry permit. (Facione, 1990, p. 4)

This definition suggests a conscious agency in which critical thinking is conceptualised as a series of skills such as 'interpretation, analysis, evaluation and inference' of evidence. The Delphi Report (Facione, 1990) also stresses the dispositional side of critical thinking as well through terms such as 'habitually inquisitive', 'honest in facing personal biases' 'prudent', and 'diligent'. Furthermore, the definition emphasises an individualistic take on critical thinking, through phrases such as 'self regulatory' and 'self-rectifying human phenomena'. A broader view might be advanced, however, by which critical thinking is envisaged as a social activity as much as it is a process in the minds of individuals. Thus, dialogue between individuals may be viewed as a vehicle by which thinking is enhanced, particularly by the introduction of competing points of view that may not surface 
during periods of egocentric thinking (Eisner, 2002). This latter point is pertinent in the context of this thesis' methodology, which tests the critical thinking of groups of teachers as they mediate the Social Sciences BES via dialogue.

While definitions of critical thinking need not shirk from complexity, particularly when compared to concise but necessarily limited definitions (see Cosgrove, 2010), a user-friendly conceptualisation of critical thinking is required for methodological application in this thesis. Fortunately, over the previous two decades, the collaboration of two American scholars has seen the development of just such a model.

\section{Paul and Elder's (2000) Critical Thinking Model as an Analytical Tool}

Richard Paul and Linda Elder are two critical thinking experts associated with the Foundation for Critical Thinking, an educational non-profit organisation with its origin at Sonoma State University, California. In order to help the reader understand the methodology and results of this thesis, this section introduces Paul and Elder's (2000) multi-dimensional critical thinking model, before presenting a modified version as a framework for the analysis of teachers' critical engagement with the Social Sciences BES. The backgrounding of Paul and Elder's (2000) model is vital, because it provides the theoretical framework for the methodological approach to analysing teacher critical thinking.

Paul and Elder's (2000) model for critical thinking is essentially based around two propositions: 1. When people think, it is for a purpose, located within a point of view, based on assumptions from which they draw conclusions; and 2. Good thinking uses data, facts and experiences to make inferences and judgements, based on concepts and theories to answer a question/solve a problem. Their model (see Figure 2.3) comprises three theoretical components: 1. Elements of reasoning (skills embedded in critical thinking); 2. Standards (criteria for evaluating levels of reasoning); and 3. Intellectual traits of mind (dispositions, or what it is to be a critical thinker). For purposes of clarity, the next section offers an outline of each of the three components of the model. 


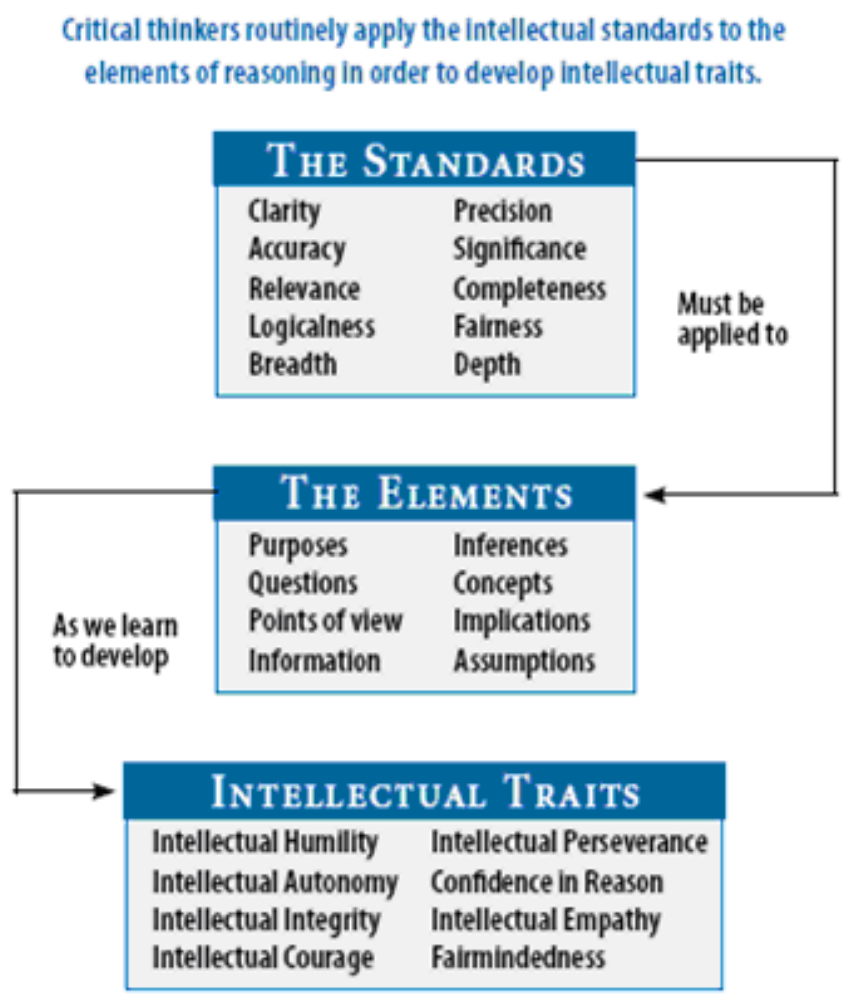

Figure 2.3: Paul and Elder's (2000) Critical Thinking Model

\section{Elements of Reasoning}

Paul and Elder (2000) analyse the concept of critical thinking by breaking it down into eight distinct, although often overlapping, components of thought. These 'elements of reasoning' highlight the multi-faceted nature of critical thinking. Paul, Elder and Bartell (1997) suggest the complexity of critical thinking is not appreciated by teachers and scholars alike, who often profess to develop critical thinking in their students, yet tend to describe critical thinking in one dimensional fashion. Their model is multi-faceted which may help teachers' reasoning surface through the questions they pose when engaging with published research evidence: "Can I define the key concept in this research?"; "Is the concept we are talking about the same as the author's?"; "what question(s) is this research attempting to answer?"; or "what are some of the assumptions made about learners when research describes events like this?"

By adopting elements of reasoning, a high degree of rationality is signposted. Thinking comes in many other forms, such as the thinking that stems from emotional responses to information. Nevertheless, while rationality may not be the only realm 
of thinking, it is still important. As has been argued by others, it is the invisibility of the rational thinking process that is problematic for many teachers (Richetti \& Tregoe, 2001). It is my aim that introducing teachers to Paul and Elder's (2000) model will allow critical thinking to be made more visible to teachers, and potentially enhance their thinking about Social Sciences BES research evidence.

\section{The Standards}

Paul and Elder (2007) advocate that the level of critical thinking should be evaluated by a series of standards that will assess the power of critical thinking. The diagram below indicates a range of questions that may help evaluate thinking.

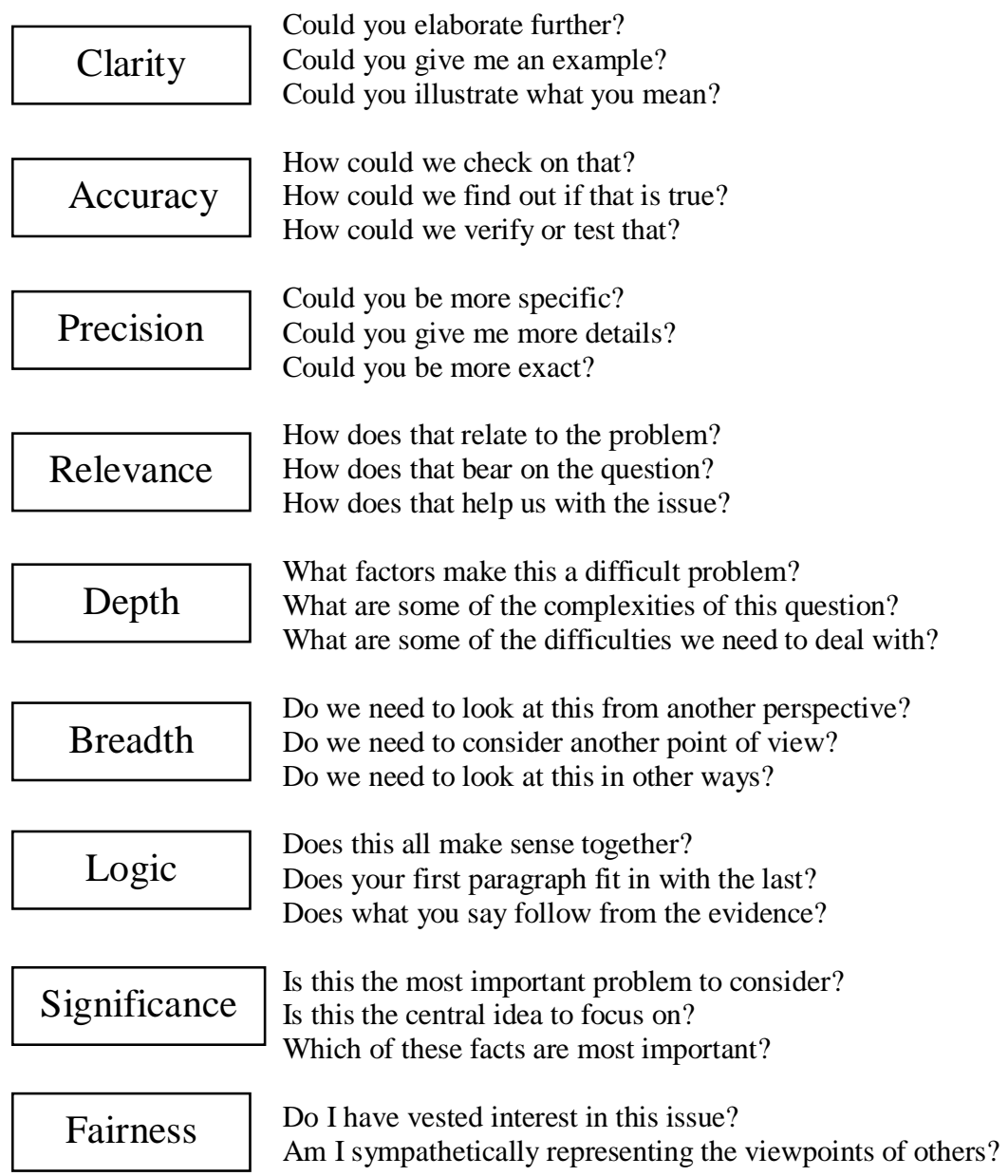

Figure 2.4: Applying standards to thinking (Paul \& Elder, 2007)

Paul (2007) argues that these standards are measures of judgement that cut across all subject domains. Indeed, the universal nature of these criteria may be applied by teachers engaging with published research evidence. For example, "Has our thinking about this research been relevant to our inquiry?", "How precise has our thinking about x been?", or "Has our thinking about x covered a range of options?" In this 
respect critical thinking is a metacognitive activity that has a high degree of selfmonitoring and self-assessment. As explained in Chapter 3, however, these standards are not given great attention for the purpose of my methodology.

\section{Intellectual Traits}

Although the analytical and evaluative skills of critical thinking are important, for what purpose do they serve? Developing critical thinking skills may be counterproductive if, for example, an individual is not open to recognise when their own thinking is flawed or when another person raises a more salient question. Intellectual traits are, in other words, dispositions that may be viewed as the ends of critical thinking. Intellectual traits are closely linked to an ontological view of how critical thinkers should be. In teaching critical thinkers are those practitioners who not only assess the weight of evidence by reasoning about research, but take action to seek some further good for their students (Richetti \& Tregoe, 2001).

\section{An Orientation to Dialogue}

Although not explicitly represented in Paul and Elder's (2000) model, underpinning the model is the idea of dialogue. The nature of personal critical thinking might be viewed as an internal dialogue, especially as individuals weigh up competing evidence of different research findings. The importance of external dialogue generated by groups of professionals working together is important in the context of this thesis, which seeks to explore groups of teachers' interactions as they negotiate, deliberate, inquire, and seek information from the Social Sciences BES. Paul (1992) argues that critical thinking is a dialogic process; taking into account other perspectives is necessary for the assessment of truth claims. Furthermore, dialogue that is rich in critical thinking is a process by which the socio-centric nature of collaborative groups may be mitigated. Without such discussion, in which teachers can be exposed to alternative perspectives and ideas from their colleagues, group members are more likely to discuss information they already hold in common, even when there is more valuable unshared information (Elder \& Paul, 2010).

The need to consider critical thinking as a social activity based on dialogue, according to Frijters, Ten Dam and Rijlaarsdam (2006), can be explained from both cognitive and social constructivist viewpoints. From the cognitive viewpoint, 
dialogue between individuals supports an elaborative process in which explaining, reasoning, asking questions and stimulating thinking are enhanced. From a social constructivist approach, dialogue produces collaborative meaning, albeit recognising the caveat that communities of practice may inadvertently reinforce dominant beliefs if these are not held up to scrutiny (Lipman, 1995; Paul \& Elder, 2007).

While dialogue is a central part of a teacher's day, the extent to which it is critical in contexts of professional learning and development is less clear. In New Zealand for example, there have been calls to lift teacher talk from collegial pleasantries to talk that has a greater focus on challenging pedagogical practices (Annan, Lai \& Robinson, 2002). International scholarship has also questioned whether the pedagogical practices used to educate and train teachers lack the attention to critical dialogue that are signature pedagogies of the medical and legal professions (Shulman, 2005).

\section{Paul and Elder's Model Requires Adaptation for this Thesis}

For the purposes of this thesis, which seeks to explore Cherry Tree and Waterside School social science teachers' critical engagement with published research evidence, I have adapted the model for teachers to use, in order to offer a framework that is contextualised to engagement with the Social Sciences BES. The elements of reasoning are especially emphasised in this adapted framework, that is, only one of the three components of Paul and Elder's (2000) model. There are three reasons for this. The first is because the 'elements of reasoning' component explicitly attends to a multi-dimensional view of critical thinking skills. This clearly defined part of the model is particularly important because: a) if the model is going to be used as a tool by teachers to make sense of published research then it needs to be clearly understood, and b) if a clear framework is available it enhances the trustworthiness of the analysis in the findings section. In the general absence of clearly articulated models for critical thinking (Cosgrove, 2010), the choice of this model is based on the precision with which the model's concepts are described and the clarity with which they are communicated. The second reason for focusing largely on one part of the model is that the model is being used as a tool for analysis of teachers' critical engagement of Social Science BES published research literature rather than their level of critical thinking per se. To this end, while 'the standards' are acknowledged, 
they will be of minor importance to the analysis: the aim is to explore the aspects of Social Sciences BES research evidence that teachers critique rather than measure teachers' critical thinking. The third reason pertains to the reason for electing not to analyse teachers' 'intellectual traits'. This is because the short period of data collection would not do justice to what is a much longer-term project of developing the self in relation to being a critical thinker (Paul, 1992).

The adapted model is presented in Figure 2.5. The model is shown as a circle, much as Paul and Elder have done through different publications to emphasise the nonlinear relationships between the different elements (Cosgrove, 2010). Given that the focus is on the eight elements of reasoning proposed by Paul and Elder (2000), an outline of these different elements of critical thinking and their potential relationship with Social Sciences BES research literature is given.

1. Purpose: Teachers may examine the objectives of research within the Social Sciences BES to see if it will inform their own thinking and possible actions.

2. Question at issue: Teachers may think about the research question to be answered or problem to be solved. This discussion may illuminate the question at issue or be tangential.

3. Information: Teachers' dialogue may include the use of data and information that supports statements made in the Social Sciences BES research evidence.

4. Concepts: When teachers engage with the Social Sciences BES it may lead to exploration of abstract ideas and theories that underpin individual research reports. For example, they may debate the operational definitions of concepts such as the mechanisms.

5. Interpretations and conclusions: Reasoning proceeds by steps in which we reason as follows: "Because this is so, that also is so (or probably so)," or "Since this, therefore that." Such informal logic present in the Social Sciences BES may be subject to examination by teachers as they make inferences and draw conclusions about the research evidence presented. 


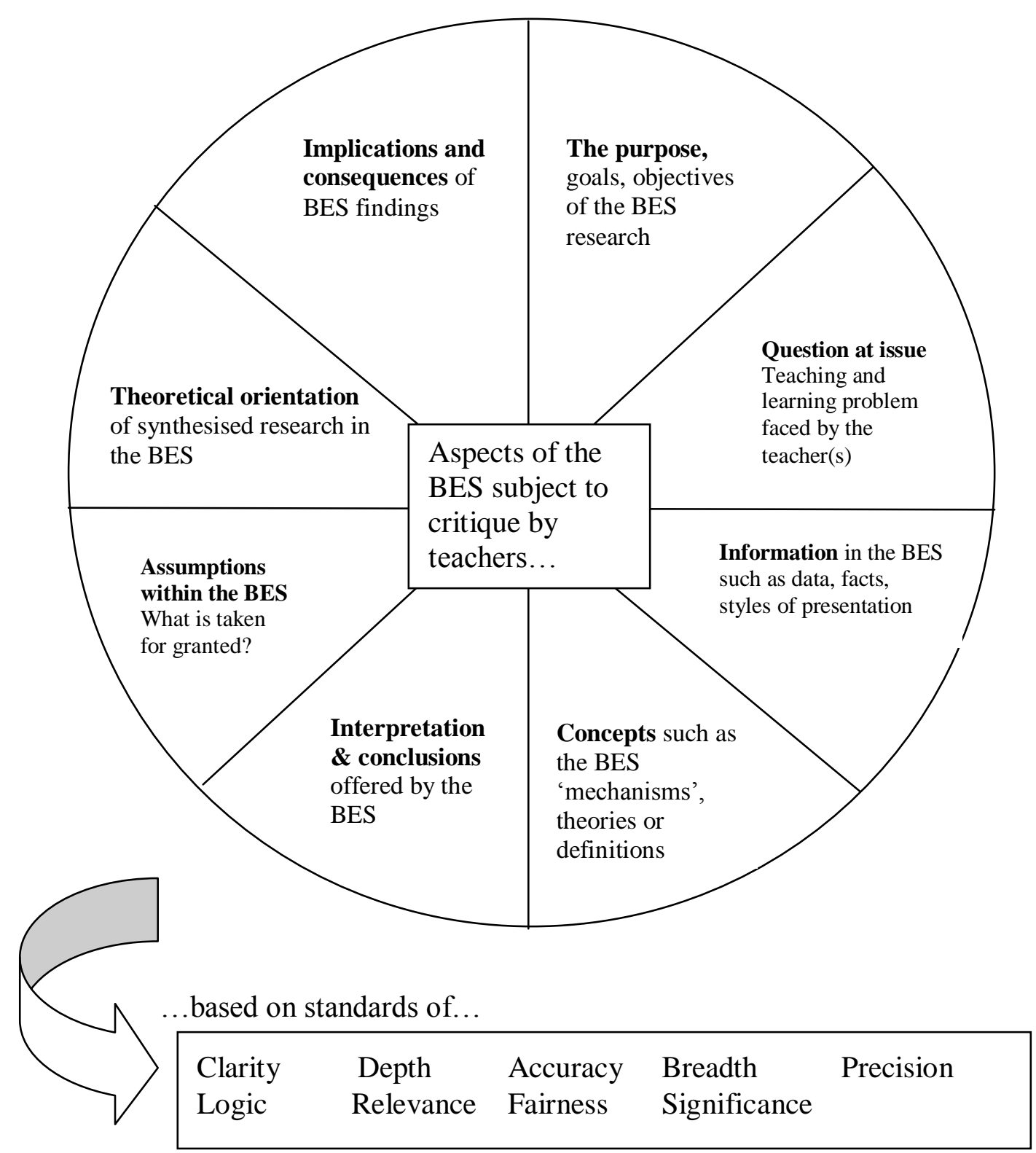

Figure 2.5 Adapted model to support critical engagement with Social Sciences BES

6. Assumptions: Teachers may think about taken for granted, pre-conceived ideas, some of which may stand up to scrutiny more or less favourably.

7. Theoretical orientation: Educational research, and indeed, our thinking, is located within some point of view or frame of reference. Teachers' critique may seek to bring the theoretical frames of reference of research to the foreground of their discussion in order to develop deep understandings about rationale and approaches to research. 
8. Implications and consequences: The complexity of teaching means that all decisions and actions are likely to have downstream effects. Teachers may see narrow or broad-ranging implications for their own and others' actions as represented in the Social Sciences BES.

In this section then, an argument has been presented for why Paul and Elder's (2000) critical thinking model is useful as an analytical tool for exploring teacher critical thinking. By introducing the model half way through the research period my aim is that it makes visible some of the reasoning that teachers may wish to apply to the Social Sciences BES. I contend that this is particularly important for teachers who do not have a great deal of experience engaging with published research literature. As the final section of this chapter indicates, teachers' lack of engagement with research evidence is not unusual.

\section{Published Research Evidence and Teachers' Day-to-Day Practice}

Despite there being a professional expectation that registered teachers critically engage with evidence and professional literature (New Zealand Teachers Council, 2010a), the extent to which they do so with published research evidence is difficult to establish. Indeed, concerns have been expressed going back at least 25 years in New Zealand (Jeffery, 1985). What is known from the international literature is that teachers use a range of evidence, and that the sources used tend to be the most readily available: colleagues for informal discussion, official curriculum documents, professional magazines/newspapers and in-service professional development (Everton, Galton, \& Pell, 2002; Ratcliffe et al., 2004; Williams \& Coles, 2007). In relation to the few empirical studies that exist about teachers' use of research evidence, Hemsley-Brown and Sharp (2003) found more teachers using research in the context of postgraduate study rather than their everyday teaching. Interestingly, in relation to this thesis, Williams and Coles (2007) found that systematic research reviews were one of the least popular evidence sources, ranked $22^{\text {nd }}$ out of 24 possible sources. However, follow-up interviews, group exercises and a discussion forum revealed that there was a greater appreciation of the need for research overviews. Williams and Coles (2007) state that this conflicting evidence may suggest teacher antipathy to the term 'systematic research review'. 
What might be the barriers to teachers' critical engagement with published research evidence? The international literature suggests that barriers arise from educational research appearing ambiguous, lacking in validity, reliability, or readily practical results. Barriers may also arise within implementation, for example, if teachers are not skilled enough to use educational research or believe it insufficiently conclusive (Broekkamp \& Van Hout-Wolters, 2007; Cordingley, 2008; Vanderlinde \& van Braak, 2009). Conversely, factors that promote teacher engagement with research include the presence of clearly communicated practical applications, clear evidence of the benefits, time to read and use the research, having intermediary support for the unpacking of the research, and government directions to use specific research (Everton et al., 2002; Gitlin, Burbank, \& Kauchak, 2005; Vanderlinde \& van Braak, 2009). However, one must be careful not to assume that teachers require simplified research. For example, Kennedy's (1999) study of the persuasiveness of educational research highlighted that the depth of description about teaching or student outcomes was important to teachers. Ratcliffe et al. (2004) also point out that while a number of teachers in their study requested short research digests to synthesise large studies, this conflicted with focus group findings which suggest that condensed reports fail to persuade teachers because of the absence of important contextual detail.

Underlying attitudes may also influence how published research evidence is used as a guide to practice. Coburn and Talbert's (2006) study identified four distinct orientations towards research use by teachers: a) an unquestioning, great faith; b) conditional faith, based upon teachers' self trialling and adaption of research; c) strategic faith, that is, citing it if it supports a pre-existing position and; ignoring it if not; and, d) scepticism. 'Conditional faith' best describes a critical thinking orientation towards research, whereas the remaining 'faiths' prove to be barriers towards critical engagement, either because teachers accepted research at face value, over-assimilated it depending on current positions, or chose to ignore the research findings.

Finally in this section, it is important to caution against over-simplistic blame of individual teachers for a lack of engagement with research (Hemsley-Brown \& Sharp, 2003). For example, while teacher standards in New Zealand aspire to the use of educational evidence (New Zealand Teachers Council, 2010a), there is no stringent accountability mechanism that promotes engagement with published 
research evidence throughout a teacher's career. Moreover, at the organisational level, the limited international empirical evidence available suggests that cultural and environmental norms of schools do not commonly foster opportunities for individuals to regularly critically engage with research evidence (Ratcliffe et al., 2004; Williams \& Coles, 2007).

\section{Summary}

This chapter drew upon literature in order to pull together two aspects of this study: critical thinking and teachers' engagement with research literature. The first section of this chapter argues that the TAI framework advocated in the Social Sciences BES is grounded in the tradition of action research, and moreover, is underpinned by the skills and dispositions characteristic of teachers who might be described as good critical thinkers. Furthermore, The TAI framework positions published research as an important contributor to the evidence mix which necessitates that teachers avoid passively consuming published research evidence, but interrogate it in a critical fashion.

In order to examine teachers' critical interrogation of research evidence this chapter presented a critical thinking model (Paul \& Elder, 2000) that, with some modification, is used as a heuristic for analysis of social science teachers' thinking about published educational research in the Social Sciences BES. My rationale for choosing this model is that it offers a very clear articulation of the multi-dimensional nature of critical thinking, which is important for both the teachers using the tool and my analysis of critical thinking.

Finally in this chapter, evidence that teachers do not regularly use published research to inform their day-to-day practice was presented. Such background highlights the commitment of the Cherry Tree School and Waterside School teachers to support each other in understanding the Social Sciences BES.

The next chapter outlines the research strategy of this thesis and the methods designed to help explore the question 'What impact does the use of a modified model for critical thinking have on secondary school teachers' critical engagement with Social Science BES research?' 


\section{Chapter 3: Methodology}

This chapter explains the methodology used in this thesis to explore two groups of teachers' critical engagement with Social Sciences BES research evidence. The first part of the chapter outlines the use of case study method as an appropriate, if contested, approach for qualitative research within an interpretive paradigm. In the second part of the chapter I examine the methods for data collection and subsequent approaches to data analysis. Considerations of ethical issues in this research are presented in the final section of the chapter, as well as its limitations.

\section{Research Strategy}

In the first section of this chapter, the research strategy for this thesis is presented. Denscombe (2007) defines a research strategy as the broad approach to research, which includes the direction of the project and its underlying philosophy. Acknowledgement of a research strategy is a recognition that no researcher - and by extension, their methods - is free of theoretical constructs about the nature of knowledge and reality.

\section{Purpose of this Thesis}

The purpose of this thesis is to explore Cherry Tree and Waterside Schools' social science teachers' critical engagement with published research evidence. The overarching research question is:

What impact does the use of a modified model for critical thinking have on secondary school teachers' critical engagement with Social Science BES research?

\section{Sub questions:}

1. What perceptions do key contributors to the Social Sciences BES have concerning teachers' critical engagement with research evidence?

2. How accustomed were Cherry Tree and Waterside teachers at engaging with research evidence? 
3. What have been the outcomes of critical engagement with the Social Sciences $B E S$ for Cherry Tree and Waterside social science teachers?

4. For Cherry Tree and Waterside School social science teachers what are the facilitators and barriers for critical engagement with Social Sciences BES research?

The exploratory nature of this work is largely dictated by a lack of studies in this research area. The research is influenced by Eisner's (2002) observation that critical thinking should be at the heart of teacher dialogue and professional development: "The current interest in teachers deliberating with teachers is an example of a professional practice ... where multiple interpretations and analysis are likely. Such contexts liberate [teachers] from a monocular perspective and a single interpretation" (p. 382). An important premise of this thesis is that social science teachers' initial exploration of the Social Science BES document is likely to be an individual or group effort; either way without the support of knowledgeable experts.

\section{A Qualitative-Interpretivist Research Paradigm}

Deciding on a qualitative-interpretivist framework is a matter of fitness for purpose. As the essence of this thesis is to seek answers to questions that stress how social experience is created and given meaning (Denzin \& Lincoln, 2005), the study is located in the broad realm of a qualitative-interpretivist paradigm. The empirical component of this thesis examines a range of views about teacher critical engagement with research literature through means of rich description. An interpretive stance is an appropriate lens through which to view this study, in which social reality is constructed by intrinsic meanings shared by members of a social group (Clark, 1997). In this way, "all interpretive research is 'grounded' in the everyday lives of people" (Noblit \& Hare, 1988, p. 12). To this end, strengths of an interpretivist approach are that its humanist orientation honours the views of the participants and simultaneously speaks to a wide range of readers familiar with the everyday life and people it depicts (Denscombe, 2007). In essence then, an interpretivist approach attempts to make the worlds of lived experience accessible to the reader by capturing the voices, emotions and actions of those being studied. The pluralisation of 'worlds' is deliberate, as an interpretivist approach rejects a search 
for objective reality, the underpinning theory reflecting multiple realities constructed through the subjective meanings of its actors.

The subjective meanings of the participants are further filtered by my own bibliographical details. The 'confirmability' (Lincoln \& Guba, 1985) of qualitative research of the type in this thesis warrants brief consideration in order to acknowledge the professional experience, personal views and potential biases in relation to the phenomena under investigation. In my case, nine years professional experiences as a secondary school social sciences teacher and seven years as a preservice teacher educator have undoubtedly informed interest in this study. Moreover, my current position as a pre-service teacher educator has afforded the time to engage with BES literature that was not achieved as a teacher. Indeed, I recall a meeting to discuss a BES publication (Alton-Lee, 2003) in which I participated when a school teacher. The enduring memory of that meeting is the many awkward silences and the all too brief conclusion that 'this aint rocket science'. Such a memory is one contributing experience that helped direct the early formation of the research questions to this thesis, as was a growing awareness of the literature about the challenges of using research as an informant to teachers' classroom practice.

One important critique of interpretive research is that it is essentially conservative in that it does not challenge the material conditions of teachers (Clark, 1997). By focusing on the different interpretations of reality it avoids looking at deeper structural contradictions that may be influencing the conflict between different interpretations in the first place. As a result, an interpretive approach takes a 'disinterested' approach to different meanings, by avoiding any kind of evaluation that may improve the lives of the teachers in this research.

\section{Case Study Research Design}

This thesis is presented through a case study research design. Case study research has been variously defined as a "study of singularity conducted in depth in natural settings" (Bassey, 1999, p. 47) and "the study of the particularity and complexity of a single case, coming to understand its activity within important circumstance" (Stake, 1995, p. xi). As early adopters of the Social Sciences BES, the groups of teachers from Cherry Tree and Waterside Schools each represent 'instrumental 
cases' (Yin, 2003) given that my aim is to explore how critical thinking about published research literature developed in each of these cases. This focus broadly aligns to the major tenets of case study design: it is a real-life context, in which two specific groups of teachers in a present day setting seek to critically consume a significant corpus of educational research.

Each group of teachers is the 'given case' (or bounded system) within which the issues pertaining to critical engagement with Social Science BES research are discovered or studied (Bassey, 1999). That the two cases described in this thesis are early adopters of the Social Sciences BES also gives weight to the idea that the cases are not only bounded by membership of each group of teachers, but also by time. Case studies of critical engagement with Social Sciences BES research 10 years after its publication are likely to offer different insights to those that the cases in this thesis provide.

While the small number of cases exposes my thesis to claims of inadequate data from which to generalise, Yin (2003) makes the point that not all sampling procedures strive for statistical generalisation. Instead, this project attempts to break ground by offering insights that may encourage the reader to make their own connections with the analysis of this thesis, or what has been termed 'transferability' (Lincoln \& Guba, 1985). Whether 2 or 20 cases were represented in this thesis, it would be unlikely to satisfy the 'generalisation critique' of qualitative case study research.

The case study design literature concerning the purpose of generalisations reflects a heavily contested terrain. Yin (2003) advocates that case study design should aim at developing 'analytical' generalisations which seek to uncover findings that correlate with general conceptual categories. As signposted in Chapter 2, the adaptation of Paul and Elder's (2000) critical thinking model provides an analytical framework through which teachers' reasoning will be able to be exemplified. Such analytical generalisability is limited to the confines of each case rather than extending to a wider population. Michael Bassey (1999) suggests that the idea of propositional generalisations have been eschewed by some case study researchers in favour of communicating research in such a rich way that the generalisation is made by the 
reader: "the individual, meeting the facts of the new case, applies them to his or her knowledge of similar cases, and so develops personal understanding" (p. 33). The case study design of this thesis cannot provide generalisations of certainty, although the use of Bassey's (1999) fuzzy generalisations, which use tentative language, might be appealing to teachers who recognise the complexity of learning environments but nevertheless seek to develop personal understanding.

The case study design for this thesis is displayed in a schematic layout in Figure 3.1. The research design had enough flexibility to follow any individual teacher who was prompted to integrate their critical engagement with their own practice. During the course of the research, Caitlin, a teacher from Cherry Tree School took steps to apply some of the subsequent thinking in her practice. The testimony of this teacher comes in for close consideration because she was the only teacher in the sample who took tentative steps towards a personal teaching inquiry as a result of her engagement

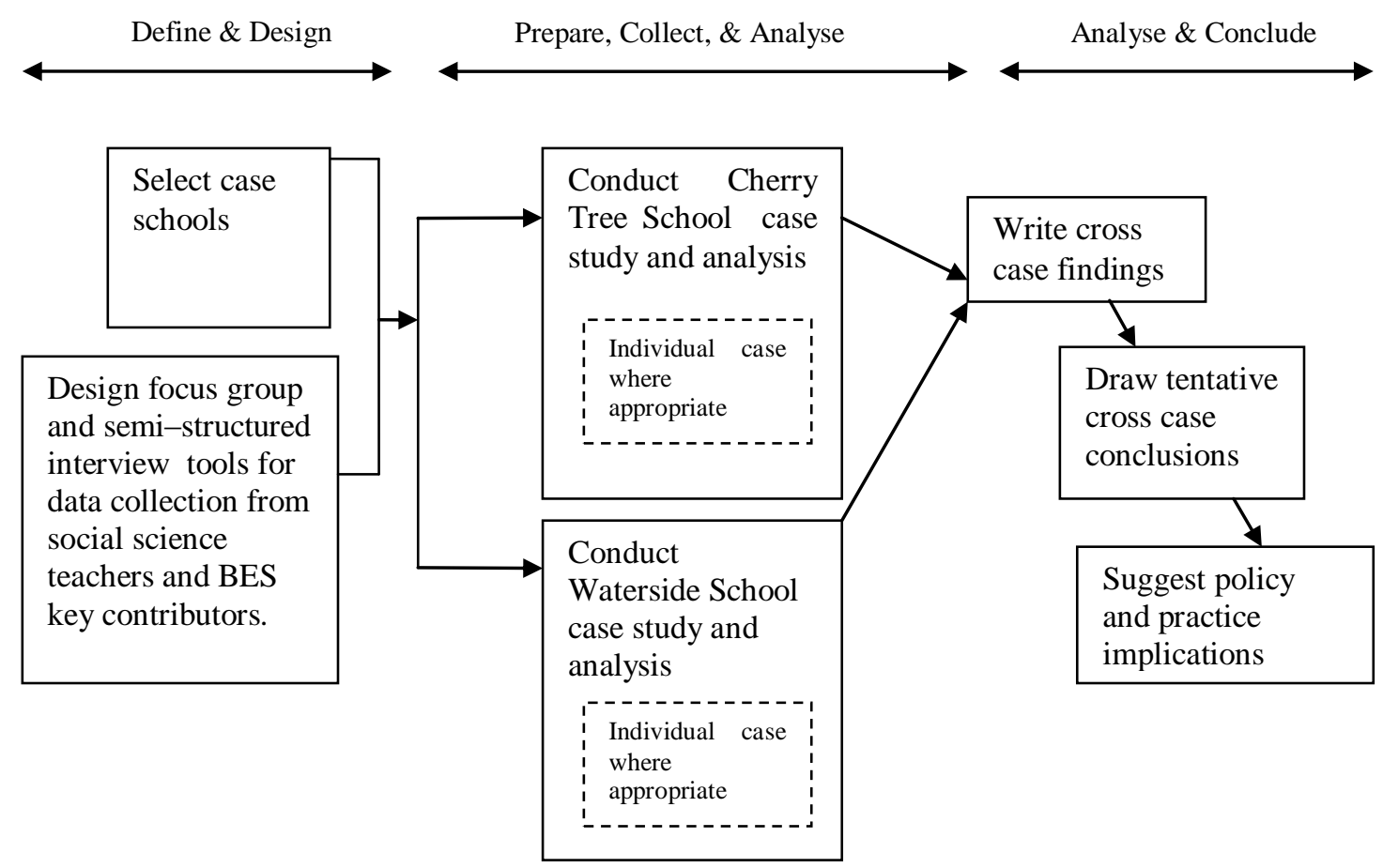

Figure 3.1 Thesis case study design

with the Social Sciences BES. The case, therefore, has special significance to the research questions addressed in the research. The emergence of such cases and the flexibility to be able to capture 'exceptional cases', is one of the hallmarks of the wider qualitative research paradigm. 


\section{Research Methods}

Having established the broad direction and underlying philosophy of this thesis, in this next section the methods, or tools, used for the collection of empirical data are described. While the choices of approaches are defensible in the context of this thesis, all approaches to social research carry with them limitations. For this reason, some of the shortcomings of the chosen approaches are also noted.

\section{Selecting the Participants}

A purposive, that is, 'hand-picked' approach was taken to selecting groups of teachers, based on those who were prepared to engage with a synthesis of social sciences research relatively soon after its release required identification. In order to capture a richness and breadth of viewpoints, identifying groups of social science teachers from a range of classical studies, economics, geography, history and social studies was desirable.

Two considerations narrowed down the potential participants (Babbie, 2008). First, at the time of this research, not all Greater Wellington secondary school social science departments were necessarily aware of the release of the document and/or were likely to be involved in other professional learning experiences that precluded them from committing their energies to a close examination of the Social Sciences $B E S$. Second, research in New Zealand has suggested secondary school department meetings are often dominated by administration, leaving less time for substantive discussion about practice (Harvey \& Higgins, 2006). Thus, groups of teachers who were willing to engage with the Social Sciences BES for a number of meetings beyond the scope of traditional department meetings were sought.

After ethics approval was granted (see Appendix B), in Term 22009 four schools were identified as potential participants, after emails were sent to ten schools in the Greater Wellington region. This involved presenting an outline of the research intentions to contact teachers which led to being invited into two schools to present the aims of the project to a wider group of teachers and an individual meeting with the principal of the schools. This resulted in Cherry Tree School accepting and another school declining to be involved. The contact teacher from the third and 
fourth schools reported that only two teachers expressed interest in participation, closing possible entry to these sites.

For much of 2009, despite efforts to elicit further participation - which included emails and conversations with teachers from several more schools - it appeared that the study would be confined to a single school. Repeat email invitations were sent, but without wanting to appear to be a nuisance to schools, it was decided that personal approaches to social science teachers may prove more fruitful. The personal approach was successful in Term 4 of 2009 when Fraser indicated that social science teachers from Waterside School were considering a 'study group' of which the focus would be the Social Sciences BES. A meeting with Fraser and the principal of Waterside School was arranged to negotiate entry before the first focus group meeting.

The demographic profile of the Cherry Tree and Waterside social science teachers who participated is shown in Table 3.1. Six of the ten teachers were 'second stage' teachers of 4 to 10 years' experience, for whom professional discussion and networking is one form of generative professional development actively sought after (Johnson, 2009; Margolis, 2008). The two most experienced teachers, Travis and

\section{Table 3.1: Study participant demographics}

\begin{tabular}{|c|c|c|c|c|}
\hline \multicolumn{5}{|c|}{ Cherry Tree School } \\
\hline Name & $\begin{array}{l}\text { Teaching } \\
\text { experience }\end{array}$ & $\begin{array}{l}\text { NZ schools } \\
\text { taught in }\end{array}$ & $\begin{array}{c}\text { Position of } \\
\text { Responsibility }\end{array}$ & $\begin{array}{c}\text { Social Science subject(s) } \\
\text { currently taught }\end{array}$ \\
\hline Marama & 13 years & 4 & HOD Faculty & Geography \& Social Studies \\
\hline Helen & 9 years & 2 & Dean & Geography \& Social Studies \\
\hline Caitlin & 9 years & 4 & TiC Transition & Social Studies \\
\hline Harry & 12 years & 2 & TiC Social Studies & History \& Social Studies \\
\hline Catherine & 5 years & 2 & & Social Studies \\
\hline \multicolumn{5}{|c|}{ Waterside School } \\
\hline Steve & 6 years & 2 & HoD History & History \\
\hline Fraser & 14 years & 4 & Senior Management & History \\
\hline Gina & 5 years & 1 & & Economics \\
\hline Ben & 8 years & 3 & HoD Commerce & Economics \\
\hline Travis & 32 years & 2 & HoD Languages & Classical Studies \\
\hline
\end{tabular}

Fraser, were also active contributors to their national subject association in leadership and/or advisory roles. The vast majority of the participating teachers held 
'middle management' roles, many of which were curriculum oriented. The Cherry Tree School teachers had a Geography-Social Studies curriculum orientation, while Waterside School teachers had a History-Economics orientation.

The Waterside School group of teachers initially had six members, although one of these withdrew from participation before the Phase 1 semi-structured interview after learning that he had gained employment in another school, precluding him from the remainder of the project.

The process of engaging schools with the thesis proposal was a salutary lesson on the demanding nature of negotiating access into schools. While meetings with principals to negotiate access were straightforward, it was the on-going relationship with the key teacher contact that was particularly important. In both schools these individuals acted as advocates for my continued presence, and following Denscombe's (2007) advice, these relationships were maintained in order that such advocacy would continue. For example, this involved continued discussion with that individual after meetings or email conversations between meetings.

\section{Data Collection}

The major methods of data collection in this thesis were focus groups and semistructured interviews. Both forms of data collection are consistent with research located in a qualitative-interpretive paradigm as they are tools which facilitate indepth explorations of phenomena (Denzin \& Lincoln, 2007). The focus groups primarily enabled me to record teacher interaction as they critically engaged with the Social Sciences BES, while the semi-structured one-to-one interviews gave the teachers the opportunity to reflect on their experiences and clarify any themes that emerged during the focus group discussions. Further detail on these two methods of data collection is described below.

\section{Focus Groups}

The focus groups took place in school settings at the end of teaching time as 'special interest group' meetings. Thus the meetings represented naturalistic settings for this type of professional activity, as it occurred in the real world of school-life rather than the artificiality of a laboratory setting (Denzin \& Lincoln, 2007). In order to 
encourage group autonomy, the contact teacher from each school organised the group of participating teachers. The only parameters given were that the group was between 4-6 individuals from a range of social science disciplines, in order to balance diverse input with depth of contribution.

The three key features of focus groups, according to Denscombe (2007), are the focus of the discussion, group interaction, and facilitation of the focus group. As the focus groups progressed, it was apparent that the three key features outlined by Denscombe (2007) overlapped with one another. This is largely because of the decision to take as 'low-key' an approach to facilitation as possible. This decision was driven by interest in the nature of critical engagement with research evidence without any provision of intermediary support. It was apparent during the focus group discussions, particularly at Cherry Tree School, that the aim to capture a snapshot of teachers guiding their own critical discussions came with a significant problem: the tendency for conversation to stray away from discussion about the Social Sciences BES. In such cases, the role of the facilitator is to refocus the group in order that optimum use of time is made. However, because a premise of this thesis is that many early adopters of the Social Sciences BES are likely to engage with it without external support, the researcher avoided taking a participant-observer role.

The discussions took place over a succession of meetings during 2009 and 2010 (Appendix C). The spacing and regularity of meetings was slightly different between the two schools, although the overall time spent, and amount of discussion were broadly comparable. The focus groups were recorded using a digital recording device from which transcriptions were made, totalling approximately 67,000 words. All teachers were given the opportunity to 'member-check' group discussion transcripts before they participated in individual semi-structured interviews.

The modified Paul and Elder (2000) critical thinking model was introduced to both Cherry Tree and Waterside Schools at the mid-way point in the focus group data collection. The intention of introducing this model was so that teachers could further apply a critical approach to the Social Science BES. Both groups of teachers were sent a copy of the model weeks in advance and also sent a link to a reading (Paul, 2007) that gave further detail to the model. Each group participated in a discussion in which 
understanding of the model was shared and questions aired. The researcher did not take an 'expert' position, allowing each group of teachers to support, develop and/or challenge each other's understanding. Both groups of teachers were requested to have the model 'at their elbow' as they discussed the research literature in the focus groups.

\section{Semi-Structured Teacher Interviews}

A two-stage process of interviewing each social science teacher took place, at the conclusion of Phase 1 and Phase 2 of their group discussion meetings. The primary purpose of interviewing the teachers was to add confirmability to the data by having individuals explicitly construct their meanings of the group discussion and associated themes.

The first stage of interviews sought to explore:

- participants' understanding of evidence-based practice

- participants' previous use of research in their teaching career

- participants' views about the critical nature of the recent group discussion of the Social Sciences BES.

The interviewing process adopted was a semi-structured approach. Such a strategy offered a flexible approach to data collection, in which emergent themes could be followed in a fluid and timely manner, while not drifting away from the focus of the interviews (Denscombe, 2007). In this way a much more naturalistic approach was established than a strategy such as a questionnaire. The preparation for such a form of data collection required considerable thought and was guided by a framework proposed by Kvale (1996) (see Appendix D for detail).

The second stage of semi-structured interviews of individual social science teachers sought to explore participants' understandings and meanings of:

- the outcomes of the group discussion process

- their views of the critical nature of their discussions

- the impact that the critical thinking model had on their discussion

- the facilitators and barriers for incorporating Social Sciences BES research into practice. 
The interview schedules for the two phases of semi-structured interviews of teachers can be found in Appendices E and F.

Conscious of the time that the teachers had given to focus group discussions, the individual semi-structured interviews were limited to 20 minutes per participant. In retrospect this could have been 30 minutes, as some of the teachers had a great deal to say about engagement with educational research. All semi-structured interviews were transcribed and participants given the opportunity to member check a hard copy before analysis was undertaken. Such an approach is an important aspect of developing the trustworthiness between researcher and participants (Denscombe, 2007).

\section{Semi-structured Interviews with Key Contributors}

By identifying three key contributors to the Social Sciences BES, a purposive approach was taken, in which the primary consideration was their expertise to the issue being studied (Babbie, 2008). The rationale for interviewing the three key contributors was to gain insight into the ways that they envisaged teachers would critically engage with the literature of the Social Sciences BES. Because the Social Sciences BES is not clear on the specific role of critical thinking, other than related references to attitudes of open mindedness, fallibility and persistence, the interviews were an opportunity to seek greater clarity.

Walford (1994) has noted that interviewing of expert participants requires significant preparation, not least because of the possibility of the interviewer being 'tested' during the interview. While the researcher never felt tested by the key contributors, on the rare occasions that there were factual inaccuracies in interviewing, these were swiftly corrected by the interviewees (see Appendix G for the interview schedules for BES key contributors). Interestingly, the second interview of one of the key contributors took less than half the time than that of the first. If future situations arise in which two or more interviews are with expert participants, it may help to organise the meetings with a longer break between the two in order to allow for personal debriefing and reflection before re-focusing thinking towards the second interview.

I chose not to run a focus group of the key contributors for three reasons. First, focus groups are designed in such a way that they allow thinking to feed off other 
participants' ideas. With such expert participants I did not feel that such a mechanism was necessary to draw out thinking. Second, I anticipated that the richness of detail that these three participants would be able to provide would be better facilitated through an individual interview. Third, and unlike the social sciences teachers who worked together on the same site, the pragmatics of a mutually convenient location for all three key contributors to come together at the same time were unlikely.

\section{Data Analysis}

As part of a qualitative research study the need for the reader to appraise the 'dependability' (Lincoln \& Guba, 1985) of data, by scrutinising processes and procedures is vital. This increases the chances of someone else coming to similar results and conclusions if they undertook the study. The following descriptions of data management aim to clarify how the themes emerged from the raw data, thus increasing the dependability of the study.

\section{Data Management}

The transcribed focus group discussions and interviews of teachers and Social Sciences BES key contributors were used as input for the qualitative analysis. The small number of key contributor transcripts $(n=3)$ allowed for coding by hand. I expected to follow the same procedure for the teacher interviews $(n=10)$, but decided that using the computer software package NVivo $^{\mathrm{TM}}$ would offer greater organisational capability and would also speed up the process as several draft iterations of coding were conducted (Bazeley \& Richards, 2000). Once focus group meetings and individual interviews were transcribed verbatim, these were uploaded as source documents in the $\mathrm{NViVO}^{\mathrm{TM}}$ software. Data management relied on two specific procedures - making sure labels for each source document were entirely unambiguous and, in the case of interviews, giving each question the same text heading level. By doing so, this allowed for my first runs of broad-brush coding to operate smoothly (Bazeley \& Richards, 2000); a practice outlined in the next section. 


\section{Data Coding}

Approaches to data coding vary a great deal, and thus it was important to decide on which approach would suit the collected data. For example, one analysis of the two phases of focus group meetings was conducted using the 'elements of reasoning' from the critical thinking model as codes. Rather than utilise an open-coding procedure at this stage, whereby themes 'emerge' from the data, the approach to coding used a pre-existing analytical framework to generate results. To this end, eight 'nodes' in NVivo ${ }^{\mathrm{TM}}$, each corresponding to an element of reasoning from the modified critical thinking model, were generated. The purpose of each node was to act as a virtual filing cabinet (Bazeley \& Richards, 2000), into which highlighted text that was representative of that node's 'theme', or in this case, element of reasoning, was deposited. An example of this approach is given in Figure 3.2. This diagram offers examples for coding decisions. The major challenge was how to break down, or 'unitise', coding (Denscombe, 2007). For example, should units of coding be attributed to each speaker who showed reasoning about a particular aspect of the

Ben: The girls felt, the comment is there, that they felt more comfortable they felt more interested in it and they felt that they knew that they had something to contribute to it.

Gina: Is there any comment in that case study that by choosing that content, what's the payoff for the dominant group? If you are choosing content to specifically encourage a minority group to have a voice, is there any discussion about what happens to the rest of the group?

Ben: I think that when you got through this, that there are lots of things that we do know about in our teaching, it's just having it all there. I think it is quite a simple solution to quite a difficult problem and I don't think doing that once was going to help. It would have to be a sustained kind of effort by the teacher to be more inclusive make things more relevant to different groups. When we were at teachers college they used to sit down the back and check how many students we asked questions and made contact with them.
No coding at this point, which is Ben's summary of a piece of research, which while helpful, is not a critical element of reasoning.

Both questions posed are coded as a single implication of the research findings being discussed.
Acknowledges that the principles of inclusivity and relevance embodied in the research case study would need to be sustained: thus coded as a second implication, as different to that raised previously by Gina. The unit code ends at Ben's reminiscing.

Figure 3.2: An example of unitizing codes from a focus group discussion 
Social Science BES? Alternatively, where dialogue between two or more teachers was along the same line of reasoning, should that exchange be coded as a single unit of reasoning? While either approach was justifiable, it was the consistency in approach that required adherence. Ultimately, it was decided to code reasoning in units that had a clear beginning and end, whether it represented the thinking of one individual or an exchange across a number of speakers.

The second coding system I used was quite different for further analysis of the interviews and focus group meetings and had two distinct approaches. To begin, a broad-brush coding approach (Bazeley \& Richards, 2000) was used to identify sections of text from my source document transcripts in which there were likely to have been obvious references to the research sub-questions. For example, the extraction of a specific question in the semi-structured interviews enabled large chunks of text to be coded relatively quickly, as the $\mathrm{NVivo}^{\mathrm{TM}}$ software recognises questions by the text heading level they are ascribed in the transcription process (Bazeley \& Richards, 2000). After this stage, repeat sweeps of other parts of the interviews and focus group discussions were undertaken to identify additional data I could also add to broad-brush nodes; for example, 'facilitators' and 'barriers'. The second stage of this coding procedure was to conduct a fine-grained coding approach, by which a number of sub-codes were identified using a comparative method across all source documents (Strauss \& Corbin, 1998). During this stage of interpretation a process reminiscent of Denscombe's (2007) 'bracketing' was used. The aim was to grasp the central meaning of the focus group meetings and interviews by lifting portions of text. As these pieces of text were coded they were allocated a relationship to what became the tree nodes of 'facilitators' or 'barriers'. Over time these codes were categorized in order to reduce the number of codes into meaningful analysis, while also reflecting congruence between codes, thus resulting in a typology of 'facilitators and barriers'.

\section{Ethical Considerations}

Education research of any kind demands that standards of ethical proprietary are observed. At the outset of this study, after the research proposal was accepted, ethics approval from the Victoria University of Wellington, Faculty of Education Human 
Ethics Committee was applied for and granted (see Appendix B). At the heart of this code of ethics are a number of principles specific to educational research which Clark (1997) identifies as: 1. Justification, 2. Informed consent, 3. Confidentiality, and 4. Deception.

\section{Justification}

Making educational research worthwhile is important (and screened through the thesis proposal stage), but questions arise concerning the primary beneficiaries of the research. Some forms of research have a strong justice focus oriented to the participants, while in other forms, the greater good supercedes the interests of participants. Clarke (1997) summarises this distinction as a division between justice and utility. This research is more orientated towards a utilitarian position in the sense that it does not attempt to specifically alter the material conditions of teacher professional practice. The justification for this research was carefully articulated to principals, in order to negotiate entry to the schools. Perhaps unsurprisingly this led to discussion and debate about the relationship of educational research to teachers.

\section{Informed Consent}

Written informed consent was sought from all the teacher participants, their principals and the three BES key contributors (see appendices H, I, \& J). Clark (1997) emphasises that consent alone from participants is insufficient. Informed consent requires that participants know exactly what the research project entails and what their contribution to it will be. As a result, the information sheets and consent forms duplicated information and it was made clear to all participants that participation was voluntary and that individuals had the right to leave the study without any prejudice whatsoever. As part of the full disclosure of expectations, and following the broader principle of minimising harm (Clark, 1997), the number of meetings and interviews and how long they would take were outlined to the teachers in the information letter.

\section{Confidentiality}

While survey research design is able to provide assurances of anonymity, observing small groups of teachers discussing ideas is unable to do so, thus confidentiality of teachers' participation was the more appropriate aim (Denscombe, 2007). As the Greater Wellington social sciences community is quite small, conducting the research 
on the host school site was the approach taken to minimise the possibility of confidentiality being breached for teachers. During the data collection phase, however, it was difficult to avoid meeting social science teachers inquisitive about my presence in their school but who were not participants in the research. In two such situations, responses carefully lacked specificity, and by asking questions the researcher helped conversation take a new direction. Confidentiality is also maintained in the submitted thesis by the use of pseudonyms for the schools and individual teachers. I determined the pseudonyms for the schools, while individual pseudonyms were given to me by teachers who expressed a strong desire to do so, or otherwise were left to my design. The confidentiality also extended to access to collected data. All electronically recorded data were stored in secure, password protected computer files, while handwritten notes were kept in locked cabinets, to which only the researcher had access to a key.

It should be noted that it was rather difficult for confidentiality to be guaranteed to the three academic key contributors - a condition that was made very clear to them as part of the informed consent process. Nevertheless, in order to maximise confidentiality, the interviews were conducted at each of the key contributors' workplace and none of the data were attributed specifically to any one of these three individuals.

\section{Deception}

The idea of deception is anathema to this researcher's personal conception of why and how educational research should be conducted -there is a minimum requirement of taking all reasonable steps to "do no harm" to the reputation of schools and the wellbeing of research participants is fundamental. This maxim includes psychological as well as physical domains, and therefore a transparent approach was undertaken, in which communications with participants allowed for a continual dialogue in order that the staff did not feel 'in the dark' about the research intentions.

\section{Limitations of this Research}

The small scale of this study means that the results cannot be generalised out to a wider population of social science teachers. Furthermore, this thesis is based on a snapshot in time. Specifically, the Cherry Tree and Waterside School teachers are 
representative of 'early adopters' in the dissemination of the Social Sciences BES (Rogers, 1962). Findings from this early stage of teacher engagement with the Social Sciences BES may be very different at later stages: assuming that the diffusion of the document and commitment to engaging with published research literature becomes more widespread.

A limitation of the credibility of data collection strategies is the predominant use of observations/recordings of group discussions and short semi-structured interviews to understand how teachers' engaged with the Social Science BES in a critical fashion. By limiting data collection to these forms, and not observing the teachers in action, a perspective was lost that might reveal further information on how teachers' critical engagement with the Social Sciences BES is shaped through teaching practice (Smylie \& Hart, 1999). What teachers reported back in the group discussions provided less of a threat than direct classroom observations, yet may have been problematic if the teachers over-reported change in their own practice or student outcomes (Cohen, Manion, \& Morrison, 2003). Following on from this line of reasoning, it might also have been instructive to explore more directly the relationship between the teachers' critical engagement with research and student outcomes.

My choice of Paul and Elder's (2000) model as a heuristic for the analysis of reasoning was based on the grounds that it gave a very clear operational definition of 'critical thinking'. However, whether my 'light-touch' approach to introducing the model to teachers and fielding any questions was stringent enough is questionable. It is possible that a more structured workshop approach in which I demonstrated use of the model with a specific piece of research may have been beneficial for the teachers as they progressed into the second phase of the research.

Only one of the ten teachers attempted to integrate research evidence from the Social Science BES into their own practice. This '1-in-10' phenomena may be because the need to critically engage with research literature requires a much greater length of time before teachers are comfortable enough to take the steps and open their doors of classroom practice towards teaching-as-inquiry (Cochran-Smith \& Lytle, 1999; Little, 1990). 


\section{Summary}

This chapter outlined the research strategy and methods used to collect and analyse data for this thesis. The research is located in the broad qualitative-interpretive tradition of educational research, adopting an instrumental case study design. The choice of focus groups and semi-structured interview research strategies is considered to be appropriate for the questions being answered. The ethical implications of the study have also been raised, noting the challenges of gaining access to schools and ensuring confidentiality of participants. All approaches to education research carry with them some limitations, thus this chapter concluded with recognition of the constraints and shortcomings pertinent to this particular thesis. 


\section{Chapter 4: \\ Towards teacher critical engagement? The views of three key contributors to the Social Sciences BES}

This chapter presents the findings of interviews with three academics who made key contributions to the Social Sciences BES document. The three key contributors all expressed a desire that the evidence in the document be held up to scrutiny by teachers and noted supports for critical thinking that existed within and beyond the Social Sciences BES text. Nevertheless, all three highlighted challenges that teachers might experience in this process.

\section{Introduction}

This chapter presents the views of three key contributors to the Social Sciences BES about teachers' critical engagement with published research evidence. A year after the release of the document, there was considerable teacher demand for the Social Sciences BES: "Without any communications strategy, 6, 989 Social Science BESs have been requested in 2,500 schools" [Key Contributor (KC) interview, lines 189191]. Such demand may well have been stimulated by the previous lack of availability of this kind of research evidence. Given that so many schools had requested this document, to what extent did the key contributors think that teachers might critically engage with it? Their insights in relation to this question are presented as three broad themes: prospects, challenges and supports.

\section{Prospects for Critical Engagement}

All three key contributors identified the TAI model as a key framework through which teachers could apply findings from the Social Sciences BES, to the extent that for one it represented the fifth key finding of the Social Science BES. Each key contributor stressed the need for critical thinking on the part of teachers because of the contingent and provisional nature of knowledge presented in the Social Sciences 
$B E S$. Moreover, the need for critical thinking was considered imperative if teachers were to challenge knowledge built on thin evidence bases, or were to avoid unintended effects such as racism and bullying. To this end, one key contributor suggested that a Popperian outlook might ideally be cultivated by teachers in order to hold their long-held beliefs up to scrutiny:

An attitude I would like to have in teachers' minds, is not to prove things but actually the opposite. To falsify dogma that we hold to: "It isn't certain, in the context that I am teaching it may not work in the way that is described, it may need some adaptation and adjusting." So that's the sort of critical attitude that I would like people to have to it. (KC lines 97-100)

All three interviewees indicated the wide scope for critical engagement with the Social Sciences BES, including one who considered that the evidence itself and its relationship to teachers' classroom contexts would benefit from critique:

I'd like to see them critically engaging with ideas about the relevance to outcomes in our curriculum; and relevance in terms of their own learners and what they know about their own learners, where they are at and what are their needs and strengths. Critiquing the methodology; some critical thinking about the nature of the methodology used. And then most importantly critical thinking about what they are going to do in their own practice. So the relationship between the research and their own practice. (KC lines 62-67)

It was very apparent from the key contributors that the design of the Social Sciences $B E S$ had evolved greatly from the early releases of the wider Iterative BES Programme in recognition that it was not only the evidence-based messages that were considered important but how that evidence was communicated. The balance between the nomothetic mechanisms and the ideographic case studies used to illustrate those mechanisms at work were just two of the design features that the key contributors highlighted. Later in this chapter a more detailed analysis of the key contributors' views about the support signalled for teachers is presented. Before this, however, the next section demonstrates the somewhat ambivalent views the key contributors had towards teacher critical thinking with published research evidence.

\section{Challenges to Critical Engagement}

As well as highlighting the potential for critical engagement, the three key contributors indicated a number of challenges that teachers might face when critically engaging with the Social Sciences BES. Three different challenges emerged from the data, related to: over-assimilation, teacher identity, and dealing with complexity. 


\section{Over-assimilation}

Despite the desire for teachers to rigorously critique the Social Sciences BES research evidence in relation to their own practice, there was a sense that implementation of the Social Sciences BES could result in being "co-opted into business-as-usual" (KC line 253). A recurring theme was that teachers might be inadvertently seduced by the Social Sciences BES co-authors' efforts to make the unfamiliar familiar. For example, reducing complex findings to a set of easy-to-remember mechanisms generates "those appealing ideas that the vast majority of teachers think, I would hazard a guess, are already at play in their classrooms" (KC line 101). In other words, where teachers use the language of the Social Sciences BES without understanding complexities underneath that veneer of simplicity then over-assimilation is possible (Alton-Lee, 2006b; Spillane, Reiser \& Reimer, 2002). The potential then is for unfamiliar ideas to be assimilated into pre-existing understandings:

That is one of our key concerns, in terms of the over-simplification of it. We know that often when implementing policy or something of this type, teachers over-assimilate what they already know and think that they are obviously doing that already. So I think that if I am honest I wouldn't expect a very high critical engagement with it. (KC lines 55-59)

Critical thinking may be seen as an antidote to the problem of over-assimilation. It is the process of critical thinking that allows the nuances, complexities and contradictions of research evidence to be made more visible.

\section{Teacher Identity}

Just as over-assimilation is a cognitive inhibitor to teachers' critical engagement with the Social Sciences BES, an equally unintended consequence is that teachers' strong identification with their own context inhibits critical thinking about research contexts that seem too dissimilar to their own. One of the key contributors' thoughts mirrored Castle's (2006) observation that privileging the uniqueness of their own classroom context can restrict teachers' engagement with pedagogical-outcomes linked improvement:

What I might hope [teachers] didn't do was to say "this isn't my context, this isn't my level, this isn't my children; this is the United States, or wherever the case study came from. So I'm sceptical and suspicious because it doesn't look like me." So that's a form of critical voice that I don't think is particularly helpful because I don't think it helps you get at the underlying meaning of what is going on. That would concern me, that type of critical voice. (KC lines 120-125) 
The unequal distribution of published research literature in the Social Sciences BES which has an overt focus on particular subjects, ${ }^{9}$ may also have implications for secondary school teachers. For secondary school teachers the first step of developing an identity is typically with their senior subject teaching specialism (Tambyah, 2008). Should such identity formation endure, secondary school teachers may be impervious to evidence that does not, on face value at least, reflect their senior subject concerns:

Take the geography teachers for example, and say "Here it is, here is the BES that will inform geography teaching" I think they'd say 'no, it doesn't do that, it isn't inclusive enough of the outcomes we have in geography. It touches on some of them, but it really isn't speaking to me enough as a geography teacher". Historians: possibly less so. Economics like Geography, would probably say there is not enough in there. So that is a problem. (KC lines 231236)

Such a problem requires critical thinking for this obstacle of teacher identity to be overcome. Kennedy's (1999) findings indicate that teachers are able to draw analogies between research evidence and their own practice, even when contextual differences such as age-level, subject or social class of students exist. To be able to do so rests on the capacity of teachers to reason about information, recognise the relevance of significant concepts, and consider the implications for changes in their own practice. Whether secondary school social science teacher identity does make this prospect unlikely is a theme that is returned to in Chapter 5.

\section{Dealing with Complexity}

All three key participants acknowledged, through different examples, the challenges of making sense of complex research evidence. Two key contributors, for instance, argued that the Social Sciences BES document should not be viewed as a prescription of pedagogy, as "we really want people not to be seeing this as something to implement and 'do' and replicate identically, but to inform their practice" [KC lines 38-39]. Avoiding interpreting the Social Sciences BES as a prescription for pedagogical approaches is not, however, an invitation to pick and choose elements of specific pieces of research without substantial reasoning about the implications of

9 Social Studies $(n=77)$; History $(n=55)$; Geography $(n=20)$; Economics $(n=13)$. The number of research articles per subject was calculated from a content analysis of all the titles in the Social Science BES reference list. This is quite a rudimentary operation, yet I am confident that the difference in numbers across the subject supports my substantive point. 
doing so. For one key contributor, the unintended consequence of cherry-picking sections of research evidence was considered problematic if the multiple variables at work were not critically appraised for their relative merits:

So I suppose the other unintended consequence, this is a real trick actually, is not realizing the importance of everything in a case study, or everything in the relationship between teaching and learning. So what I mean by that is that you might look at a case and say "well, we'll do $\mathrm{x}, \mathrm{y}$ and $\mathrm{z}$ but we won't do $\mathrm{a}, \mathrm{b}$, and c, they are not us, so we won't do a, b, and c. Because we have done $\mathrm{x}, \mathrm{y}$ $\& \mathrm{z}$, we'd like you to get the outcomes." Well it may actually have been that $\mathrm{a}, \mathrm{b} \& \mathrm{c}$ were the things that you really needed to get those outcomes. So I think one of the other unintended consequences is that people may think they are doing what the case is doing, but because they've left out a critical step or critical piece, they are not doing it. [KC lines 164-171].

The complexity of the Social Sciences BES may also be a reflection of teachers' difficulty in interpreting challenging technical language. A key contributor suggested that reducing the Social Sciences BES evidence to slim-line, easy to digest document for teachers was not necessarily helpful, despite calls to the contrary (Vanderlinde \& van Braak, 2009):

Teachers need a more complex language of practice to help. Everybody wants simple summaries, but they are not going to, in the end, help the teachers on the ground. When the language starts to make distinctions, and becomes useful to teachers, that is when you start to get change. (KC lines 286-288)

In this instance, the key contributor echoed concerns that while simplified research summaries assisted dissemination and promoted general debate, they were less likely to supply teachers with the detail required to consider approaches for substantive pedagogical change (Everton et al., 2002; Ratcliffe et al., 2004).

\section{Supports for Critical Engagement}

This section reports the perceptions of the key contributors in regards to the support that teachers might receive for critical engagement, within the Social Sciences BES text and also from their wider working environment (Kirkwood \& Christie, 2006).

\section{Within the Document}

As noted earlier, the key contributors pointed to the concerted effort that had been made to design the document in ways that might support teachers in their critical thinking about published research evidence. Many of these design features arose from research about effective curriculum design to communicate policy messages to 
teachers (Aitken, 2005). More recently, Cordingley (2010) has defined 'research tools' as resources designed pedagogically to scaffold teachers' learning from research. Design features such as consistent colour coding, thumb tags, indexing and cross-referencing being included to encourage teachers to make links to wider sources of evidence are examples of such research tools. In addition, and in response to the trap of over-assimilation reported in the previous section, one of the key contributors highlighted the misconception alerts in the document:

There's a section at the end which we wrote as we became aware of the unintended consequences. People saying to us, "this is the same as" and we wanted to say "actually, no, it isn't the same as!" So one of the ways we tried to mitigate the risks, and I don't know whether teachers are using this, it will be fascinating to know when you have written your thesis, whether they are. It was something I felt particularly strong about: "this is what we are saying this is not what we are saying". We hope that by putting that, especially the negative there, it would just stop people doing what we call over-assimilation. There's a lot of research in implementation that says that is a major issue. (KC lines 204-211)

The contested nature of research evidence was another factor that key contributors felt was signalled in the document and all three considered that the transparency of the methodology was particularly important in this regard. A key contributor indicated that the methodology section offered a "matrix in there about the quality of evidence, just to signal our own critical thinking about the nature of the evidence included in the effort" (KC lines 51-52). The need for methodological clarity is a feature of the wider Iterative BES Programme, although because of the nature of synthesis, it does not necessarily offer support to teachers who seek to explore the methodological approaches of individual pieces of published research evidence contained within it.

Another feature of the Social Sciences BES which, in the view of the key contributors, promoted critical thinking, was the case studies. Beyond the clarity with which these cases were communicated and the surface design features noted earlier, the case studies offered detailed evidence which could be subject to scrutiny:

The cases in the BESs really matter. I did a lot of looking at when research helps teachers change practice and when it doesn't. I think one of the most likelihoods of change is if a whole staff works with just one case for a period of time and uses the [TAI] cycle. (KC lines 286-288). 


\section{Beyond the Document}

Whether the research tools embedded within the Social Sciences BES would be sufficient was treated with caution by the key contributors. A question posed by one interviewee was "how much can a document itself be knowledgeable expertise to help teachers?" (KC line 247). The same interviewee believed that a shift in school leadership policy from an organisational to a pedagogical orientation would benefit teachers' engagement with the Social Sciences BES. Nevertheless, a long-term view was anticipated:

They need a chance to try it out, check it, and multiple opportunities to try it, and work in depth with the new ideas. I do think that they need 1-2 years of really in-depth professional learning to get to grips with that. (KC lines $250-$ 252)

The findings of Timperley, Wilson, Barrar, and Fung (2007) were also influential for the other two key contributors, one of whom pointed to the need for teachers to engage not only with the document but to "get people working around real things, real artefacts and documents that they can identify with. You won't change student achievement with broad scoping discussions about what you do" (KC lines 73-74). The inference here was that talking about pedagogy in an abstract way was unlikely to produce change in the way that discussions focused on issues related to authentic student outcomes was likely to (Alton-Lee, 2006b).

The role of expert intermediaries, as facilitators for teachers engaging with published research, may be the circuit-breaker needed for teachers who are not used to engaging with academic literature (Vanderlinde \& van Braak, 2009). While one key contributor believed the Social Sciences BES was designed to be engaged with by groups of teachers without expert help, a caveat was soon offered:

There is no substitute of course, for somebody who has worked intimately with it to be able to take a group of teachers through it. So I would think that PD focused on what it is and isn't saying would be useful. That's the sort of PD I would be doing on it. (KC lines 212-214)

Another key contributor suggested that expert intermediaries would likely be located in universities which offered postgraduate courses with pedagogy-outcomes linked papers. In this key contributor's view, the credentialing function of universities would offer the external motivation for teachers to engage in action research 
projects. It is difficult to know to what extent the implication of this pathway would encourage TAI being viewed as an additive task or the beginning of a life-long learning orientation to pedagogical-outcome linked teacher inquiry (Cochran-Smith et al., 2009). Even if postgraduate education did support a transformative approach to pedagogical practice, it is unclear what this would mean for teachers without the resources to undertake such study. Nevertheless, studies in Scotland have shown modularised university-based credentialising courses for 'Chartered Teacher' status have a positive impact on teachers engaging with and in research (Kirkwood \& Christie, 2006).

\section{Summary}

This chapter has presented data from three key contributors to the Social Sciences $B E S$. The focus has been on the prospects for critical engagement, the challenges facing teachers of doing so, and the support mechanisms for teachers' critical engagement with the Social Sciences BES. While all interviewees felt that a critical orientation to evidence was imperative, and that numerous features of the Social Sciences BES signalled this to teachers, they were nonetheless ambivalent about the extent to which teachers would engage critically with the document. 


\section{Chapter 5: Teachers' critical engagement with the Social Sciences BES}

This chapter presents the findings of Cherry Tree and Waterside School social science teachers' critical engagement with Social Sciences BES research evidence. The analysis of focus group and interview data suggest that Paul and Elder's (2000) modified critical thinking model may have had some very short-term impact on teachers' reasoning about published research evidence, but it is doubtful that this was sustained. The analysis of a sole teacher who took steps towards integrating research evidence into her practice suggests how the lack of reasoning may have implications for teacher inquiry. Finally in this chapter, I identify a range of facilitators and constraints to Cherry Tree and Waterside teachers' critical engagement with Social Sciences BES research evidence.

\section{Introduction}

In this chapter the focus of teachers' critical engagement with the Social Sciences $B E S$ research evidence is presented through the analysis of data collected from focus group meetings and semi-structured interviews from Cherry Tree and Waterside Schools' social science teachers. The three questions constructed to test the impact of a critical thinking model on teachers' engagement with Social Sciences BES research are:

1. How accustomed were Cherry Tree and Waterside teachers at using research evidence?

2. What have been the outcomes of critical engagement with the Social Sciences $B E S$ for Cherry Tree and Waterside social science teachers?

3. What were the facilitators and constraints for critical engagement with Social Sciences BES research? 


\section{How Accustomed were Cherry Tree and Waterside Teachers at Using Research Evidence?}

Social Sciences teachers in both groups did not regularly use research evidence as part of the mix of informants to direct decisions they made in their practice. Harry was typical of many of the teachers when he stated:

Research is not something I have paid a lot of attention to before. I mean, I was very traditional in my first years; I just wanted to get to grips with the curriculum. I was very content focused and orientated, and I think it is only in the last five years that I have started to look at how students learn best, rather than what they are learning [Harry, Cherry Tree School (CTS), Interview1, lines 20-23]

Despite the fact that research evidence was not considered a substantial feature of their professional day-to-day decision making, when asked directly, six of the 10 teachers articulated a conception of evidence-based practice that highlighted the transfer of what is working to their own practice and/or adjusting their own practice in light of a new source of information. Furthermore, seven of the teachers indicated that an evidence-based approach drew from a number of different sources of evidence:

The way I understand evidence-based practice is that you are kind of looking at using information or research that people have already done that shows that these kind of things work for them. Or that these kinds of things don't work well. And also thinking about your own teaching and what has or hasn't worked. And especially with assessments and therefore basing your practice on what you do from that. So it's sort of looking at research findings and your own assessment and your own experiences really. [Marama, CTS, Interview 1, lines 11-16].

Far from placing systematic research at the peak of a hierarchy of evidence, typical sources of evidence cited were the value of experience and intuition, evidence emerging from the classroom, and professional development courses. For all the teachers, engaging with published research evidence was not considered significant to professional practice, especially when other priorities dominated:

I never really read educational research at all to be honest. I did most of my reading in the subject, so I read the NZ Journal of History, which was about content wasn't it? I'd go to History things and it was about getting my head around History. And so much of our energy went into assessment. So the professional development was about assessment, so I don't think I read much about pedagogy at all until I studied [at post graduate level]. [Fraser, Waterside School (WS), Interview 1, lines 31-36] 
The notion of evidence-based practice received some critical attention from the Waterside teachers. For example, Fraser questioned the assumption that research findings could be replicated in other teaching contexts, while the following exchange between Steve and Travis indicated critical thinking about the implications of evidence-based practice:

Steve: I kind of wonder, when we make it explicit, that people actually lose sight of what they're actually already doing instinctively well, because they can't articulate it in this way. I just think, sometimes when you make things official, it almost suffocates you. It almost makes you feel like "I'm not doing it enough", or you suddenly feel like you're failing at what you're doing, rather than doing well or feeling confident with what you already are. So it's kind of hard to do a cookie cutter thing, you know, like here's the way you should do it, here's the Best Evidence Synthesis, this is the way you should teach that's going to get the best results, 'cause some people will be good at parts of it and not good at others, and...

Travis: That's not the intention, is it?

Steve: $\quad$ No, but I'm talking about how we can apply it and what can we do with it.

Travis: But, I mean, I think it is quite useful to analyse and abstract what a good practitioner does, provided it doesn't become a template for what all practitioners must do on every occasion. That's the danger, that if you don't follow what is here in some way you will be inadequate. Well, there are always going to be exceptions, both teacher exceptions and student exceptions, who somehow fall outside these parameters. But I'm still quite happy to look at it.

Steve: Yeah, I mean, we're quite happy to look at it, 'cause we're the kind of practitioners that are prepared to sit down and look at these things. I'm kind of thinking about communicating this to hundreds of people, or to social sciences departments - how do you do that in a way which doesn't make them feel like they're not doing stuff? Does that make sense? Like, you're trying to empower people to feel confident to go on and try things, rather than saying "if you're not doing these, you're not really a good practitioner" [WS meeting 4, lines 69-108]

The example above highlights Steve's and Travis' desire to engage with evidence for purposes of empowerment while being mindful against the possibility of 'entrapment' (Elliott, 2004). The danger according to these two teachers is if research evidence is used as a blueprint for teacher practice, or worse still, causes teachers to feel inadequate about their current approaches. 


\section{What have been the Outcomes of Critical Engagement with the Social Sciences BES for Cherry Tree and Waterside Social Science Teachers?}

In this section I present the perceptions of the teachers involved as well as my own analysis of group discussions. I first analyse the case of Cherry Tree School social science teachers, including the embedded case of Caitlin. After this I analyse the case of Waterside School social science teachers. In both cases I consider the teachers' critical thinking before and after the introduction of a model for critical thinking.

\section{Cherry Tree Social Science Teachers' Reasoning}

The content analysis of Cherry Tree School teachers' reasoning is shown in Figure 5.1. The radar charts have eight axes radiating from the centre point, each of the axes representing an 'element of reasoning' as defined by Paul and Elder's (2000) critical thinking model. Each axis is also scaled to represent the frequency of discussion coded as critical. The radar chart at the top of Figure 5.1 represents the totality of critical discussion in the first three meetings before Cherry Tree teachers were introduced to Paul and Elder's (2000) modified critical thinking model, while the radar chart below shows the reasoning in the second phase of meetings, after the introduction of the critical thinking model. The very small amount of focused critical thinking in the first three meetings was adequately summed up by Helen's reflection, "I don't know whether we did critically analyse it very well. We were a bit all over the show really, weren't we?" (Helen, CTS, Interview 1, Lines 87-88). The first three discussions, before the critical thinking model was introduced, were characterised by tangential and off-topic discussions that focused on anecdotes of experiences in previous schools, contexts influencing their current practice, and recounts of conversations with students rather than deliberating evidence presented in the Social Sciences BES.

Moreover, it appeared that there was some expectation among this group that the Social Sciences BES would champion particular teaching strategies:

Caitlin: The thing about this chapter is that it didn't tell us...is this the one that didn't tell us what to do? 


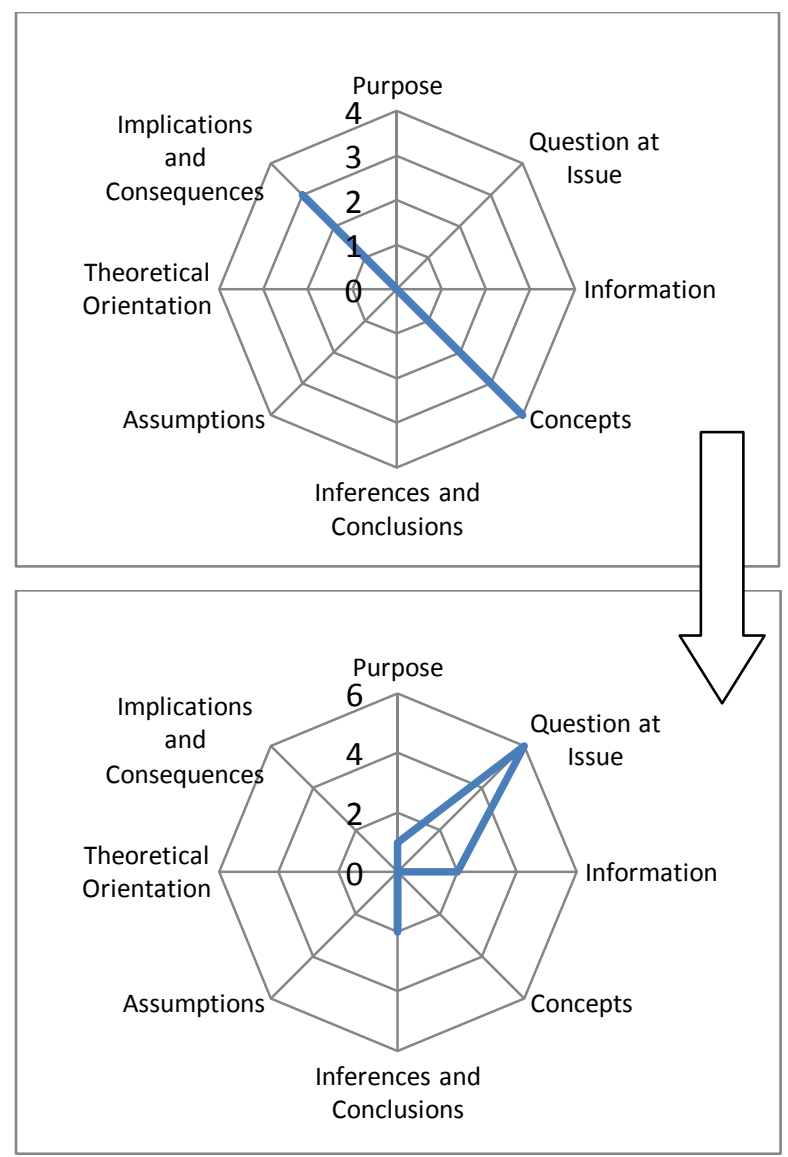

Phase 1: Before critical thinking model introduced

Phase 2: After critical thinking model introduced

Figure 5.1: Cherry Tree teacher reasoning before and after the introduction of the Critical Thinking Model ${ }^{10}$

Marama: It doesn't. It just tells you all this stuff but it doesn't make any recommendations.

Helen: Because you want them to tell you some basics.

Caitlin: Well no, it doesn't say you should do this, this, this.

Marama: It says this is not very good but there's not many examples of what is really good practice.

Caitlin: That's what I would have liked. If you know all this stuff, what is it? I thought maybe it is somewhere else.

Helen: They could give us some stuff about what works. [CTS meeting 3, lines 337-346]

Before the introduction of the modified critical thinking model, Cherry Tree teachers expressed the view that their personal and group engagement with the Social Science

10 Data derived from the code given to a section of text unified by one 'element of reasoning' (Paul \& Elder, 2000). For example, a code may have been given to a single speaker's reasoning or be spread across multiple speakers who are engaged in dialogue. 
$B E S$ did not extend to a great deal of critical reading of the material. For these teachers their reading was largely orientated towards a scanning of ideas:

There have been lots of very good ideas and it has been enlightening in a lot of ways, but there hasn't been a great critique of the whole thing... Being critical about it? I don't know if we have gone down that line at all to be honest. It's just been almost like an encyclopaedia of information. [Harry, CTS, Interview 1, lines 87-90]

Harry's use of the encyclopaedia simile is a telling choice of language. In the manner of requiring quick reference material, it suggests seeking information in an off-theshelf fashion. By using this simile Harry is suggesting that the passive consumption of information took precedence over the exercising of critical judgement of research evidence.

In interviews after the introduction of the model, retrospective reflection indicated there was no clear consensus over which elements of reasoning had been at the forefront of their discussions during their first phase of meetings. Those most often cited were information, interpretation, and concepts. However, as Catherine indicated, the reasoning over concepts was largely limited to comprehension rather than reasoning about the role those concepts played in the research evidence of the Social Sciences BES:

We had to go over some of the concepts, some of the words that they were using, as we came up to speed with the jargon. Such as 'iterative', that was one of the first that came out that needed clarification! It's not in my day-today vernacular. Some of the terms don't make a connection with those that are reading it. [Catherine, CTS, Interview 2, lines 90-93]

A broader consensus was given regarding the elements of reasoning that the group felt were absent from their thinking. Most commented on the absence of discussion about the assumptions and theoretical frameworks underlying individual pieces of research in the Social Sciences BES:

But not so much stepping back and saying, 'hang on, where are they coming from when they are doing this?' Maybe because we are teachers, we tend to look for the information and concepts, and interpreting, rather than thinking 'why is it like that?'[Marama, CTS, Interview 2, lines 69-71]

I don't think that assumptions and theoretical orientation, I don't tend to make them a big part of my natural 'what do I think about when I am reading it?'I do tend to read it at face value, and forget to think about the assumptions that are being made...[Helen, CTS, Interview 2, lines 48-50] 
The second phase of Cherry Tree School meetings, after the critical thinking model was introduced, became more focused with a greater range of reasoning, including thinking about the 'question at purpose', 'information', and 'inferences and conclusions'. An example of an elaborated group effort is shown in Figure 5.2, which demonstrates how group dialogue facilitated reasoning as the teachers came to an increased level of shared understanding (Frijters, Ten Dam, \& Rijlaarsdam, 2006).

The modest increase in the range of reasoning after the critical thinking model had been introduced supports McGee and Lawrence's (2009) observation that critical reflection takes time and is often not part of the initial immediate reflections when inquiring into practice. This lack of critical reflection was lamented by Caitlin in her second interview:

Just because someone has written a paper and had it published, doesn't mean that it's the 'truth'. As a group maybe we were in awe of it: "Look at this flash document, it's Best evidence, so it must be good". You felt like you couldn't challenge it. [Caitlin, CTS, Interview 2, lines 66-69]

Such a group interpretation of 'Best' was, however, caught up in the idea of the irrefutable nature of evidence from which, as this thesis has made clear, the Iterative BES Programme is keen to distance itself (Alton-Lee, 2006b). This is one reason why intermediary 'knowledge-brokers' would be of high value to networks of teachers seeking to explore evidence in the Social Sciences BES, as it would allow for the type of professional development advocated by a key contributor in the previous chapter.

In summary, Cherry Tree teachers' view was that their engagement with the Social Sciences BES literature approximated the 'storytelling and scanning for ideas' approach described by Little (1990). This reflects the experience of a group of teachers for whom engagement with research evidence was largely a novelty, and for whom reassurance rather than critique was the group-norm. 
Helen begins to unpack the meaning of the information of the diagram, until she stumbles on the sequencing of coded boxes, prompting a question to her colleagues

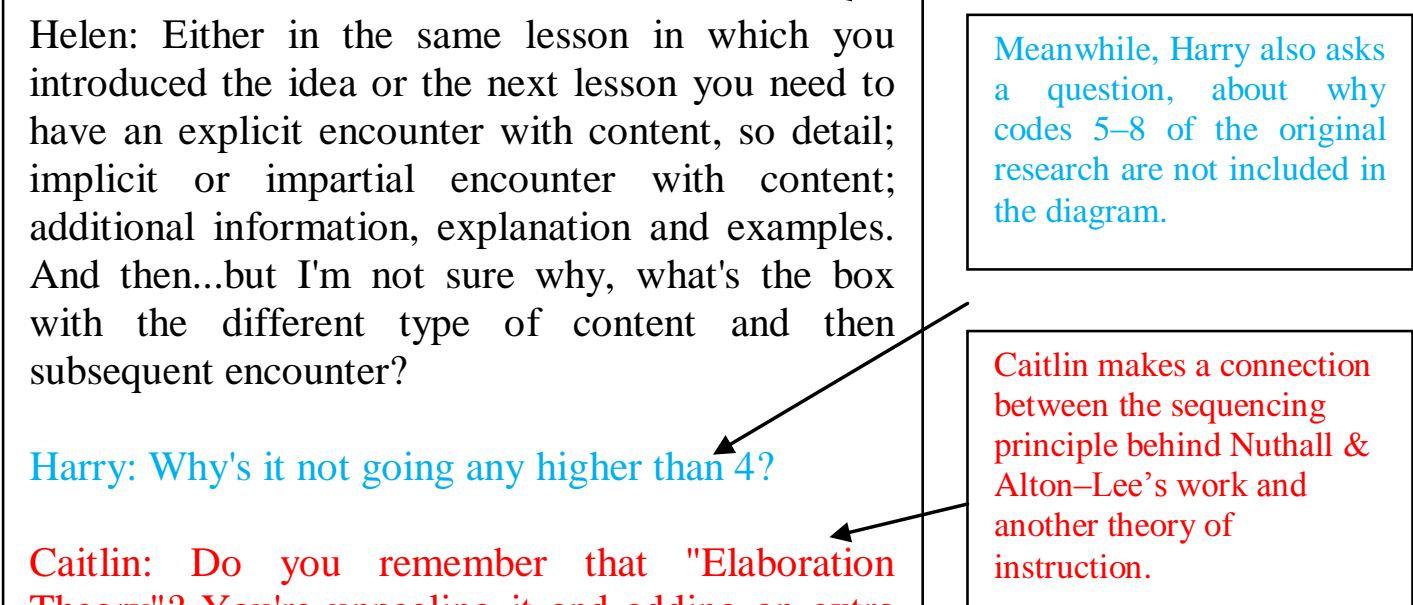
Theory"? You're unpeeling it and adding an extra layer.

Harry: I'm reading here on p. 112, that you could only have 2 encounters but as long as they are the specific encounters that complement the other. So for instance, if you use 2,3 or 4 as it quotes in the bullet point, the next time you encounter it has to be a 1 , a content style $1 \ldots$

Caitlin: Because you haven't had explicit Harry: If you start with the explicit one then the next time around you have to repeat the explicit one then do some implicit/partial stuff, then the additional stuff on top of it.

Helen: Does that mean you do all of those or can it be either?

Harry: I think that is what the connections are for. So if you do 2, 3 or 4 you've got to , it says...

Caitlin: You've got to link it to $1 \ldots$

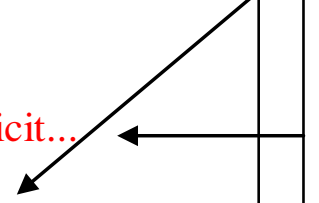

Following his initial question, Harry's reasoning for the importance of codes $1-4$ is supported by his search for information.

Caitlin's reasoning of information also makes the link between the sequencing in the research

Harry: Link it to 1 or in some cases alternatively to two encounters with the information types 2 or 3.

Harry correctly identifies Nuthall \& Alton-Lee's finding (cited in Aitken \& Sinnema, 2008) that student learning is possible without intended understanding being explicitly included, but that it will require a greater number of activities at the implicit level in order to embed learning in the working memory.

Figure 5.2: Cherry Tree teacher's reasoning during engagement with Social Sciences BES 


\section{Caitlin}

The story of Caitlin's engagement with the Social Sciences BES is particularly interesting in relation to the focus of this research. Richetti and Tregoe (2001) have argued that teacher-leaders who display criticality go beyond the analysis of sources of evidence and put that thinking into action. During the research period, Caitlin was the single teacher who took such steps: perceiving that something was wrong, asking questions, seeking knowledge from others, taking risks, and reflecting on results (Castle, 2006). Her story provides insight into how over-assimilation and inattention to the complexity of research evidence risks undermining the integrity of teacher inquiry.

\section{Introducing Caitlin}

Having entered the teaching profession as a second career, Caitlin had taught in three secondary schools before her appointment at Cherry Tree School. She had also completed a postgraduate qualification in education. Most of her teaching experience has involved working with students unlikely to progress beyond Year 11. In Caitlin's view, she was a fringe member of the Faculty given she had only recently arrived and only taught one Year 9 social studies class. Nevertheless, her participation in the focus group meetings had "certainly helped me to integrate into the social science department and get to know them and them get to know me" [Caitlin, CTS, Interview 2, lines 5-6]. Similar to the wider group, Caitlin had expressed frustration that the Social Science BES did not appear to offer concrete strategies of a 'best practice' approach:

I was a bit disappointed. I'm not convinced yet that this document provided me with sufficient practical tools to use. I felt it left me wanting in some parts. It has challenged me somewhat and frustrated my thinking at the same time. It was ok, some things you can pick up and run with, [but] it hasn't given me enough tools to run with. [Caitlin, CT, Interview 1, lines 69-73]

Nevertheless, Caitlin's questions and gentle challenges to colleagues' thinking in the Cherry Tree group discussion had suggested that she was more adept at thinking critically than her colleagues.

\section{Caitlin's Inquiry}

In the fifth of the six focus group meetings, Caitlin noted that her Year 9 learning support class rarely reflected on their learning which was, in her opinion, confirmed 
by the evidence of a number of blank exit slips. ${ }^{11}$ She also reflected that some of these learners were concerned that they had not completed the final piece of work. This led Caitlin to "think about the fact that they might be slapping a magazine together rather than thinking about the learning, so I want to change that" (Caitlin, CTS, meeting 5, lines 205-207).

Earlier in this meeting, the Cherry Tree group discussion (see figure 5.2) had centred on findings from the Understanding Learning and Teaching Project (ULTP) research $(1993,1993,1994,1999$, cited in Aitken \& Sinnema, 2008). The focus of the dialogue was on eight coding categories used in this research and their relationships to the working memory structures of learners. Caitlin felt two of these categories, 'being explicit' and 'key words', would be particularly beneficial for raising the achievement of her students:

that's one of my aims I think, having the key words and being explicit. You have to be explicit with a learning support class anyway but I think it has just drawn my attention about how you have to explicitly say what you mean and how you want to do it. [Caitlin, CTS meeting 5, lines 351-354]

Following on from her identification of the two ULTP coding categories, Caitlin framed a question to focus her inquiry: 'What strategies can I use that ensures learning happens during a project, instead of [students] experiencing a sense of incompletion?' In order to move from a focus-inquiry into a teaching-inquiry (Aitken \& Sinnema, 2008), Caitlin scoped activities focused on 'being explicit' and 'key words' from a number of sources, including a DVD that provided a range of literacy strategies aiming to support students with diverse language needs in the English and Social Studies learning areas (Ministry of Education, 2007b) as well as searching various internet sites with a literacy focus.

Having trialled these approaches in a sequence of lessons, Caitlin reported the shifts in her teaching to the rest of the discussion group. In the context of the achievement objective about "how people pass on and sustain culture and heritage for different reasons and that this has consequences for people" (Ministry of Education, 2007a n.p.), Caitlin reported that she had reinforced the idea of myths and legends as a

11 Exit slips, as used by Caitlin, were a place for learners to record their understanding of work and reflections on what they found successful and challenging about learning they had completed. 
vehicle for passing on tribal history by building this into her questioning and textbook-based activities. Further, students' presentations were required to use key words associated with the passing on of cultural heritage. Caitlin reported that while she had always written key words on the whiteboard, her approach to making them visible to students was far more focused over this period. She reported drawing attention to the words through use of colour on the whiteboard, elaborating on them and linking them back to the learning with high frequency in each lesson.

In a subsequent meeting, Caitlin presented evidence of three focus students' learning to her colleagues, using photographs of work samples, observations of their speeches to the principal, and examples of exit slips. Her account of student progress touched upon a range of outcome sets identified in the Social Sciences BES, affirming that she had understood the pedagogy-outcomes orientation of the Iterative BES Programme. First, Caitlin emphasised the students' visibly positive response, producing work of which they were proud and happy to communicate to the principal. In their 'exit slips', all three students showed a significant improvement on a continuum that indicated their satisfaction compared to their previous unit of work. Second, these exit slips also indicated knowledge outcomes. For example, they stated that the main purpose of a Māori myth or legend was to "pass down the trible [sic] history", "part of the Māori history", "to pass on the history". While Caitlin acknowledged these statements were extremely modest in their scope, they indicated a basic knowledge which she had not seen from these three students previously. Third, Caitlin reported that the students were observed to have engaged in their learning in a far more constructive participatory fashion, to the extent that Caitlin viewed this as "the peak of our year" [Caitlin, CTS meeting 6, Line 52].

\section{Analysing Caitlin's Critical Engagement with BES Literature}

What follows is an analysis of Caitlin's critical thinking during her personal learning journey. Caitlin reflected on her largely intuitive choice to focus on explicit teaching and focusing on key words because she "hoped that they would work. I didn't know if they would work, in fact I still don't know" (Caitlin, CTS meeting 6, line 50-51). She recognised that a number of contributing factors may have influenced the gains her focus students made: 
I think you have got to question yourself whether learning is happening. Was it this, was it that? Was it the topic that helped? Was it the fact that it was hands on? Was it that they had to do a presentation at the end of it? Or was it that I was explicit with the key words? If I'd have taken that out would I have got the same outcome? You'll never really know. [Caitlin, CTS meeting 6, lines 66-69].

The most revealing aspect of this acknowledgement to her colleagues lies in the absence of reference to the ULTP research which originally drove Caitlin's inquiry into her practice. In this section I identify aspects of reasoning about Social Sciences $B E S$ evidence that were largely absent in Caitlin's thinking which may have resulted in a clearer alignment between Caitlin's inquiry into her practice and the findings of the ULTP research.

\section{Absence of a Theoretical Orientation}

Although Caitlin focused on her teaching and student outcomes, there was little acknowledgement of the learning process that linked the two. While the broad notion of 'alignment' as a learning mechanism was hinted at, the theories of cognitiveinformation processing and schema theory were not articulated, despite both being outlined in the Social Sciences BES (Aitken \& Sinnema, 2008). There was no discussion about the theoretical viewpoint of the ULTP research in the group setting, which may explain why the framing of her inquiry question lacked a theoretical vision, instead attempting to pose a question about the efficacy of particular techniques. As a result, Caitlin was not in a position to link her teaching methods with larger understandings of students as learners (Cochran-Smith, et al., 2009). Caitlin's lack of reasoning about the theoretical orientation of research evidence supports the view of her colleagues, who, as noted earlier, recognised that such thinking was an absent element of reasoning in their group discussion.

\section{Over-assimilation of Concepts}

The group discussion concerning the ULTP research gave limited attention to the precise meaning of concepts that lay behind the coding system employed by the ULTP researchers. For example, the 'explicit' code was a very specific concept for the ULTP researchers that referred to the relationship between the information of a learning experience and the information required to fully answer a test question. By the time Caitlin had finished her inquiry, however, her focus had moved to the explicit use of key words, even though the Social Sciences BES makes it clear that 
such an approach in the ULTP research has no predictive capacity for students to build knowledge constructs into long-term memory. Ironically perhaps, Caitlin's own schema, which was strongly oriented to improving the literacy skills of low achieving students, may have over-assimilated the ULTP research codes 1 ('explicit') and 5 ('key words') and brought them together to rationalise her approach (Spillane, Reiser \& Reimer, 2002).

\section{Methodological Information}

Caitlin's methodological approach of assessing knowledge using exit slips may have resulted in further self-scrutiny had she explored more information about the methodology of the ULTP research. The 'immediate post-tests' of the ULTP research provided evidence of knowledge outcomes through a mixture of multiple choice and short answer questions. Furthermore, the evidence from these assessment tools was triangulated by interviews of focus students, conducted 2-3weeks after the period of learning. This combination suggests a fit-for-purpose assessment tool for examining the activation of short-term working memory being activated, whereas Caitlin's choice of exit slips as tools for measurement was less convincing. The need to critically explore the methodological information of evidence synthesised in the Social Sciences BES may be one reason for seeking out the original published literature. If Caitlin had done so, it may have led to greater evaluation of whether exit slips were a reliable way of measuring knowledge embedded in the short-term memory. Furthermore, the ULTP research measured the planned learning of hundreds of knowledge constructs. While Caitlin's resources could not stretch to this, a single knowledge construct may be considered a less robust barometer of success.

\section{Reasoning About Purpose of Research}

Finally, and relating to the three previous points, it did not appear that Caitlin had grasped the extent to which the ULTP project had such significant focus on the knowledge outcomes of students. Thus, while Caitlin was happy to report student gains in affective and participatory outcomes (albeit in quite limited terms), this was some distance removed from the major purpose of the ULTP research aims, which was to investigate the ways in which students do or do not acquire knowledge 
through typical classroom activities, even when they are engaged in the same activities and interacting with the same curriculum materials (Nuthall, 1999).

In summary, this analysis highlights problems that a lack of reasoning may have on particular stages of inquiry into practice. Should critical thinking about research fail to peel away the different layers of complexity, then there is a chance that it becomes over-assimilated such that the framing of the inquiry, methodological approach and drawing of conclusions lack the rigour envisaged for a profession-wide knowledge building exercise (Saunders, 2007).

\section{Waterside Social Science Teachers' Reasoning}

In the Waterside group, and in contrast to the Cherry Tree teachers, the majority of the participants perceived their discussion to be critical. Two teachers believed that their first phase of discussion was critical because the group sought to make sense of the evidence for their own context, as indicated by Steve:

Immediately we have looked at the BES for what it can offer us, but also how we can use the BES...to be critical about the BES because that's the best way to do it. Not critical in the sense 'that's dumb' but critical in the sense of 'what can we actually take from it? What relevance does it have?' [Steve, WS Interview 1, lines 111-113]

The content analysis of the discussion at Waterside School (see figure 5.3) revealed that during the first phase of meetings all but one of Paul and Elder's (2000) eight element of reasoning were traversed. During this phase the reasoning was more extensive for the 'Purpose' and 'Question at Issue' elements of reasoning emerging from the Social Sciences BES research. In the second phase of meetings, during which the focus was on the Social Sciences BES in general, the number of dialogue units coded as critical was less, as was the range of elements of reasoning. Typically at Waterside School, the first phase of meetings had a strong dialogical element in which ideas were interchanged, challenged and modified, as group thinking drew upon several elements of reasoning. An example of such discussion is shown in figure 5.4 below, which also demonstrates how different elements of reasoning overlapped with one another in the messy practice of critical thinking (Baildon \& Sim, 2009). Before and after the introduction of the critical thinking model, over half the data coded as being critical were categorised in the 'purpose' and 'question at 


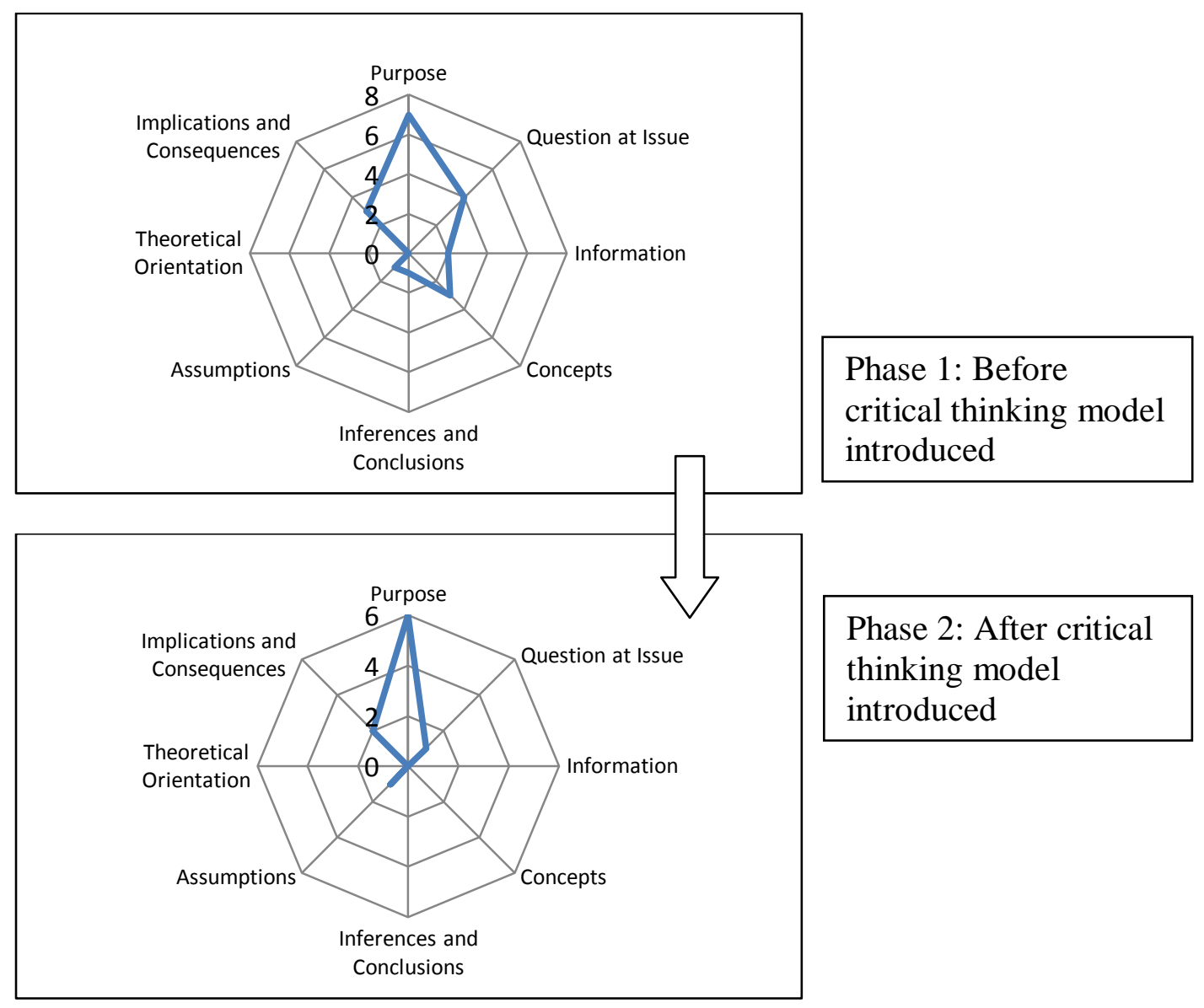

Figure 5.3: Waterside teachers' reasoning before and after the introduction of the critical thinking model

issue' category. The data reflect a group of teachers whose reasoning gravitated to the question of 'What is this all about?'. One such example was the critique of a case study that sought to address the silence of girls in classroom discussion (Nairn, 1994, 1995, 1997, cited in Aitken \& Sinnema, 2008) (see figure 5.5). This dialogue marked a moment in which the methodology of a piece of Social Sciences BES research was critically scrutinised, whereby the limitation of what the case study could say prompted reasoning about the question at issue. 
Travis: The Classics case study was on page $258 \ldots$ it basically involved drawing in a group of students who weren't often engaged, by using a comparison between the classical studies context of the ancient Roman World and their own culture, which happens to be Samoan. It's a very good example I suppose of helping students...the idea of drawing upon prior knowledge and perhaps involving parents in discussion and making them feel part of the learning could be quite valuable for a disengaged part of your class. Useful as an idea.

Steve: I'm trying to think that when I teach a History class with something that is conceptually new or a little difficult to imagine this kind of idea of making comparison always happens. But I have to keep reminding the students, "same, but different", "same but different" all the time because often we say that "It's like this" and it's actually watering down the content too much. So I kind of use it as a gateway...

Fraser: It's a hook

Steve: ... to get them to think about it, but actually it's nothing like that whatsoever. If at the end of the lesson they still think it's the same then I have failed! It's a way of trying to get them to think, "Perhaps there's a way I can get into this". Those knowledge comparisons are very tenuous that we make in classrooms.

Travis: I think that this is a very good comparison and it might allow a quiet student who is basically ignorant, and looking at these first grades [examining graph] they don't know much. Highest mark is $38 \%$ so basically they've got no knowledge at all. If they are able to talk about their own culture it might give them something to say, so I agree it's a hook, but a very useful one.

Steve: But if they went away thinking that the British colonisation of Ireland with Henry II, Irish Clans and their wars is the same as what happened here...there are way more differences than it is similar. But the idea is that they are now listening and involved.

Fraser: This one's more about taking some big concepts and making people aware of their own cultural things first...

Steve: Yeah, sure

Fraser: ... and making them connect.

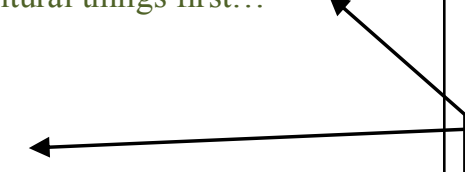

Travis: The other point that they make, which I guess is quite a good one is that the teacher, and I guess the rest of the class, also learnt something about a new culture that they didn't know previously; about Samoan religious practices. And that's quite a valuable outcome I guess in a multicultural school. And it's quite interesting to draw in, if you have students with very different experiences, to draw those into the lesson.

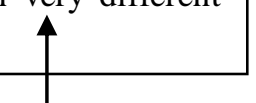

Travis recognises the implication of the case study, especially in relation to participatory outcomes for diverse learners

Steve initially recognises the idea of using analogous examples as a way of increasing student understanding; before reasoning unintended implications that may arise.

Fraser sums up Steve's reasoning for using analogies.

Steve reasons further on the potential for misconceptions through the use of misleading analogies

Travis' reasoning draws on information from the case study to support the power of the 'big idea' of cultural connection to support learning.

Steve's reasoning continues... before acknowledging the benefits that hooks bring to new learning.

Fraser's reasoning moves away from the simple idea of a hook, to a deeper appreciation of the case study's exemplification of the concept (mechanism) of connection to support identity outcomes.

Travis' reasoning draws upon more information that supports the approach from the point of view of knowledge and identity outcomes for diverse learners.

Figure 5.4: Waterside teachers' reasoning during engagement with Social Sciences BES 
Gina reasons whether the research intervention, to offer a better balance of gender specific content, may have the consequence of being viewed negatively by boys
Gina: It would have been quite interesting in this case study if she had done that and followed the model without it being something so clearly aimed at the girls. The boys would have been sitting there saying 'this is dumb'.

Travis: Ah, but isn't it saying that the girls are usually sitting there going 'this is dumb'?

Gina: But I wonder if it is that or that they don't want to participate. It would be interesting to know whether a different structure to the class would have got them to participate as much as trying to choose [content] that is so blatantly biased towards the girls' interest.

Fraser: I think it comes back to this: if we can get students to be intellectually curious and critical thinkers. Not just the girls but different types of students, if you can make it inclusive so that they learn about something different.

Gina: It seems like they have done two things in the case study. One is pick content and the other is perhaps structure of the lesson. And it would be interesting to see what those two things were like separately.
Travis' reasoning is redirecting Gina to the original question at issue of the research: that girls in the class are not contributing to discussion.
Gina questions whether the approach by the researcher recognises that the question at issue may have been resolved by focusing on structure rather than selection of resource materials.
Fraser's reasoning suggests an implication of the research.

Gina restates that the intervention in the research consisted of two distinct elements. She reasons whether the impact of the two elements could be isolated to see which has greater consequence for raising the participation of girls during class discussion.

\section{Figure 5.5: Waterside teachers' critique of a section of the Social Sciences BES}

In summary, Waterside teachers were largely in agreement that their focus group meetings contained critical elements. Analysis of the focus group discussions suggested that the group reasoning was oriented to thinking about the purpose of the Social Science BES and specific case studies contained within it. This also led to the question at issue in many of these case studies being the subject of reasoning.

But to what extent did Paul and Elder's (2000) critical thinking model promote of teacher critical thinking? That, and other factors, are the subject of the final section in this chapter. 


\section{What were the Facilitators and Constraints for Critical Engagement with Social Science BES Research?}

\section{Facilitators}

In this section I outline four facilitators for teachers' critical engagement of Social Sciences BES literature in this study. The data are based on the convergence of teacher perceptions and the content analysis of focus group meetings. What the method does not allow is an appraisal of the extent to which each of these facilitators played a part in enhancing thinking, as many operated concurrently.

\section{The Critical Thinking Model}

As indicated earlier in this chapter, Cherry Tree teachers' reasoning increased after the introduction of Paul and Elder's (2000) modified critical thinking model. Marama indicated that the introduction of the model encouraged the group to focus and look beyond surface features:

I think we started using this model so that we didn't get so off track. I think the model did bring a deeper level of thinking and critiquing. It felt at the start that it was "Oh we don't like this, oh that wouldn't work". Whereas once we started looking at the model it gave you other areas to think about reading the BES that you hadn't thought about before. [Marama, CTS, Interview 2, lines 36-40]

Having the model as a support to reading appealed to both Helen and Catherine, the latter recognising that the skill of reading research was not something that was part of her professional practice:

To have it as a tick box if you were reading a piece of research would actually be quite useful, because it reminds you to look for some elements which you might not have picked up....to me it's good to have but you would have to be pretty clued up on research full stop, to be able to précis it or judge it. I found that to be the really big difficulty: to be conscious of how to critique the research. [Catherine, CTS meeting 4, lines 45-51]

For the Waterside teachers, however, the range and quantity of critical thinking was less after the introduction of Paul and Elder's (2000) modified model, which casts some doubt on how useful it was for these teachers. Nevertheless, all five of the Waterside group said that the critical thinking model helped them access material in the Social Science BES. For Gina and Steve in particular, having the model offered a focus for their reading as they began to engage with the BES: 
I think the model did help, because when we first started looking at the model it gave you a way of going through the BES, as opposed to just taking a gigantic document. It meant you could break it up a wee bit, into how you were going to look at it. So in terms of when you are first approaching the BES it is definitely useful. [Gina, WS, Interview 2, lines 39-42]

To have that as a framework or gate to engage, started the conversation in a different way. So I think having the critical thinking model was really helpful to us, or for me anyway. To enable us to engage with the BES deeper than face value. [Steve, WS, Interview 2, lines 75-77]

Although Fraser and Ben perceived that their critical engagement deepened in the session after they were introduced to the model, they indicated that it was not something that continued in subsequent discussion:

Having this model probably helped us at a time when we might have said what we already could from a surface level about it, without spending hours looking at the document. So I would say it was of some help, but I don't know if it was something we sustained. [Fraser, WS, Interview 2, lines 57-59]

It was a good thing to bring to one of the sessions, but I haven't used it since. It generated quite a bit of discussion. I think that for critiquing the BES it is another step that can be used to figure out what is in the BES, and what might be helpful. [Ben, WS, Interview 2, lines 58-60]

The stronger endorsement of the model from Cherry Tree teachers may reflect that their base level critical engagement with the literature from the Social Sciences BES was less than their counterparts in Waterside school.

\section{Group Dialogue}

As argued in Chapter 2, critical thinking is a social activity which involves selfreflection in light of additional perspectives offered by the dialogue of group members. All but one of the teachers commented on the positive outcome of hearing alternative views about pedagogy from colleagues. Echoing Eisner's (2002) contention that contexts in which groups of professionals network to discuss educational issues liberate individuals from a "monocular perspective and a single interpretation" (p. 382), Fraser considered that the experience challenged the traditional balkanization of social science teaching at Waterside School:

I think that it has brought together people from different subject areas in a school where there is not really a close social science faculty, and where people are very subject bound. So I think that has been a real strength of it, people from Classics, Economics and History talking about those sort of things that focus on learning. [Fraser, WS, Interview 2, lines 1-3] 
The power of dialogue to shape thinking is demonstrated in the following extract from a Cherry Tree School meeting (figure 5.6), in which the group moved towards a

Caitlin asks a question to the group to clarify a conceptual
understanding which Harry also queries.
Caitlin: This is the bit that annoyed me, page 217:
"Caution: it is not sufficient that activities be interesting."
Harry: Why not?

Marama: That needs to be pushed out to parents, because the amount of parental complaints I have got at the moment about "Uhhh, it's not interesting." I feel like saying to the parents "I'm sorry, I didn't think we were the circus. Life's not interesting all the time."

Caitlin: Yeah but it was like it has got to be interesting, not only interesting, but does learning happen?

Helen: It's interesting that they say, 'students can be highly motivated and actively engaged in interesting classroom activities, but not learning anything new'. But surely you would incorporate [something new] in terms of the knowledge that they are gaining through the activity. That would be something new to them. Is that maybe something to do with pre-tests and things like that and working out what they already know and that kind of thing?

Caitlin: But then it went on about that no-one could remember what they learned from a very interesting activity.

Helen: Well that's the thing isn't it? What does it say here "Interesting activities that are aligned to student activities foster student engagement", then "Interesting activities are interesting but not sufficient"

Caitlin: What's 'sufficient'? I didn't know what to make of that bit. I don't know who wrote that but...

Helen: I think that they are talking about using a variety of activities but [pause] are they just putting the point out there that you've got to make sure that it is a valid activity, not just for the sake of it?

Marama: Not just sticking a video on for the sake of sticking a video on.
This comment suggests a mis-conception, whereby 'not sufficient' is being equated with 'not important'.
Caitlin challenges Marama's interpretation by clarifying the concept of 'suffiency' in the statement from p. 217 of the Social Science BES.

Helen articulates her own assumption that teaching activities bring new learning. The diagnostic assessment comment seems to be a red herring.

Caitlin identifies cognitive dissonance.

Helen draws on information to highlight the dissonance.

Caitlin searches for more concept clarification.

Helen offers clearer conceptual focus by suggesting that the sufficiency being referred to involves both interest and validity (alignment).

Marama concurs (showing a shift in her original conceptual understanding) with the common example of 'video' as a medium that may be interesting yet may not promote new learning. 
shared conceptual understanding that challenged the pre-existing belief that learning will occur if students simply engage in interesting activities. The interaction among the teachers was critical in nature because it demonstrated an unpacking of the concept of 'alignment' which, according to the findings of the Social Sciences BES, needs to complement 'interest' for effective learning to occur.

\section{Focusing on Specific Pieces of Research}

Across both groups, the scope of reasoning increased when each group focused on a relatively small section of text. The Cherry Tree School group accessed the Social Sciences BES literature by exploring each chapter of the four explanatory mechanisms, before taking a more personalised approach for the last two meetings. The Waterside group predominantly focused their attention on the more detailed case studies. This early focus on case studies was reflected by a wider range of reasoning which was reduced in their last meeting, when the discussion focused on the role of the Social Sciences BES more broadly. For the Cherry Tree teachers, their ambitious attempt to explore each of the Mechanism 'chapters' produced very little focused critical engagement with the research. In conjunction with the introduction of Paul and Elder's (2000) modified model, a focus on some specific sections of evidence resulted in a wider range of reasoning during their second phase of meetings.

A perceived need for limiting the size of the document was considered necessary by most Waterside teachers if the document was not to gather dust on shelves, as signposted by Travis:

I am expecting that the key ideas in the BES will be captured in half a dozen pages in the teaching and learning guidelines, which I am hoping will be much more widely read...I can see its place at training college when you start your career: it seems an invaluable document to me. But it will be quite hard unless there is in some way some selected pages are chosen for close analysis for it to get much traction. [Travis, WS, Interview 2, lines 93-96]

With Travis' suggestion, however, comes a conundrum: would a summary version of the Social Sciences BES - requested by six of the ten teachers in this study - focus on the broad abstract findings, thereby inhibiting the possibility for critical thinking to take place as part of the close analysis of specific pieces of research? While a summary might be worthwhile for teachers initially put off by the size of the document, it would not be sufficient for substantive critical engagement with the research evidence within. 


\section{Constraints to Critical Thinking}

While the introduction of Paul and Elder's (2000) model was designed to support teachers' critical thinking, this did not preclude teachers from being constrained in their thinking as a result of engaging with Social Sciences BES evidence itself. The data indicated three substantive constraints: 1) Lack of group structure and accountability; 2) Challenges to teacher identity; and 3) Socio-centric dialogue.

\section{Lack of Group Structure and Accountability}

Although the genesis of communities of practice was considered a worthwhile outcome by all, the extent to which they had a significant impact on teacher critique of Social Sciences BES research evidence was questioned:

I wasn't sure how this was going to work out at the start and whether we should say "let's pick out a section and trial it out in class and come back and report back". That's perhaps what I was expecting might happen, rather than the discussions that we've had...It's a time consuming thing to do but could have been beneficial if we had chosen a mechanism each, taken a few sections and trialled a few things and reported back. [Ben, WS, Interview 2, lines 4145]

The presence of accountabilities to enhance the quality of critical engagement was something that Fraser identified as being successful in other pedagogy related professional learning that staff elsewhere in the school had participated, but reflected that this was not the case with the Social Sciences BES:

I think the weakness of this focus group is that there's been a disconnect for me personally, from what I do in my classroom. Maybe the professional learning group structure that we've got, where you are actually meeting and there's an implication that you'll go away and try something or actually do something with your class and then report back, might be a better forum for this...and said next time, having looked at this, we will go and then each try...hold each other accountable, try something in each class. [Fraser, WS Meeting 4, lines 190-194]

Most Cherry Tree teachers voiced their opinion that their discussion, particularly before the critical thinking model was introduced, had a tendency to go off at tangents, through historical examples of teaching, anecdotes of how other schools operated their social science learning, and stories about particular classroom experiences. Helen viewed this absence of critical engagement in the first three meetings as a result of a lack of a specific focus: 
I don't know whether we did critically analyse it very well. We were a bit all over the show really weren't we? I guess some structure would be good and to have a particular point or particular things we were looking for, first of all. Like maybe, having an overall goal or kind of structure in mind of how we were going to analyse it. [Helen, CTS, Interview 1, lines 87-90]

As Levine and Marcus (2010) have recently reported, pedagogical aspects of teacher practice are not likely to be addressed without a clear focus and structure, to the extent that strongly protocol-guided meetings may offer the necessary support for teacher talk to predominantly focus on instructional practice. Moreover, these authors suggest that calls for collaboration in the abstract, without specifying structures and aims, are the wishful thinking of an unstated professional network belief that if you build it, they will learn (Levine \& Marcus, 2010). The problem of such an assumption was supported by the opinions of teachers across both groups who suggested that levels of accountability needed to be built into the meetings in order for more focussed critical engagement to occur.

\section{Challenges to Teacher Identity}

A further constraint to critical engagement with Social Sciences BES literature was, according to both Cherry Tree and Waterside teachers, the moments in which it was difficult to identify with published research literature. This lack of identification was largely framed in terms of the teachers' own identification with specific subjects, leading to feelings that "if you don't feel that particular context operates for you, you can have a negative attitude and wipe it" [Travis, WS Meeting 3, line 128-129]. Fraser argued that the very essence of criticality in the Waterside group was the refusal to dismiss as irrelevant research located in early childhood and primary school settings. Nevertheless, teachers across both groups commented that because some of the research was different from the context of their classroom it did not warrant great attention:

There's research that makes sense that I can use, and there's some of this that I think, "So what?" If it was relevant to me because of that situation in the class I'd take more interest in it. [Catherine, CTS, Interview 2, lines 40-42]

And I think also that it has to be relevant to what you are doing. There are some case studies in the BES that are primary, so you are wondering whether this will fit in a secondary context. And there are case studies in there that are History that are quite different to the topics and subject that I teach. So I guess in some ways you have to be mindful of those kinds of things. [Ben, WS, Interview 2, line 19-23] 
As noted in Chapter 4, one of the key contributors had signalled that Geography and Economics teachers may identify less with the Social Sciences BES document than those who identified with History, which certainly seemed to be the view of Ben, who strongly identified with Economics. This may be problematic if, as Classical Studies specialist Travis indicated, subject identification is so strong that it obscures thinking about how to enhance learning through effective pedagogy:

I think that what drives most Classical Studies teachers is a passion for the subject and if they had a choice, a little bit of time, I think it is unlikely that they would pick up the BES. I think the reason is, the intrinsic interest in the content often. This appears more stimulating to many than pedagogy. Even the word 'pedagogy' puts some people off. [Travis, WS, Interview 2, lines 100-103]

Travis' view was in contrast to some of his colleagues, for whom a focus on pedagogy clearly was a significant aspect of their identity. Nevertheless, some of these teachers also recognised that their identity as teachers could also be challenged as a result of engaging with the Social Sciences BES. For example, Steve indicated that a focus on "pedagogy can come across as you're not a good enough teacher, which is counterproductive to me" [Steve, WS, Interview 2, line 22-23] while Harry articulated "the initial shock of thinking that you are not as effective as you thought you were" [Harry, CTS, Interview 2, lines 13-14]. The affront to identity was particularly keenly felt by Caitlin, who took the step to publicly acknowledge what she could have done better to her peers; a process that may not be easy for all teachers:

You put yourself out there when you say 'Actually I can do a lot better'. For teachers sometimes to admit that 'If I made a little effort or changed something I could make it a lot better'. We all say we're busy, busy, busy, can't do it, can't do it. The first thing is to admit that you could do better. [Caitlin, CTS, Interview 2, lines 19-22]

Such an admission is a courageous step to overcome a disconnect between teachers' use of educational research and their practice which, in part, may be driven by reluctance to open their practice up to their colleagues (Miretzky, 2007).

\section{Socio-centric Dialogue}

While dialogue was considered a facilitator of critical thinking, it was also clear that it provided a barrier to reasoning when it narrowed thinking. Interestingly, none of the two groups began their sessions with an agreed framework for negotiating what 
might become difficult conversations. Most of the Cherry Tree School social science group had rarely engaged in pedagogical conversations with one another before, let alone conversations in which there may be some disagreement and debate, thus a framework for challenging conversations had yet to materialise. The Waterside teachers appeared far more comfortable and used to challenging each other's ideas; reflecting a group of teachers for whom recent pedagogical conversations were more common place. Nevertheless, even in the Waterside group, seeking ways that might take the sting out of personal critique was, in part, a conscious reason for the focus on the Social Science BES case studies:

Another thought is that a case study in itself allows you to discuss issues in a neutral way. So you are not being critical, in the wider sense, of each other's practice or saying that this is what I do, but you are starting from another point. [Fraser, WS, Interview 2, Lines 87-88]

Caitlin did attempt to challenge one piece of research (see Aitken \& Sinnema, 2008, p. 114) on the basis of its external validity, although as figure 5.7 shows below, the group effort largely had the consequence of narrowing thinking about the research. Unfortunately, the search for information led the teachers to question whether the research was helpful given that some of the parameters between two examples of student learning (topic choice and timeframe) were so different. While the teachers questioned the information they were reading, it succeeded in side-tracking them from a key point that the research was focused on the process of learning, irrespective of the social studies topic being studied. This example, in my analysis, suggests how social dialogue can also be a barrier to thinking, as well as a facilitator (Lipman, 1995; Paul \& Elder, 2007). 
Caitlin identifies a piece of Social Sciences BES that is problematic for her because of what she perceives to be two pieces of research with differences that are not taken account of.

Caitlin: I have a perfect example in the book which I hooted and laughed at, and I 'm not sure where anyone else did but it said...it's the 'Mia learning about crime in New York'. How interesting is that? Then 'Kim NOT learning about the Magna Carta'. Now what I

wanted to see was Mia learning about the Magna Carta actually.

Marama: It's two different things, isn't it?

Caitlin: New York, Magna Carta [weighing up with hands], Crime in New York...I would have liked to have seen Kim not learning about Crime in New York. So that I could say that it is fair...I felt that we had the wool pulled over our eyes on that page, 114, because it is comparing apples with pears here. You know, it has sort of got aligned up things here, and talking about mugging here, and here you are talking about colouring a market place picture. You're not really comparing...

Helen: Different days too, different parts of the teaching too.

Marama: But even the timeframe, because this starts at day 15

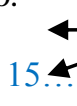

Helen: Yeah, that's what I said, you can't compare this day with this day. Kim didn't do this but Mia did this so obviously she is learning about it appropriately, you know? You kind of need to match it up

Caitlin: Somewhere else in one of the chapters it was saying how so and so 6 months later, was it Mia remembered this, but Kim didn't remember that.

Helen: And is it the type of activities that they are doing? Who knows?

Caitlin: I think that is what they are trying to say isn't it? Read a story...

Helen: And also maybe Kim would have learned more about crime in New York because it is more interesting

Caitlin: Yeah a story about gang violence or a copy the sentence and fill the gap about the charter [Magna Carta]

Catherine: Pretty dry

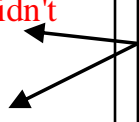

Caitlin: But I suppose that was an extreme example just to show us. But it would have been nice to show us the same topics...

Helen: And it would just be easier, we wouldn't have to do so much thinking!
Marama reinforces

Caitlin's concern.

Caitlin elaborates that the difference in the content may be attributable to the difference in learning.

Both Helen and Marama miss the point that it is the gaps between subsequent learning activities that contribute to Kim's inability to fix learning in his working memory.

Helen and Caitlin then focus on the type of activities being the source of the problem (rather than exploring the relationship between the information given and information required).

Helen reverts back to the idea of difference in subject matter being a key variable; supported by Caitlin \& Catherine.

The challenge to critically engage with research literature becomes evident.

Figure 5.7: Socio-centric dialogue at Cherry Tree School 
This final section of the findings has identified some of the facilitators and constraints for teacher critical engagement Social Sciences BES. The use of Paul and Elder's (2000) modified model enhanced reasoning in Cherry Tree School, although less of an impact was felt in Waterside School. Focused dialogue on small extracts of research literature supported reasoning skills. Constraints to critical engagement were the lack of group structure and accountability, the inhibiting effect of teacher identity to research that was perceived to have limited value to their context and the socio-centric nature of dialogue.

\section{Summary}

This chapter has drawn together analysis of the focus discussions of Cherry Tree and Waterside Schools. Furthermore, it has presented the perspectives of the teachers involved in consideration of the question 'What impact does the use of a modified model for critical thinking have on secondary school teachers' engagement with Social Science BES research?' The analysis indicates that Paul \& Elder's (2000) modified critical thinking model may have had some very short-term impact on teachers' reasoning about published research evidence, although this was not sustained by either group of teachers. The analysis of Caitlin, who took some of the steps towards a personal inquiry into her teaching demonstrates how a lack of reasoning about research evidence can be problematic for systematic, credible, local knowledge building exercises (Saunders, 2007). The data also show lack of group structure and accountability; teacher identity and socio-centric discussion acted as constraints to teachers' thinking about Social Sciences BES research evidence. 


\section{Chapter 6: Conclusions}

The argument that I have put forward in previous chapters is that if the Social Sciences BES is to be a "key-informant" (Aitken \& Sinnema, 2008, p. 52) for social sciences teachers' pedagogical inquiry, then they need to critically assess those findings. While teacher inquiry is not as stringent as the teacher-as-researcher concept in some respects (Cordingley, 2003), it is the premise of this study that TAI is, in part, informed by teachers' critical engagement with published research evidence. In the last decade, teachers' relationship with published educational research evidence has increasingly been the focus of academic attention in light of critiques that suggest there is a disconnect between education research and education practice (Hargreaves, 1996). This study adds to that body of research because a) it focuses on social sciences teachers, whose curriculum stresses critical thinking; b) it attends to New Zealand Best Evidence Synthesis research literature, a unique approach to the synthesis of large bodies of research; c) it is based on teachers' dialogue about research without the aid of an expert intermediary / knowledge broker; and d) it explores whether a modified critical thinking model can support teachers' critical engagement with research evidence. Moreover, it is the novelty of the combination of a) to d) that make this an original contribution to the field. As I have highlighted in earlier parts of this thesis, the design of the Social Sciences BES is itself testament to what is already known about factors which influence teachers' engagement with research. Nevertheless, as one key contributor pithily commented, "how much can a document itself be knowledgeable expertise to help teachers?" This study then, contributes to the body of work by exploring teachers' engagement with a 'new generation' of synthesised research that is designed, in abstract and concrete ways, to support teachers' critical engagement with research evidence.

This study's findings support the contention that the policy expectations of classroom teachers to engage with published research evidence is challenging in practice (Bell et al, 2010; Elliott, 2004; Vanderlinde \& van Braak, 2009). The study has demonstrated a degree of congruence between the key contributors' perceptions and the experiences of teachers. The findings suggest that the likelihood of teacher 
critical engagement with Social Sciences BES research evidence is difficult for groups of teachers who 'go-it-alone'. In this study, two groups of teachers, to different degrees, found it challenging to critically engage with Social Sciences BES evidence. Moreover, the adapted critical thinking model used as an intervention to support their thinking and dialogue, offered only short-term critical engagement with research evidence. Their engagement with Social Sciences BES research evidence suggested a 'scanning for ideas' approach at an early stage of engagement (Little, 1990). Both groups of teachers voiced the opinion that they did not engage deeply with evidence that did not seem to reflect their own settings, although the Waterside group's use of case studies was a notable effort of attempting to make connections between the big ideas of the research and issues in their own school setting. Further analysis of teacher inquiry suggested over-assimilation, whereby ideas from the Social Sciences BES were appropriated in ad-hoc and superficial ways (Spillane, Reiser, \& Reimer, 2002).

An underpinning challenge for teachers' critical engagement with the Social Sciences BES was to overcome the structural and group dynamics that were operating. Generally, a non-critical norm of dialogue prevailed, particularly in Cherry Tree School, where dialogue lacked focus while privileging anecdotal story telling. In Waterside School, teachers were reasonably comfortable with challenging each other's ideas, yet the lack of accountability was considered problematic for connecting the Social Science BES research with their own practice. These findings resonate with Marcus and Levine's (2010) critique of the professional network idea that idealises a 'bring them together and they will learn' expectation. Rather, the lack of formal protocols to construct shared aims and accountability for using Social Sciences BES research resulted in critical thinking about the research being disconnected from inquiries into their own practice. Much critical thinking literature emphasises that strong reasoning skills are beneficial if they help teachers make good decisions through their actions (Richetti \& Tregoe, 2001). While 10 teachers came together in this study to explore the Social Sciences BES, it only motivated a single teacher to lead with some pedagogical inquiry. It is worth noting that ' 1 in 10 ', if extrapolated across the profession, might well be considered an encouraging result for the very early stage of engagement with Social Sciences BES research, especially if the occasion becomes a transformative experience in which a new world 
of personal learning connected to enhancing student outcomes is the net result. However, the evidence from this study suggests that teachers 'going-it-alone' with the Social Sciences BES integrated it into a business-as-usual approach.

The findings of this study have implications for the type of institutional support that teachers are offered in order to critically engage with published research evidence. The New Zealand Teachers Council's twelfth criterion for registered teachers is to demonstrate 'critical inquiry into their professional practice' of which an indicator of meeting this standard is 'to systematically and critically engage with evidence and professional literature to reflect on and refine practice' (New Zealand Teachers Council, 2010a). Although a 'standard', a great deal of subjective interpretation of what this might entail is required. Interestingly, the Teachers Council resource to support teacher self-review towards meeting this standard raises more questions than provides guidance (see Appendix A). On the one hand, this aligns with the notion of 'teaching-as-inquiry'; on the other it lacks detail. For example, 'systematic' and 'critical engagement' are expected, yet there is no guidance to suggest that teachers might need to think about issues of validity and reliability related to research evidence.

The development of career pathways for classroom teachers is one avenue by which teachers' critical engagement with research may be promoted. For example, in secondary schools, Specialist Classroom Teachers are expected to be conversant with current educational research and share it with teachers they are mentoring (Ministry of Education, 2011a). This is some way short of some international career pathways for secondary school teachers. For example, the standards for Chartered Teachers in Scotland, are closely linked to university provision of postgraduate qualifications. These standards require that Chartered Teachers demonstrate evidence of informing their teaching by reading and research; for example, by engaging in professional enquiry and action research, reflecting critically on research evidence to modify practice as appropriate, and testing theoretical perspectives in the classroom (Kirkwood \& Christie, 2006). While Robinson's (2003) vision is of a profession shaped by teachers-asresearchers, the inclusion of the TAI model in the New Zealand Curriculum (Ministry of Education, 2007a) is an indication of policy direction making steps in that direction. The intensive resources required for educating and training teachers-as-researchers suggests it will be a long term endeavour. In the meantime, then, the TAI model might 
be seen as a suitable halfway house that supports reflective inquiry into practice, of which critical engagement with research literature is one small, yet significant component.

There are a number of institutional levers that may offer the prospect of critical engagement with published research evidence in general. As New Zealand social sciences teachers work in self-managed schools, school leadership teams that help create an environment of evidence-informed enquiry might be a starting point. It is however, doubtful whether a willingness to provide the time and space for social science teachers to form networks of critical enquiry is sufficient (Timperley et al., 2007). What this study shows is the difficulty that teachers may have in breaking down non-critical norms in their strongly collegial professional settings in the absence of an expert intermediary. For many decades, advisers from school support services have supported teachers in such expert intermediary roles. The provision of social science specific advisory services for secondary school is, however, in an increasingly threatened position because of alternative government priorities for education spending (Ministry of Education, 2011b).

Both the key contributors and the teachers in this study were aware of the challenge of creating the favourable conditions for effective critical engagement with the Social Sciences BES. The findings presented in Chapter 5 indicated that an in-depth focus on a specific piece of research, connected to an authentic teaching dilemma, located within an expectation of group accountability, and with expert knowledgebrokerage support, was likely to enhance the critical engagement with the Social Sciences BES. In the case of Caitlin, the first two of these necessary elements helped instigate tentative teaching inquiry steps. However, the lack of an intermediary to help Caitlin and her peers engage deeply with the component of Social Sciences BES research ultimately resulted in a fragile inquiry. While the teaching inquiry demonstrated by Caitlin was never intended to meet the exacting standards of research conventions, greater critical engagement would likely have resulted in more robust teaching-as-inquiry outcomes (Saunders, 2007).

If the institutional support is not sufficient within schools, and social sciences school support services are unlikely to have the capacity to meet demand, then postgraduate 
study and university credentialisation may be another option for providing the most effective institutional support for teachers to engage with and in research (Everton et al., 2002). In such environments teachers have access to the very latest journal databases as well as academics whose expertise is in the critique and construction of new educational knowledge. Postgraduate study has long encouraged teachers to engage in action research orientated papers and requirements for completion of a thesis are likely to increase the chance of teachers undertaking substantive, systematic, critically engaged research endeavours within the contexts of their classrooms. In New Zealand, the Quality, Teaching, Research \& Development (QTR\&D) project took this approach further by establishing collaborations between teachers, lecturers, researchers, students and their families in university postgraduate and classroom settings (Sinnema, Sewell, \& Milligan, 2011). The findings of the QTR\&D project emphasised the need for collaborative enquiry that went beyond networks of teachers and which drew upon outcomes linked evidence directly from classrooms and indirectly from published reports. The QTR\&D approach might go some way to responding to David Hargreaves' (1996) critique of the low utility value of educational research to teachers. While it was noticeable that the teachers in this study who contributed most critical discussion had all participated in postgraduate study in the previous five years, it remains an open question, as to what extent teachers sustain an orientation to critical inquiry or instead view such experiences as isolated projects, removed from their day-to-day experiences as classroom teachers (Cochran-Smith et al., 2009).

Enrolment in postgraduate courses is not the only way that teachers might make connections with researchers, and published research evidence in New Zealand. Another pathway, for example, is the Teaching and Learning Research Initiative (TLRI), which has the express aim of developing teacher-researchers under the careful eye of academic mentorship. It is common for these projects to last one to two years and is another avenue by which teachers may benefit from academic mentoring in the engagement with and in research (Teaching \& Learning Research Initiative, 2010). One of many such examples set in a secondary school was the investigation of Linwood College's response to diversity (Conner, Greenwood \& Buyers, 2004). In this study, an aim to discover how Linwood College responded to diversity was, in part, measured through the pedagogical approaches of eight 
teachers. Furthermore, an aim that reflected the wider TLRI brief was, through mentorship from experienced academics, to "develop critically reflective practitioners who have the capacity and capability within the school to research their own practice, and thus build a research platform for change." (Conner, Greenwood \& Buyers, p.1). As powerful as the TLRI initiative is, however, its limited funding makes the prospect of a profession wide orientation to teachers-as-researchers a somewhat distant proposition.

The discussion so far has largely focused on the provision of some sort of expert intermediary to support critically engaging with published research evidence. It was the hope of one key contributor that the written style of the Social Sciences BES would be accessible for teachers, unlike the unintelligible language that has traditionally marked academic writing (Vanderlinde \& van Braak, 2009). Moreover, the Social Sciences BES contains a number of 'research tools', such as misconception alerts and caution statements designed to pedagogically scaffold teachers' learning about the research. For Waterside School teachers, who displayed more critical engagement with the Social Sciences BES, these were acknowledged as providing useful reminders about what should and should not be inferred from the research. The design of 'Research tools' as scaffolds to support teacher engagement with research have received recent attention for their potential to actively support and structure professional development dialogue (Cordingley, 2010). The previously mentioned TLRI, for example, produces research briefings, which are summaries of longer studies designed to be read by busy teachers. The Ministry of Education's web based 'Learning Stories' (Ministry of Education, 2009) are another example of research tools for teachers engaging with research evidence. It remains, however, an open question as to whether these resources facilitate teacher dialogue about research evidence or are simply the dissemination of 'good news' stories.

The significance of secondary school teacher identity is another major finding of this study that appears to influence teachers' engagement with the Social Sciences BES research. There was suggestion from a Social Sciences BES key contributor that subject identity in particular might prove a barrier to critical engagement. Such a phenomenon has, for example, been reported as a barrier for changes to geography teachers' classroom teaching in the context of curriculum reform (Reinfried, 2004). 
Such an undercurrent of thought was revealed during individual teacher interviews, even from some of the Waterside teachers whose group discussion had lifted above the particular in order to search for general ideas that may have meaning for their practice. Subject identity was, however, not the only barrier voiced by teachers. Other identity coalescing variables, such as age group, student ability, and student motivation were all used to rationalise why research was not considered immediately relevant. To some extent, this barrier contributed to a position of scepticism about research (Coburn \& Talbert, 2006). An implication of this finding is the need to encourage teachers to see beyond the particularities of research evidence in order that they do not dismiss its wider reaching value. This may be difficult in the context of pedagogical-outcomes linked research, however, especially if such research is perceived by teachers to serve an engineering function though its 'what works' framework (Biesta, 2007b). A long-term approach to this problem may be found in initial teacher education programmes, which are, after all, one of the main educational stakeholders that the Iterative BES Programme seeks to influence (Alton-Lee, 2006a). While acknowledging the limits of what can be achieved within a typical one-year postgraduate diploma for secondary school teaching, the need to begin a culture of critical engagement with research is a desirable outcome at the same time as meeting demands from beginning teachers to have a range of strategies-for-teaching-success at their fingertips. It might be hoped that initial teacher education is able to a) develop porous teacher identity boundaries which are able to be permeated by research findings from different sectors and disciplines, and b) avoid teachers passively accepting the findings of research evidence. This is not a straightforward task, however, and it cannot be assumed that teacher education has gone through its own process of critically examining the latest available research about how students learn (Cameron \& Baker, 2004).

A further role for initial teacher education providers is the development of cultural norms for critical dialogue in order to facilitate critical engagement with research. This study demonstrated the power of group dialogue leading to deeper shared understanding (Eisner, 2002) but also highlighted how the socio-centric nature of dialogue can inadvertently suppress critical thinking (Paul \& Elder, 2007). The need for critical dialogue norms, not dissimilar to legal and medical training conventions, may be one aspect of a signature pedagogy that is required to be consistent across all 
teacher education providers (Shulman, 2005). Such an aim has significant implications for the quality of mentorship arrangements in initial teacher education programmes, especially in the task of fostering critical teacher talk and de-privatising practice (Annan, Lai, \& Robinson, 2003; Little, 1990).

To conclude, the findings of this thesis support Cordingley's (2008) view that,

All research, however large-scale, brilliantly conceived, executed and communicated, needs to be actively interpreted by users for their own context...generic policy interventions will not work as recipes - they will always depend upon skilled teacher interpretation and judgement if they are to impact on day-to-day practice. (p. 49)

Moreover, the findings show that with all the best will in the world, and despite the best endeavours of the Social Sciences BES authors to make their work accessible, that critical engagement with research literature is a challenging task. It is for this reason that the next section offers a range of recommendations for different levels of the education system that may help facilitate critical engagement with Social Sciences BES research.

\section{Recommendations for enhancing critical engagement with the Social Sciences BES}

In order to further develop teachers' critical engagement with Social Sciences BES research a number of broad recommendations are offered on the basis of the findings of this thesis.

\section{Recommendations to the Ministry of Education}

\section{Increase funding for teachers to enrol in part-time postgraduate study.}

Increasing the funding for part-time post-graduate study may support more teachers to inquire into their own practice. The benefit of utilising universities for this purpose is because research-led institutions have a credentialing function which may appeal to teachers seeking to enhance qualifications at the same time as their regular teaching activities. 
Develop web-based 'research tools' that support critical dialogue with specific extracts of Social Sciences BES research evidence.

The BES web pages (http://www.educationcounts.govt.nz/topics/BES) have developed second tier resource materials to support use of the BES documents. Over the course of writing this thesis, the website has included summary reports of two of the BES documents, and a search engine for research included in each BES document. While these support dissemination of research, I recommend that 'research tools' which encourage critical dialogue and are specific to the Social Sciences BES (and other releases) are developed for this website. Given that the BES website has a weblink to the Centre for the Use of Research and Evidence in Education it may start by drawing on their ideas of 'research tasters' and 'practitioner applications'.

\section{Recommendations to providers of Initial Teacher Education}

\section{Integrate systematic teacher inquiry into courses}

So that student teachers are inculcated into cycles of evidence-informed inquiry this should be a significant component of their initial teacher education programme. This should include, inter alia, supporting student-teachers to know about the basics of good research.

\section{Embed critical-norms of dialogue as a signature pedagogy for teacher- education}

This thesis has demonstrated that critical, evidence-informed dialogue, is challenging for teachers. Developing such critical norms throughout teacher education requires attention to lecture hall pedagogy, tutorial discussion, teaching practice mentorship (from university and school based staff) as well as forms of assessment.

\section{Recommendation to Secondary Schools}

\section{Support staff capacity to engage in critical dialogue about research evidence within a framework of teaching-as-inquiry.}

This thesis recognises the in-depth commitment to professional improvement (via student improvement) that the Teaching-as-Inquiry model demands. Schools should 
especially support professional development initiatives requested by staff that emerge from authentic evidence-based classroom problems. The longer term nature of these forms of professional development may require a combination of in-house expertise (e.g., Specialist Classroom Teachers) and external expert mediators to support teachers in their TAI endeavours.

\section{Recommendations to Social Science Teachers}

\section{Establish a clear set of expectations and protocols for meetings}

This research has demonstrated that if critical engagement is to flourish then dialogue needs to focus on the specifics of research. Moreover, accountability needs to be built into meetings, such as reporting back on teaching that has integrated ideas from the Social Sciences BES

Identify and engage with specific research from the Social Sciences BES where appropriate

By establishing a mutually agreed purpose for meetings based on evidence-informed teaching problems, the identification of one or two specific Social Sciences BES literature extracts may generate more focused critical engagement than would otherwise happen with a broad scoping discussion of the document.

\section{Future Research Directions for Critical Engagement with Social Sciences BES}

In recognition that educational research is a cumulative exercise, three avenues of research that warrant further exploration are suggested. Although the findings of this thesis suggest that teachers going-it-alone with research evidence from the Social Sciences BES may face a number of challenges, the likelihood remains that the majority of teachers will not have available to them expert mediators. Therefore the following three research directions may all provide further insights for those teachers that are keen to engage with Social Sciences BES research evidence.

First, the heuristic critical thinking model had little discernable impact on teacher learning. This does not mean that the development of a research tool for teachers to 
use to interpret educational research is without merit (Gough, Oliver, Newman, \& Bird, 2009). The development of a robust tool would need to address some of the limitations of this study. For example, the rationale for the tool would likely be informed by more than one theoretical base, and multiple design iterations would require empirical testing by a large number of social science teachers focusing on just a few studies from the Social Sciences BES rather than the entire synthesis of work.

Second, research that investigates the work of school-based 'Social Sciences BES champions' who are currently, or have recently participated in post-graduate research might offer insights of how teachers might support each other in their critical engagement with published research evidence. Such a project might offer substantive evidence of 'trickle-down effects' of post-graduate engagement with research evidence.

Third, Timperley et al (2007), report finding only 100 studies from a total of 28000 professional development and in-service teacher education studies that included systematic attention to student outcomes. In keeping with the outcomes-linked orientation of the wider Iterative BES Programme, research that explores the direct or indirect relationships between teachers' critical engagement with Social Sciences $B E S$ research and student outcomes could be explored. 


\section{Bibliography}

Aitken, G. (2005). Curriculum design in New Zealand social studies: Learning from the past. Unpublished Doctoral Thesis, University of Auckland, Auckland.

Aitken, G., \& Sinnema, C. (2008). Effective pedagogy in social sciences / tikanga a iwi: Best evidence synthesis iteration [BES]. Wellington: Ministry of Education.

Alton-Lee, A. (2003) Quality teaching for diverse students in schooling: Best evidence synthesis iteration [BES]. Wellington: Ministry of Education

Alton-Lee, A. (2004). Guidelines for generating a best evidence synthesis iteration. Retrieved November 15, 2009, from http://www.educationcounts.govt.nz/ data/assets/pdf_file/0016/6640/BES-Development-Guidelines-27-07-04.pdf

Alton-Lee, A. (2005a). Quality teaching for diverse learners: How an evidence based approach can help. Paper presented at the ACSA Forum: Quality Teachers: Quality Teaching - Creating a New Agenda for Action by Practitioners, Researchers and Policy Makers.

Alton-Lee, A. (2005b, May). Quality teaching for diverse learners: How an evidence based approach can help. Paper presented at the ACSA Forum: Quality Teachers: Quality teaching - creating a new agenda for action by practitioners, researchers and policy makers. Melbourne. Retrieved from http://www.educationcounts.govt.nz/_data/assets/pdf_file/0016/8062/QualityTeaching-2005.pdf

Alton-Lee, A. (2006a). How teaching influences learning: Implications for educational researchers, teacher educators and policy makers. Teaching and Teacher Education, 22, 612-626.

Alton-Lee, A. (2006b). Iterative best evidence synthesis: Strengthening research, Policy and practice links to improve outcomes. Paper presented at the 4th Annual Policy Evolution Conference. Retrieved from http://www.educationcounts.govt.nz/ topics/BES/bes-journal-conference-and-oecd-papers

Alton-Lee, A. (2007). It's time for a new learning agenda in policy, research and practice in education: Making a bigger difference in desired educational outcomes for diverse learners through collaborative cultures of inquiry and development. Paper presented at the Pacific Circle Consortium. Retrieved from http://educationcounts.govt.nz/goto/BES

Alton-Lee, A. (2008). Making a bigger difference for diverse learners: the iterative best evidence synthesis programme in New Zealand. In G. Wan (Ed.), The education of diverse student populations: A global perspective (Vol. 2, pp. 253-271). Dordrecht: Springer.

Annan, B., Lai, M. K., \& Robinson, V. (2003). Teacher talk to improve teaching practices. Set: research information for teachers, 1, 31-35.

Ashton-Warner, S. (1963). Teacher. New York: Simon \& Schuster.

Atkinson, E. (2000). In defence of ideas, or why 'what works' is not enough. British Journal of Sociology of Education, 21(3), 317-330.

Babbie, E. (2008). The basics of social research. Belmont, USA: Thomson Wadsworth.

Baildon, M., \& Sim, J. (2009). Notions of criticality: Singaporean teachers' perspectives of critical thinking in social studies. Cambridge Journal of Education, 39(4), 407-422.

Bassey, M. (1999). Case study research in educational settings. Buckingham: Open University Press. 
Bazeley, P., \& Richards, L. (2000). The NVivo qualitative project book. London: Sage.

Bell, M., Cordingley, P., Isham, C., \& Davis, R. (2010). Report of professional practitioner use of research review: practitioner engagement in and/or with research. Retrieved May 9, 2011, from http://www.curee-paccts.com/node/ 2303.

Biesta, G. (2007a). Why "what works" won't work: Evidence-based practice and the democratic deficit in educational research. Educational Theory, 57(1), 1-22.

Biesta, G. (2007b). Bridging the gap between educational research and educational practice: The need for critical distance. Educational Research and Evaluation, 13(3), 295-301.

Broekkamp, H., \& Van Hout-Wolters, B. (2007). The gap between educational research and practice: A literature review, symposium, and questionnaire. Educational Research and Evaluation, 13(3), 203-220.

Cameron, M., \& Baker, R. (2004). Research on initial teacher education in New Zealand: 1993-2004. Literature review and annotated bibliography. Wellington: New Zealand Council of Education Research

Campbell, A., Freedmand, E., Boulter, C., \& Kirkwood, M. (2003). Issues and principles in educational research for teachers. Southwell: British Educational Research Association.

Carr, W., \& Kemmis, S. (1986). Becoming critical: Education, knowledge and action research. Basingstoke: Falmer Press.

Castle, K. (2006). Autonomy through pedagogical research. Teaching and Teacher Education, 22, 1094-1103.

Clark, J. (1997). Educational research: Philosophy, politics, ethics. Palmerston North: ERDC Press.

Coburn, C., \& Talbert, J. E. (2006). Conceptions of evidence use in school districts: Mapping the terrain. American Journal of Education, 112, 469-495.

Cochran-Smith, M., Barnatt, J., Friedman, A., \& Pine, G. (2009). Inquiry on inquiry: Practitioner research and student learning. Action in Teacher Education, 31(2), 17-32.

Cochran-Smith, M., \& Lytle, S. L. (1999). Relationships of knowledge and practice: teacher learning in communities. Review of Research in Education, 24, 249305.

Coghlan, D., \& Brannick, T. (2010). Doing action research in your own organisation. London: Sage.

Cohen, L., Manion, L., \& Morrison, K. (2003). Research methods in education ${\left(5^{\text {th }}\right.}^{\text {the }}$ ed.). London: RoutledgeFalmer.

Cohen, M. S., Salas, E., \& Riedel, S. L. (2002). Critical thinking: Challenges, possibilities, and purpose. Arlington, VA: Cognitive Technologies.

Conner, L., Greenwood, J., \& Buyers, P. (2004). Investigating responses to diversity in a secondary environment. Retrieved May 62011 from http://www.tlri.org.nz/assets/A_Project-PDFs/9228_summaryreport.pdf

Cordingley, P. (2003). Research and evidence-based practice: focusing on practice and practitioners. In L. Anderson \& N. Bennett (Eds.), Evidence-informed policy and practice in educational leadership and management. Milton Keynes: Open University.

Cordingley, P. (2008). Research and evidence-informed practice: Focusing on practice and practitioners. Cambridge Journal of Education, 38(1), 37-52. 
Cordingley, P. (2010, May). Stepping stones, bridges and scaffolding: Effective tools, artefacts and professional learning processes for research use. Paper presented at the American Educational Research Association (AERA) Conference, Denver, CO.

Cosgrove, R. (2010). Critical thinking: Lessons from a continuing professional development initiative in a London comprehensive secondary school. Unpublished MPhil thesis, University of Cambridge.

Crown. (2005). Making a bigger difference for all students: The schooling strategy 2005-2010. Wellington: Crown

Denscombe, M. (2007). The good research guide ( $3^{\text {rd }}$ ed.). Maidenhead: McGraw Hill / Open University Press.

Denzin, N. K., \& Lincoln, Y. S. (2005). Introduction: Entering the field of qualitative research. In N. K. Denzin \& Y. S. Lincoln (Eds.), The sage handbook of qualitative research (3rd ed.). Thousand Oaks: CA: Sage.

Denzin, N. K., \& Lincoln, Y. S. (Eds.). (2007). Strategies of qualitative inquiry ( $3^{\text {rd }}$ ed.). Thousand Oaks: Sage.

Dreaver, K. (2009). Teachers as learners: Improving outcomes for Māori and Pasifika students through inquiry. Retrieved May 6, 2011, from http://nzcurriculum.tki.org.nz/inquiry

Earl, L. M., \& Timperley, H. (Eds.). (2008). Professional learning conversations: Challenges in using evidence for improvement. London: Springer.

Edwards, T. (2000). 'All the evidence shows...': reasonable expectations of educational research. Oxford Review of Education, 26(3\&4), 299-311.

Eisner, E. W. (2002). From episteme to phronesis to artistry in the study and improvement of teaching. Teaching and Teacher Education, 18, 375-385.

Elder, L., \& Paul, R. (2010). The thinker's guide to analytical thinking: How to take thinking apart and what to look for when you do. Retrieved September 13, 2011, from http://www.criticalthinking.org/files/SAM_Analytic_Think2007b.pdf

Elliott, J. (2004). Using research to improve practice: The notion of evidence based practice. In C. Day \& J. Sachs (Eds.), International handbook on the continuing professional development of teachers (pp. 264-290). Maidenhead: Open University Press.

Evans, J., \& Benefield, P. (2001). Systematic reviews of educational research: Does the medical model fit? British Educational Research Journal, 27(5), 527-541.

Everton, T., Galton, M., \& Pell, T. (2002). Educational research and the teacher. Research Papers in Education, 17(4), 373-401.

Facione, P. A. (1990). Executive summary: Critical thinking: A statement of expert consensus for purposes of educational assessment and instruction. Milbrae, CA: The California Academic Press.

Figazzolo, L. (2009). Impact of PISA 2006 on the education policy debate. Education International. Retrieved from http://download.eiie.org/docs/IRISDocuments/Research\%20Website\%20Documents/2009_ 00036-01-E.pdf

Frijters, S., Ten Dam, G., \& Rijlaarsdam, G. (2006). Effects of dialogic learning on value-loaded critical thinking. Learning and Instruction, 18(1), 66-82.

Gitlin, A., Burbank, M. D., \& Kauchak, D. (2005). The struggle for legitimate knowledge: teachers' thinking on research. In F. Bodone (Ed.), What difference does research make and for whom? (pp. 111-128). New York: Peter Lang. 
Gough, D., Oliver, S., Newman, M., \& Bird, K. (2009). Transparency in planning, warranting and interpreting research. Teaching and learning research briefing, 78. London: Institute of Education.

Guba, E. G., \& Lincoln, Y. S. (2005). Paradigmatic controversies, contradictions, and emerging confluences. In N. K. Denzin \& Y. S. Lincoln (Eds.), The sage handbook of qualitative reserach $\left(3^{\text {rd }}\right.$ ed.). Thousand Oaks: Sage.

Hancock, H. C., \& Easen, P. R. (2004). Evidence-based practice: An incomplete model of the relationship between theory and professional work. Journal of Evaluation in Clinical Practice, 10(2), 187-196.

Harding, S., Johnston, L., Michel, J., Ramanathan, A., La Flamme, A., Sasse, A. et al. (2011, August). High on treatment platelet reactivity is common and differs among ethnic groups. Paper presented at the Cardiac Society of Australia and New Zealand Annual Scientific Meeting, Perth, Australia.

Hargreaves, D. (1996). Teaching as a research-based profession: Possibilities and prospects. In M. Hammersley (Ed.), Educational research and evidence based practice. London: The Open University / Sage.

Harvey, R., \& Higgins, J., with Jackson, L. (2006). Evaluation of secondary numeracy pilot project 2005. In Evaluations of the 2005 secondary numeracy pilot project and the CAS pilot project (pp. 36-68). Wellington: Ministry of Education.

Hemsley-Brown, J., \& Sharp, C. (2003). The use of research to improve professional practice: A systematic review of the literature. Oxford Review of Education, 29(4), 449-470.

Hillage, J., Pearson, R., Anderson, A., \& Tamkin, P. (1998). Excellence in research on schools. London: Department for Education \& Employment.

Hopkins, D. (1994). A teacher's guide to classroom research $\left(2^{\text {nd }}\right.$ ed. $)$. Buckingham: Open University Press.

Jeffery, P. L. (1985). The utilization of "Set: Research Information for Teachers" in selected educational institutions. Melbourne: Australian Council for Educational Research.

Johnson, S. M. (2009, April). Second-stage teachers and coaching: Building school capacity and a teaching career. Paper presented at the American Educational Research Association, San Diego, CA.

Kennedy, M. M. (1999). A test of some common contentions about educational research. American Educational Research Journal, 36(3), 511-541.

Kennedy, M. M. (2002). Knowledge and teaching. Teachers and Teaching, 8(3), 355-370.

Kennedy, M. M. (2007). Defining a literature. Educational Researcher, 36(3), 139147.

Kirkwood, M., \& Christie, D. (2006). The role of teacher research in continuing professional development. British Journal of Education Studies, 54(4), 429-448.

Korthagen, F. A. J. (2007). The gap between research and practice revisited. Educational Research and Evaluation, 13(3), 303-310.

Kvale, S. (1996). Interviews: An introduction to qualitative research interviewing. London: Sage.

Levine, T. H., \& Marcus, A. S. (2010). How the structure and focus of teachers' collaborative activities facilitate and constrain teacher learning. Teaching and Teacher Education, 26(3), 389-398.

Lewin, K. (1946). Action research and minority problems. Journal of Social Issues, 2(4), 34-46. 
Liberty, K., \& Miller, J. (2005). Research as a resource for evidence-based practice. Melbourne: Thomson/Dunmore Press.

Lincoln, Y. \& Guba, E. (1985). Naturalistic Enquiry. Newbury Park, CA: Sage.

Lipman, M. (Ed.). (1995). Thinking and education. Cambridge: Cambridge Univesity Press.

Little, J. W. (1990). The persistence of privacy: autonomy and initiative in teachers' professional relations. Teachers College Record, 91(4), 509-536.

Lortie, D. C. (1975). Schoolteacher. Chicago: University of Chicago Press.

Maclure, M. (2005). 'Clarity bordering on stupidity': Where's the quality in systematic review? Journal of Education Policy, 20(4), 393-416. Retrieved from http://dx.doi.org/10.1080/02680930500131801

Mantzoukas, S. (2006). A review of evidence-based practice, nursing research and reflection: Levelling the hierarchy. Journal of Clinical Nursing, 17, 214-223.

Margolis, J. (2008). What will keep today's teachers teaching? Looking for a hook as a new career cycle emerges. Teachers College Record, 110(1), 160-194. Retrieved from http://www.tcrecord.org/library. doi:14567

Maxwell, J. (2004). Causal explanation, qualitative research, and scientific inquiry in education. Educational Researcher, 33(2), 3-10.

McGee, A., \& Lawrence, A. (2009). Teacher educators inquiring into their own practice. Professional Development in Education, 35(1), 139-157.

Michelson, J. (2004). Critique of (im)pure reason: Evidence-based medicine and common sense. Journal of Evaluation in Clinical Practice, 10(2), 157-161.

Ministry of Education. (2007a). The New Zealand curriculum. Wellington: Learning Media.

Ministry of Education. (2007b). Making language and learning work 2: Integrating language and learning in secondary English and social sciences. Wellington: MOE.

Ministry of Education. (2009). Statement of intent 2009-2014. Retrieved from http://www.minedu.govt.nz/ /media/MinEdu/Files/TheMinistry/StatementOfIn tent2009.pdf

Ministry of Education. (2011a). Guidelines for the appointment of Specialist Classroom Teachers (SCT) in Secondary Schools. Retrieved from http://www.minedu.govt.nz/NZEducation/EducationPolicies/Schools/SchoolO perations/EmploymentConditionsAndEvaluation/SpecialistClassroomTeacherS pecialistTeacher.aspx

Ministry of Education. (2011b). Variation 5 school support services 2011, Contractor Victoria Link Ltd. Wellington: Ministry of Education.

Miretzky, D. (2007). A view of research from practice: voices of teachers. Theory into Practice, 46(4), 272-280.

Moore, P. (2006). Iterative best evidence synthesis programme evidence based policy project. Wellington: Ministry of Education.

New Zealand Teachers Council. (2010a). Registered teacher criteria handbook 2010. Wellington: NZTC.

New Zealand Teachers Council. (2010b). Supporting resources for the registered teacher criteria. Retrieved October 6, 2011, from http://www.teacherscouncil.govt.nz/rtc/ rtcworkshopresources.stm

Neyland, J. (2010). Rediscovering the spirit of education after scientifc management. Rotterdam: Sense.

Noblit, G. W., \& Hare, R. D. (1988). Meta-ethnography: Synthesizing qualitative studies. Newbury Park: Sage. 
Nuthall, G. (1999). The way students learn: acquiring knowledge from an integrated science and social studies unit. The Elementary School Journal, 99(4), 303-341.

Nuthall, G. (2004). Relating classroom teaching to student learning: A critical analysis of why research has failed to bridge the theory-practice gap. Harvard Educational Review, 74(3), 273-306.

Openshaw, R., \& Ball, T. (2008). New Zealand. In T. O'Donoghue \& C. Whitehead (Eds.), Teacher education in the English speaking world (pp. 155-171). Charlotte, NC: Information Age.

Organisation of Economic Co-operation and Development. (2000). Knowledge management in the learning society. Paris: Author.

Paul, R. (1992). Critical thinking: What every person needs to survive in a rapidly changing world $\left(2^{\text {nd }}\right.$ ed.). Santa Rosa, CA: Foundation for Critical Thinking.

Paul, R. (2007). Critical thinking in every domain of knowledge and belief. Paper presented at the Annual International Conference on Critical thinking. Retrieved from http://www.criticalthinking.org/articles/27thconf-keynote.cfm

Paul, R., \& Elder, L. (2007). The minature guide to critical thinking concepts and tools. Available from http://www.criticalthinking.org/files/Concepts_Tools.pdf

Paul, R. W., \& Elder, L. (2000). Critical thinking: Basic theory and instructional structures handbook ( $2^{\text {nd }}$ ed.). Santa Rosa, CA: Foundation for Critical Thinking.

Paul, R. W., Elder, L., \& Bartell, T. (1997). California teacher preparation for instruction in critical thinking: Research findings and policy recommendations. Sacramento, CA: California Commission on Teacher Credentialing.

Pawson, R., \& Tilley, N. (1997). Realistic evaluation. London: Sage.

Pettigrew, M., \& Roberts, H. (2006). Systematic reviews in the social sciences: A practical guide. Malden: Blackwell.

Porta, M. (2004). Is there life after evidence-based medicine? Journal of Evaluation in Clinical Practice, 10(2), 147-152.

Pring, R. (2004). Philosophy of educational research ( $2^{\text {nd }}$ ed.). London: Continuum.

Ratcliffe, M., Bartholomew, H., Hames, V., Hind, A., Leach, J., Millar, R. et al. (2004). Science education practitioners' views of research and its influence on their practice. York: University of York.

Reinfried, S. (2004). Do curriculum reforms affect classroom teaching in geography? The case study of Switzerland. International Research in Geographical and Environmental Education, 13(3), 239-250.

Richetti, C. T., \& Tregoe, B. B. (2001). Analytical processes for school leaders. Alexandria, VA: ASCD.

Robinson, V. (2003). Teachers as researchers: a professional necessity? Set: Research Information for Teachers, 1, 27-29.

Rogers, E. M. (1962). Diffusion of innovations. New York: Free Press.

Rosenfeld, J. A. (2004). The view of evidence-based medicine from the trenches: Liberating or authoritarian? Journal of Evaluation in Clinical Practice, 10(2), $153-155$.

Sackett, D., Rosenberg, W., Muir Gray, J., Haynes, B., \& Richardson, W. (1996). Evidence-based medicine: What it is and what it isn't: It's about integrating individual clinical expertise and the best external evidence. British Medical Journal, 312(7023), 71-72.

Saunders, L. (2007). Supporting teachers' engagement in and with research. Retrieved May 9, 2011, from http://www.tlrp.org/capacity/rm/wt/saunders2.html. 
Schön, D. (1983). The reflective practitioner. London: Temple Smith.

Scott, D. (2010). Education, epistemology and critical realism. Abingdon, Oxon: Routledge.

Shulman, L. (2005). Signature pedagogies in the professions. Doedalus, 134(3), $52-59$

Sinnema, C., Sewell, A., \& Milligan, A. (2011) Evidence-informed collaborative inquiry for improving teaching and learning. Asia-Pacific Journal of Teacher Education, 39(3), 247-261

Simpson, E., \& Courtney, M. (2002). Critical thinking in nursing education: A literature review. International Journal of Nursing, 8(2), 89-98. Retrieved from http://onlinelibrary.wiley.com/doi/10.1046/j.1440-172x.2002.00340.x/pdf

Slavin, R. E. (1986). Best-evidence synthesis: An alternative to meta-analytic and traditional reviews. Educational Researcher, 15(5), 5-11.

Smylie, M., \& Hart, A. (1999). School leadership for teacher learning and change: A human and social capital perspective. In J. Murphy \& K. Seashore Louis (Eds.), Handbook of research on educational administration. San Fransisco, CA: Jossey-Bass.

Spillane, J. P., Reiser, B. J., \& Reimer, T. (2002). Policy implementation and cognition: reframing and refocusing implementation research. Review of Educational Research, 72(3), 387-431.

Stake, R. E. (1995). The art of case study research. London: Sage.

Strauss, A. L., \& Corbin, J. (1998). Basics of qualitative research: Techniques and procedures for developing grounded theory. Thousand Oaks, CA: Sage.

Tambyah, M. (2008). Teacher identity: Some issues raised by the problematic nature of SOSE. Curriculum Perspectives, 28(1), 69-74.

Teaching \& Learning Research Initiative. (2010). Partnership. 11. Retrieved from http://www.tlri.org.nz/assets/newsletters/Newsletter-July-10.pdf

Timperley, H., Wilson, A., Barrar, H., \& Fung, I. (2007). Teacher professional learning and development: Best evidence synthesis iteration. Wellington: Ministry of Education.

Tooley, J., \& Darby, D. (1998). Educational research: A critique. London: Office for Standards in Education.

Torbert, W. R., \& Associates. (2004). Action inquiry. San Fransisco: BerretKoehler.

United States Department of Education. (2004). Four pillars of NCLB. Retrieved October 28, 2009, from http://www.ed.gov/nclb/overview/intro/4pillars.html

Vanderlinde, R., \& van Braak, J. (2009). The gap between educational research and practice: Views of teachers, school leaders, intermediaries and researchers. British Educational Research Journal, 36(2), 299-316.

Walford, G. (1994). Researching the powerful in education. In G. Walford (Ed.), Researching the powerful in education (pp. 222-231). London: UCL Press.

Walshaw, M. (2008). Best evidence research redefined in mathematics education. In E. De Freitas \& K. Nolan (Eds.), Opening the research text: Critical insights and in(ter)ventions in mathematics education. Dordrecht: Springer.

Weiss, C. (1977). The enlightenment function of social research. Policy Analysis, 3(4), 531-545.

Williams, D., \& Coles, L. (2007). Teachers' approaches to finding and using research evidence: An information literacy perspective. Educational Research, 49(2), $185-206$.

Yin, R. K. (2003). Case study research ( $3^{\text {rd }}$ ed.). Thousand Oaks: Sage. 


\section{APPENDICES}

Appendix A: New Zealand Teachers Council Teacher Self Assessment Tool Appendix B: Ethics approval.

Appendix C: Time line of Data Collection.

Appendix D: Framework for Participant Interviews (After Kvale, 1996).

Appendix E: Phase 1 interview schedule.

Appendix F: Phase 2 interview schedule.

Appendix G: Interview schedule for BES key contributors.

Appendix H: Principal Information Sheet and Consent form.

Appendix I: Teacher Information Sheet and Consent form.

Appendix J: Key Contributor Information Sheet and Consent form. 


\section{Appendix A: New Zealand Teachers Council Teacher Self Assessment Tool}

\begin{tabular}{|c|c|c|c|}
\hline \multicolumn{2}{|c|}{$\begin{array}{l}\text { Criterion 12: } \\
\text { use critical inquiry and problem-solving } \\
\text { effectively in their professional practice }\end{array}$} & \multicolumn{2}{|c|}{$\begin{array}{l}\text { Self Assessment: (mark line at your current level and also at your aspiration level) } \\
\text { Beginning } \quad \text { Meets Criterion }\end{array}$} \\
\hline Key Indicators: & Questions I might ask myself: & Strategies that might help me: & Reflections: \\
\hline $\begin{array}{l}\text { i. systematically and critically } \\
\text { engage with evidence and } \\
\text { professional literature to } \\
\text { reflect on and refine practice }\end{array}$ & $\begin{array}{l}\text { - What impact does higher level } \\
\text { teaching and learning have on the } \\
\text { students I teach? } \\
\text { - Where can I source information }\end{array}$ & $\begin{array}{l}\text { - } \quad \text { Professional reading. } \\
\text { - } \quad \text { Professional development. }\end{array}$ & $\begin{array}{l}\text { - Am I demonstrating } \\
\text { commitment to critical enquiry? } \\
\text { What professional practice do I } \\
\text { do well? }\end{array}$ \\
\hline $\begin{array}{l}\text { ii. respond professionally to } \\
\text { feedback from members of } \\
\text { their learning community } \\
\text { iii. critically examine their own } \\
\text { beliefs, including cultural } \\
\text { beliefs, and how they impact } \\
\text { on their professional practice } \\
\text { and the achievement of ākonga }\end{array}$ & $\begin{array}{l}\text { - Who uses critical enquiry } \\
\text { currently in my learning } \\
\text { community? } \\
\text { - What changes will I make with } \\
\text { regard to the feedback? } \\
\text { - How do I keep this a manageable } \\
\text { part of my development? } \\
\text { - What evidence do I seek that my } \\
\text { teaching is advancing the } \\
\text { learning of all my ākonga? }\end{array}$ & $\begin{array}{l}\text { - Classroom observations. } \\
\text { - } \quad \text { Professional discussions. } \\
\text { - Include in lesson planning. } \\
\text { Engages in positive dialogue regarding } \\
\text { feedback. }\end{array}$ & $\begin{array}{l}\text { know? } \\
\text { Have I been able to establish a } \\
\text { manageable and realistic } \\
\text { approach to this? } \\
\text { - Is it impacting on my time } \\
\text { management } \\
\text { - Is there a better way? } \\
\text { - Should I seek further feedback } \\
\text { and advice? }\end{array}$ \\
\hline
\end{tabular}

Appendix A: New Zealand Teachers Council Teacher Self Assessment Tool ${ }^{12}$

${ }^{12}$ This is one sheet of many in the tool that has been designed to support teachers to self assess their progress against 12 criterion for the Registered Teacher Standards (New Zealand Teachers Council, 2010b). 
Appendix B: Ethics Approval

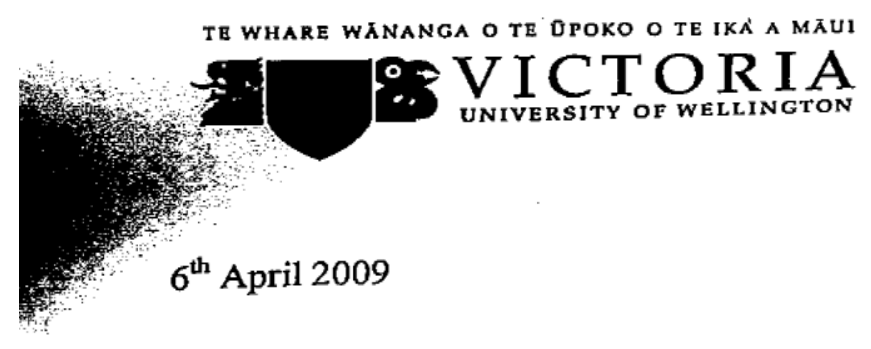

Mike Taylor

Dear Mike

RE: Ethics application SEPI/2009/11, RM 16389

I am pleased to advise you that your ethics application 'The impact of a critical thinking model on Teachers' engagement with Social Science Best Evidence synthesis Research' with the requested amendments, has been approved by the Victoria University of Wellington College of Education Ethics Committee. Please note that the approval for your research to commence is from the date of this letter.

Good luck with your research.

Yours Sincerely<smiles>CC1(C)CCCCCCCCCCCCC1</smiles>

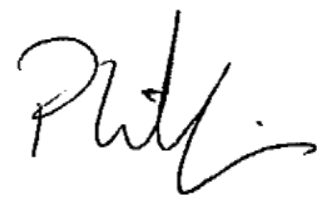

Hazel Phillips

Co-Convener

Victoria University of Wellington College of Education Ethics Committee 


\section{Appendix C: Time line of Data Collection}

\begin{tabular}{|c|c|c|c|c|c|c|c|c|c|c|c|c|}
\hline & \begin{tabular}{|l|l} 
April \\
09
\end{tabular} & $\begin{array}{l}\text { May } \\
09\end{array}$ & $\begin{array}{l}\text { June } \\
09\end{array}$ & $\begin{array}{l}\text { July } \\
09\end{array}$ & $\begin{array}{l}\text { Aug } \\
09\end{array}$ & $\begin{array}{l}\text { Sept } \\
09\end{array}$ & $\begin{array}{l}\text { Oct } \\
09\end{array}$ & $\begin{array}{l}\text { Nov } \\
09\end{array}$ & $\begin{array}{l}\text { Dec } \\
09\end{array}$ & $\begin{array}{l}\text { Mar } \\
10\end{array}$ & $\begin{array}{l}\text { April } \\
10\end{array}$ & \begin{tabular}{|l} 
May \\
10
\end{tabular} \\
\hline \multicolumn{13}{|l|}{ Contact potential cases } \\
\hline \multicolumn{13}{|l|}{ Initial meeting with Cherry Tree School principal \& teachers } \\
\hline $\begin{array}{l}\begin{array}{l}\text { Observation/recording of Cherry tree School social science } \\
\text { discussion groups (phase 1) }\end{array} \\
\end{array}$ & & & $\mathrm{X} 2$ & & & & & & & & & \\
\hline \multicolumn{13}{|l|}{ Transcripts sent to social science teachers for member checking } \\
\hline \multicolumn{13}{|l|}{ Cherry Tree social science teachers semi-structured interviews \#1 } \\
\hline \multicolumn{13}{|l|}{$\begin{array}{l}\text { Critical thinking heuristic presented to Cherry Tree School social } \\
\text { science teachers }\end{array}$} \\
\hline Observation/recording of Cherry Tree discussion groups (phase 2) & & & & & & $\mathrm{X} 2$ & & & & & & \\
\hline \multicolumn{13}{|l|}{ Transcripts sent for member checking } \\
\hline \multicolumn{13}{|l|}{ Cherry Tree social science teachers semi-structured interviews \#2 } \\
\hline \multicolumn{13}{|l|}{ BES Author Semi Structured Interviews } \\
\hline \multicolumn{13}{|l|}{ Initial meeting with Waterside School principal \& teachers } \\
\hline \multicolumn{13}{|l|}{$\begin{array}{llllll}\begin{array}{l}\text { Observation/recording of } \\
\text { discussion groups (phase 1) }\end{array} & \text { Waterside } & \text { School social science } \\
\end{array}$} \\
\hline \multicolumn{13}{|l|}{ Transcripts sent to social science teachers for member checking } \\
\hline \multicolumn{13}{|l|}{ Waterside social science teachers semi-structured interviews \#1 } \\
\hline \multicolumn{13}{|l|}{$\begin{array}{l}\text { Critical thinking heuristic presented to Waterside School social } \\
\text { science teachers }\end{array}$} \\
\hline \begin{tabular}{|lrlrl}
$\begin{array}{l}\text { Observation/recording of } \\
\text { discussion groups (phase 2) }\end{array}$ & Waterside School social science \\
\end{tabular} & & & & & & & & & & & & \\
\hline Transcripts sent for member checking & & & & & & & & & & & & \\
\hline Waterside social science teachers semi-structured interview & & & & & & & & & & & & \\
\hline
\end{tabular}


Appendix D: Framework for Participant Interviews (After Kvale, 1996)

\begin{tabular}{|c|c|}
\hline $\begin{array}{l}\text { Kvale's recommendations } \\
\text { for interviewing }\end{array}$ & $\begin{array}{l}\text { Interview strategies at Cherry Tree and Waterside } \\
\text { Schools }\end{array}$ \\
\hline $\begin{array}{l}\text { Structured and clear } \\
\text { (Making clear the purpose } \\
\text { of the interview and } \\
\text { keeping to the point) }\end{array}$ & $\begin{array}{l}\text { - The purpose of the research and the interviews } \\
\text { was outlined and the initial information and } \\
\text { gone through verbally prior to each interview. } \\
\text { The interviews were semi-structured with key } \\
\text { guiding questions prepared and reviewed by } \\
\text { my supervisor in advance. } \\
\text { - The participants were emailed copies of the } \\
\text { interview questions prior to each interview. } \\
\text { - A written copy of the questions was given to } \\
\text { the participants at each face-to-face interview } \\
\text { to help guide them. } \\
\text { Prompts were developed prior to interviews in } \\
\text { case they were needed to help participants. }\end{array}$ \\
\hline $\begin{array}{l}\text { Gentle, open and sensitive } \\
\text { (Enabling participants to } \\
\text { say what they want to say in } \\
\text { its entirety and in their own } \\
\text { time and way) }\end{array}$ & $\begin{array}{l}\text { - The time and the venue for interviews were } \\
\text { chosen by the interviewees. } \\
\text { - The questions were asked, then the } \\
\text { interviewees were given as much time as they } \\
\text { needed to answer each question. }\end{array}$ \\
\hline $\begin{array}{l}\text { Remembering } \\
\text { (Recalling earlier } \\
\text { statements or experiences } \\
\text { and relating to them during } \\
\text { the interview) }\end{array}$ & $\begin{array}{l}\text { The interviewer would refer back to ideas or } \\
\text { statements made in previous group } \\
\text { discussions, copies of which each teacher was } \\
\text { given before the interview took place for the } \\
\text { purpose of 'member checking'. }\end{array}$ \\
\hline $\begin{array}{l}\text { Interpreting and questioning } \\
\text { (Clarifying, confirming and } \\
\text { disconfirming the } \\
\text { interviewee's statements } \\
\text { with the participant) }\end{array}$ & $\begin{array}{l}\text { - Additional questions were asked in the semi- } \\
\text { structured interviews to seek further } \\
\text { information on points of interest to the } \\
\text { research, or clarification of a statement made. } \\
\text { Each interview was audio recorded. This } \\
\text { allowed the interviewer to concentrate on } \\
\text { actively listening to the participant's answers } \\
\text { during the interview. Digital recording was } \\
\text { chosen for ease of data management and } \\
\text { transcription. } \\
\text { The transcription of each interview was typed } \\
\text { up and emailed to each participant with the } \\
\text { purpose of the interviewee to confirm (or } \\
\text { correct) that what had been recorded was what } \\
\text { they had meant. }\end{array}$ \\
\hline
\end{tabular}




\section{Appendix E: Phase 1 teacher interview schedule}

The interview will proceed as follows:

I will welcome the interviewee, and remind them of the purpose of the research.

I will then describe the process for the interview, including reading out the list of questions. I will indicate that we'll take one question at a time, and that the interviewer will take notes in addition to digitally recording the interview.

Proceed to the first question, to be read out again by the researcher. Interviewee contributions will be recorded digitally. The same process is repeated for each question until all questions have been addressed.

Once all questions are completed and no later than 20mins after the start of the interview, I will thank the interviewee and ask if there are any final issues missed. I will reaffirm the importance of their input into the research.

Questions:

1. Please give a very brief summary of your teaching career - e.g., how long teaching, number of schools taught in, and social science subjects taught, post graduate study/qualifications?

2. What do you understand by the phrase evidence-based practice?

3. In what ways has the BES encouraged you to think about social science teaching and learning, and your own practice in particular?

4. Do you think the Social Science BES helps teachers in the way that research should? What has helped and/or hindered your understanding of the Social Science BES research? What has helped hindered incorporation of BES findings into your practice?

5. In what ways would you describe you and/or your departments' reading and/or discussion of the BES as critical? 


\section{Appendix F: Phase 2 teacher interview schedule}

The interview will proceed as follows:

I will welcome the interviewee, and remind them of the purpose of the research.

I will then describe the process for the interview, including reading out the list of questions. I will indicate that we'll take one question at a time, and that the interviewer will take notes in addition to digitally recording the interview.

Proceed to the first question, to be read out again by the researcher. Interviewee contributions will be recorded digitally. The same process is repeated for each question until all questions have been addressed.

Once all questions are completed and no later than 20mins after the start of the interview, I will thank the interviewee and ask if there are any final issues missed. I will reaffirm the importance of their input into the research.

Questions:

1. What do you think have been the outcomes/results/impact of your early engagement with the BES over the last couple of terms?

2. In what ways would you describe you and/or your departments' engagement with the BES as critical?

a. Have there been different levels of critical engagement?

b. Can you give any examples or say why you thought that was good critical thinking about the Social Science BES?

c. In what ways has critical engagement encouraged you to think about social science teaching and learning, and your own practice in particular?

3. In what ways, if any, has the critical thinking model helped you to explore the BES research and/or your own practice?

4. What has helped and/or hindered incorporation of Social Science BES research into your practice? What would help you more in the future?

5. How do you think you might use the BES in the future, if at all? 


\section{Appendix G: Interview schedule for BES key contributors.}

The interview will proceed as follows:

I will thank the interviewee, and remind them of the purpose of the research.

I will then describe the process for the interview, including reading out the list of questions. I will indicate that we'll take one question at a time, and that the interviewer will take notes in addition to digitally recording the interview.

Proceed to the first question, to be read out again by the researcher. Interviewee contributions will be recorded digitally. The same process is repeated for each question until all questions have been addressed.

Once all questions are completed and no later than 60mins after the start of the interview, I will thank the interviewee and ask if there are any final issues they would like to comment on. I will reaffirm the importance of their input into the research.

Questions:

1. What was the need for:

- BES research for NZ schools

- Effective Pedagogy in Social Science/Tikanga-ā-iwi BES?

2. What meaning might teachers make of the Social Sciences BES?

3. What should teachers be critically thinking about as they discuss and use findings from the Social Sciences BES?

4. What feedback, if any, has been received from teachers about adoption of the Social Science BES?

5. In your opinion, are there possible risks/unintended consequences of teachers using the Social Sciences BES?

6. How might such risks be reduced:

a. by the design of the Social Sciences B.E.S. itself

b. externally to the Social Sciences B.E.S.

Thank interviewee for their participation. 


\title{
Appendix H: Principal Information Sheet and Consent form
}

\author{
VICTORIA UNIVERSITY OF WELLINGTON \\ Te Whare Wananga o te Upoko o te Ika a Maui

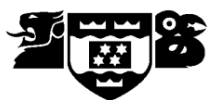

\section{Information Sheet for Principals}

\section{The Impact of a Critical Thinking Model on Teachers' Engagement with Social Science Best Evidence Synthesis Research. \\ Researcher: Mike Taylor, VUW College of Education}

I am a Masters student studying Education at Victoria University. As part of my degree I have the opportunity to conduct a research thesis. My study aims to provide a snapshot of ways in which teachers critically engage with the recently released 'Effective Pedagogy in Social Sciences/ Tikanga-a-iwi BES Iteration' (Aitken \& Sinnema, 2008), and whether a critical thinking model can support this process.

I have invited members of your social science department to participate in this study. I believe that this opportunity provides social science teachers with an opportunity for professional development that links up-to-the minute research evidence with their classroom practice. The design of the study (approved by the VUW College of Education Ethics Committee) involves teacher participation in the following ways:

- discussing the Social Science BES in relation to their practice in three focus group meetings during Term 4, 2009 \& Term 1, 2010.

- participating in a further 3 focus groups during term 4, using a critical thinking model to support their discussion of the Social Science BES.

- teachers being interviewed on two occasions for their reflections on how critical engagement with the Social Science BES has influenced their professional practice.

Focus group and interview data will be aggregated so that your school or individual teachers cannot be identified. Pseudonyms will be used to further protect identities of those involved. All information will be kept confidential. Only my supervisor and I will see or hear interview data, which will be kept in password protected electronic files.

An informed consent form for your consideration is supplied with this information sheet.

If you have any further questions, please do not hesitate to contact me, mike.taylor@vuw.ac.nz Tel: (04) 463 9619, or my supervisor, Andrea Milligan, Lecturer at VUW College of Education: Andrea.Milligan@ vuw.ac.nz Tel: (04) 4639614.

Yours sincerely,

Mike Taylor 


\section{VICTORIA UNIVERSITY OF WELLINGTON \\ Te Whare Wananga o te Upoko o te Ika a Maui

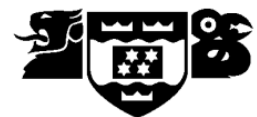

\section{Informed Consent Form for Principals}

\section{The Impact of a Critical Thinking Model on Teachers' Engagement with Social Science Best Evidence Synthesis Research.}

I give my consent for members of my school's social science department to take part in the research described. I have read the information sheet that I will keep for my records. I have had the opportunity to ask questions and am happy with the answers.

By ticking the boxes below, I agree that consent is being sought for:

Collection of data at a series of social science department focus group discussions and interviews during Terms 4, $2009 \& 1,2010$, as outlined in the information sheet.

Use of the collected data to be submitted for marking as a thesis, and to be deposited in a VUW library.

Dissemination of the research at educational conferences or academic journals.

By ticking the boxes below I understand that:

no information that could lead to the identification of any individual or my school will be disclosed in any reports on the project or to any other party other than the researcher and his supervisor.

I will be sent an electronic copy of the final study after it has been submitted for marking as part fulfilment towards a Masters in Education.

Name:

Date:

Signature:

Email. 


\title{
Appendix I: Teacher Information Sheet and Consent form
}

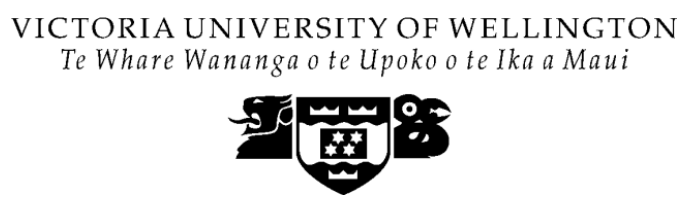

Information Sheet for Teachers

\section{The Impact of a Critical Thinking Model on Teachers' Engagement with Social Science Best Evidence Synthesis Research.}

\author{
Researcher: Mike Taylor, VUW College of Education
}

I am a Masters student studying Education at Victoria University. As part of my degree I have the opportunity to conduct a research thesis. My study aims to provide a snapshot of ways in which teachers critically engage with the recently released social sciences BES, and whether a critical thinking model can support this process. I believe that this opportunity provides social science teachers with an opportunity for professional development that links up-to-the minute research evidence with their classroom practice.

I am inviting you to participate in this study. The design of the study (approved by the VUW College of Education Ethics Committee) involves participation in the following ways:

- discussing the Social Science BES in relation to your practice with a group of colleagues at 3 focus group sessions during term 4 , lasting an hour each.

- Being introduced to a critical thinking model by the researcher.

- participation in another 3 focus groups (Term 1, 2010) using the critical thinking model to support your discussion of the Social Science BES.

- being interviewed on two occasions for your reflections on how critical engagement with the Social Science BES has influenced your professional practice. Each interview will take approximately 20 minutes, one at the end of Term 4, 2009 and one at the end of Term 1, 2010.

After your participation in the focus groups and interviews, you will be given an opportunity to amend or delete what has been recorded before analysis of data commences. You will have the right to withdraw your contributions at any point up to the end of data collection. Focus group and interview data will largely be aggregated so that any school or individual cannot be identified. All information will be kept confidential and only my supervisor and I will see or hear interview data. All audio recordings and transcripts will be kept in password protected files. The audio recordings will be wiped after three years. 
If appropriate, I would be very happy to present my study intentions to a full department meeting for your consideration. This should last 5-10 minutes, of which most time would be a 'Question and Answer' format.

This project is an opportunity to provide the social science teaching community and MoE policy makers with evidence of ways in which teacher sense making of the Social Science BES is having an impact on their professional practice. Participation in the study may also contribute to the professional development expectations of your school's Senior Management Team.

If you have any further questions, please do not hesitate to contact me, mike.taylor@vuw.ac.nz Tel: (04) 463 9619, or my supervisor, Andrea Milligan, Lecturer at VUW College of Education: Andrea.Milligan@vuw.ac.nz Tel: (04) 463 9614.

Yours sincerely,

Mike Taylor 


\section{VICTORIA UNIVERSITY OF WELLINGTON \\ Te Whare Wananga o te Upoko o te Ika a Maui}

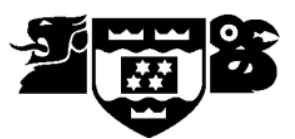

\section{Informed Consent Form for Teachers}

\section{The Impact of a Critical Thinking Model on Teachers' Engagement with Social Science Best Evidence Synthesis Research.}

I give my consent to take part in the research described. I have read the information sheet that I will keep for my records. I have had the opportunity to ask questions and am happy with the answers.

I understand that by agreeing to take part means that I am willing to:

- Take part in a series of departmental focus group discussions during Term 4, 2009 and Term 1, 2010.

- Be interviewed twice, each taking approximately 20 minutes.

By ticking the boxes below, I agree that consent is being sought for:

collection of data at a series of focus groups and interviews during Term $3 \& 4$, as outlined in the information sheet.

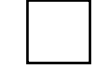

use of the collected data to be submitted for marking as a thesis, and to be deposited in a VUW library.

dissemination of the research at educational conferences or academic journals.

By ticking the boxes below I understand that:

all audio recordings will be wiped after three years, having been kept in a password protected file.

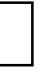

any information I provide is confidential and that no information that could lead to the identification of any individual or school will be disclosed in any reports on the project or to any other party other than to those indicated in the information sheet.

my participation is voluntary, that I can withdraw at any stage of the project without being disadvantaged in any way. I may withdraw all my contributions from the project up to the end of data collection and prior to its analysis. 
I will be given the opportunity to amend/delete the contributions I make in the focus group and individual interviews by viewing a transcription of the recording.

information I provide cannot be used except for this study and the dissemination of the research results.

I will be sent an electronic copy of the final study after it has been submitted for marking as part fulfilment towards a Masters in Education.

Name:

Date:

Signature:

Email: 


\title{
Appendix J: Key Contributor Information Sheet and Consent form
}

\author{
VICTORIA UNIVERSITY OF WELLINGTON \\ Te Whare Wananga o te Upoko o te Ika a Maui

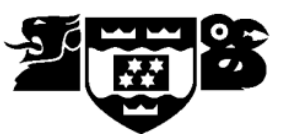 \\ Information Sheet for BES Key Contributors

\section{The Impact of a Critical Thinking Model on Teachers' Engagement with Social Science Best Evidence Synthesis Research.}

\section{Researcher: Mike Taylor, VUW College of Education}

I am a Masters student studying Education at Victoria University. As part of my degree I have the opportunity to conduct a research thesis. My study aims to provide a snapshot of ways in which teachers critically engage with the recently released Social Science BES at an early implementation stage.

I am inviting you, as a key contributor to 'Effective Pedagogy in Social Sciences/Tikanga-a-iwi BES' to participate in this study. The design of the study (approved by the VUW College of education Ethics Committee) involves:

- Interviewing key contributors of the Social Sciences BES for their perspective on how teachers might critically engage with the Social Sciences BES. Each interview will take no longer than an hour.

- Recording a series of teacher focus group discussions about the Social Sciences BES.

- Teachers being introduced to a critical thinking model before continuing with further focus group discussion.

- Teachers being interviewed for their thoughts on how critical engagement with the Social Science BES has influenced their professional practice.

Should you agree to participate in this study, I propose visiting your workplace, or some other mutually agreeable location, where I can digitally record an interview with you. This should take no longer than an hour. A few weeks after the interview you will be given the opportunity to check that the transcription is faithful to the interview, while making any amendments/deletions you see fit.

Only my supervisor and I will see or hear interview data, which will be kept in password protected electronic files. Given your role in the Iterative BES programme, guaranteeing anonymity will be impossible and confidentiality also difficult to assure in the final thesis. For this reason I suggest that, should you agree to participate, that I will liaise with you regarding the final presentation of the analysis of interview data before the study is submitted for marking. 
I believe this study has the potential to provide the social science teaching community and MoE policy makers with evidence of ways in which teacher engagement with the Social Science BES is having an impact on their professional practice.

If you have any further questions, please do not hesitate to contact me, mike.taylor@vuw.ac.nz Tel: (04) 463 9619, or my supervisor, Andrea Milligan, Lecturer at VUW College of Education: Andrea.Milligan@vuw.ac.nz Tel: (04) 463 9614.

Yours sincerely,

Mike Taylor 


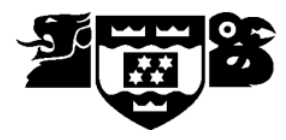

\section{Informed Consent Form for BES Key Contributors}

\section{The Impact of a Critical Thinking Model on Teachers' Engagement with Social Science Best Evidence Synthesis Research.}

I give my consent to take part in the research described in the information letter. I have read the explanatory statement that I will keep for my records. I have had the opportunity to ask questions and am happy with the answers.

I understand that by agreeing to take part means that I am willing to:

- Participate in a semi-structured interview as outlined in the information letter sent to me

By ticking the boxes below, I agree that consent is being sought for:

Collection of data during a semi-structured interview, lasting no longer than $1 \mathrm{hr}$.

Use of the collected data to be submitted for marking as a thesis, and to be deposited in a VUW library.

Dissemination of the research at educational conferences or academic journals.

By ticking the boxes below I understand that:

all digital audio recordings will be wiped after their transcription.

I will be given the opportunity to add to, amend or delete what has been recorded in the interviews.

that because of my role, although no comments will be personally attributed to me, anonymity or confidentiality is not assured. I will have the opportunity to liaise with the researcher before the study is submitted to agree a protocol for representation of my interview.

my participation is voluntary, that I can withdraw at any stage of the project without being disadvantaged in any way and that I may withdraw my contributions from the project up to the end of data collection and prior to its analysis. 
the information I provide cannot be used except for this study and the dissemination of the research results.

I will be sent an electronic copy of the final study after it has been submitted for marking as part fulfilment towards a Masters in Education.

Name:

Date:

Signature:

Email: 